\title{
Microstructure and Mechanical
} Performance of the Friction Stir Welds Made on Neutron-Irradiated Steel with Helium

Approved for public release. Distribution is unlimited.
M. N. Gussev

W. Tang

N. Bibhanshu

T. M. Rosseel

August 2021 


\section{DOCUMENT AVAILABILITY}

Reports produced after January 1, 1996, are generally available free via US Department of Energy (DOE) SciTech Connect.

Website http://www.osti.gov/scitech/

Reports produced before January 1,1996, may be purchased by members of the public from the following source:

National Technical Information Service

5285 Port Royal Road

Springfield, VA 22161

Telephone 703-605-6000 (1-800-553-6847)

TDD 703-487-4639

Fax 703-605-6900

E-mail info@ntis.gov

Website http://classic.ntis.gov/

Reports are available to DOE employees, DOE contractors, Energy Technology Data Exchange representatives, and International Nuclear Information System representatives from the following source:

Office of Scientific and Technical Information

PO Box 62

Oak Ridge, TN 37831

Telephone 865-576-8401

Fax 865-576-5728

E-mail reports@osti.gov

Website http://www.osti.gov/contact.html

This report was prepared as an account of work sponsored by an agency of the United States Government. Neither the United States Government nor any agency thereof, nor any of their employees, makes any warranty, express or implied, or assumes any legal liability or responsibility for the accuracy, completeness, or usefulness of any information, apparatus, product, or process disclosed, or represents that its use would not infringe privately owned rights. Reference herein to any specific commercial product, process, or service by trade name, trademark, manufacturer, or otherwise, does not necessarily constitute or imply its endorsement, recommendation, or favoring by the United States Government or any agency thereof. The views and opinions of authors expressed herein do not necessarily state or reflect those of the United States Government or any agency thereof. 


\title{
Microstructure and Mechanical Performance of the Friction Stir Welds Made on Neutron- Irradiated Steel with Helium
}

\author{
M. N. Gussev \\ W. Tang \\ N. Bibhanshu \\ T. M. Rosseel
}

Date Published: August 2021

\author{
Prepared under the direction of the \\ U.S. Department of Energy \\ Office of Nuclear Energy \\ Light Water Reactor Sustainability Program \\ Materials Research Pathway \\ Prepared by \\ OAK RIDGE NATIONAL LABORATORY \\ Oak Ridge, TN 37831-6285 \\ managed by \\ UT-BATTELLE, LLC \\ for the \\ U.S. DEPARTMENT OF ENERGY \\ under contract DE-AC05-00OR22725
}


(This page intentionally left blank) 


\section{CONTENTS}

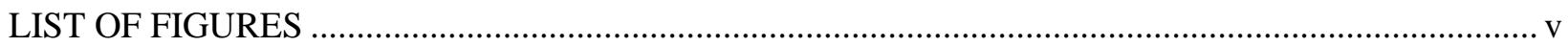

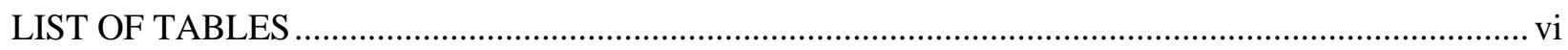

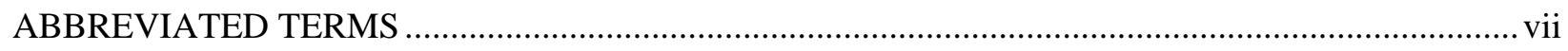

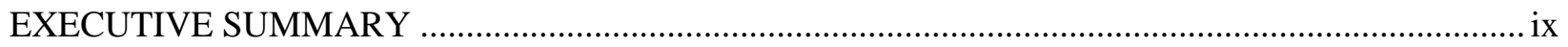

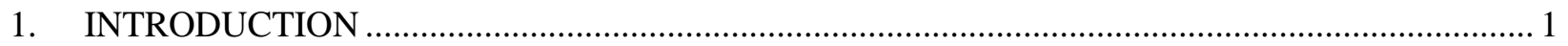

1.1 Accumulation of helium in the in-core materials and its impact on welding........................... 1

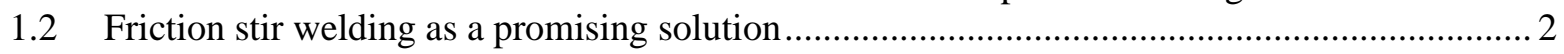

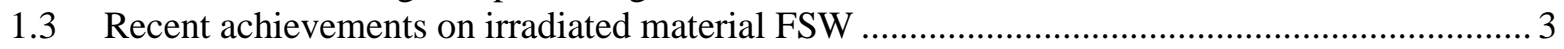

2. MATERIALS AND EXPERIMENTAL METHODS …....................................................... 4

2.1 Custom 304L SS composition, fabricating, and processing .............................................. 4

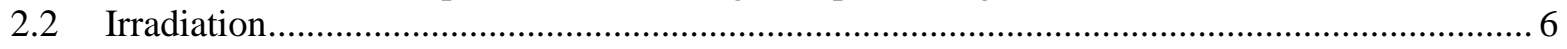

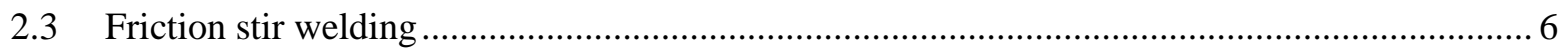

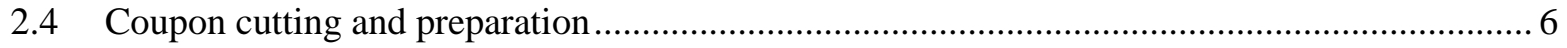

2.5 Microstructure analysis ............................................................................................. 7

2.6 Targeted tensile specimen manufacturing and testing ...................................................... 7

3. FRICTION STIR WELD WITH 5.2 appm He (304C HEAT) ...................................................... 10

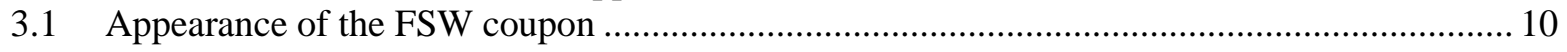

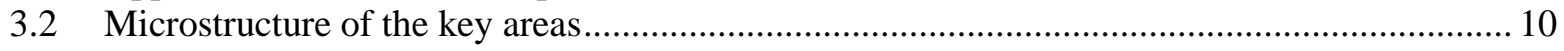

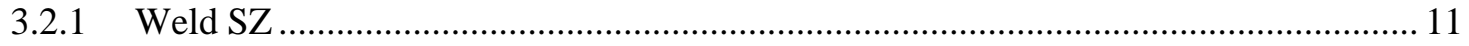

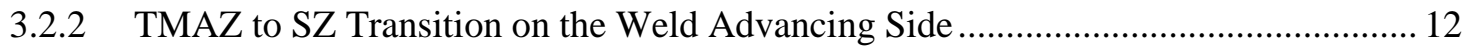

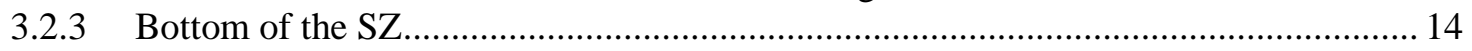

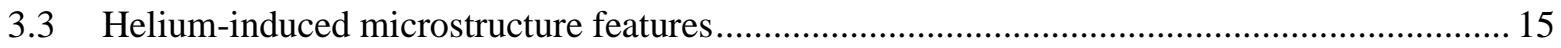

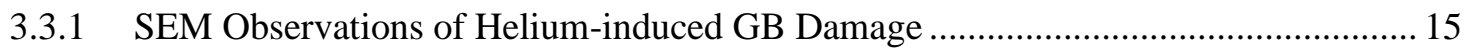

3.3.2 Crystallography Analysis of Helium-induced Degradation......................................... 18

4. DEFORMATION MECHANISMS IN THE FRICTION STIR WELDED COUPON WITH

5.2 appm He

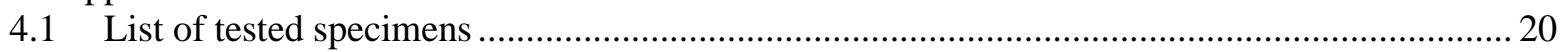

4.2 Pre-deformed microstructure and texture...................................................................... 20

4.3 Tensile behavior of specimens from different metallurgical zones ....................................... 22

4.4 Strain-induced processes and active deformation mechanisms ............................................. 24

4.4.1 Local misorientation change and lattice gradients formation ................................... 24

4.4.2 Grain Boundary Evolution and Formation of In-grain Boundaries ........................... 25

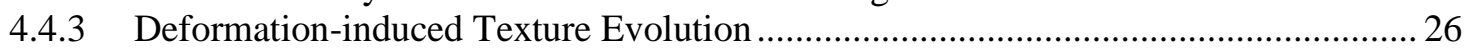

4.5 Impact of helium-induced damage on material performance................................................. 27

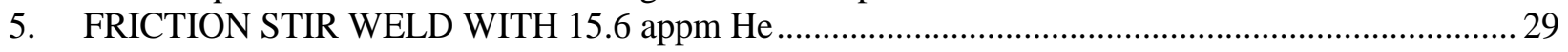

5.1 Visual appearance of the 15.6-appm He FSW coupon ......................................................29

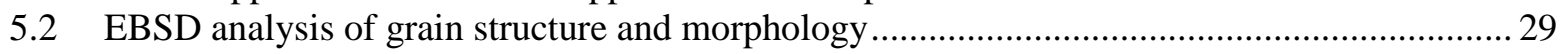

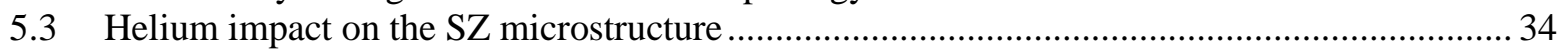

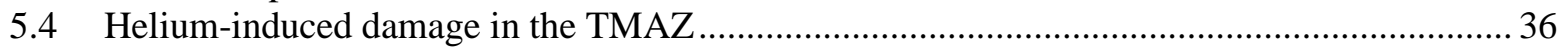

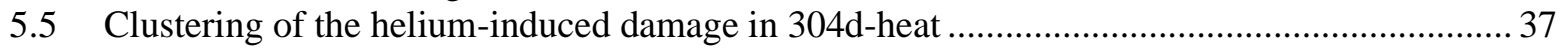

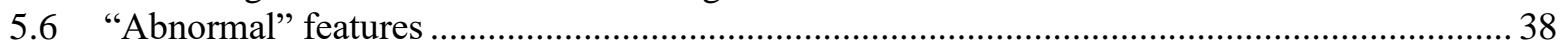

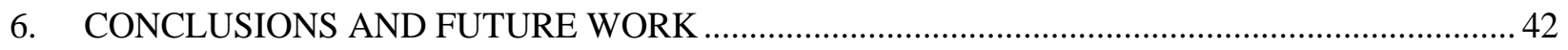

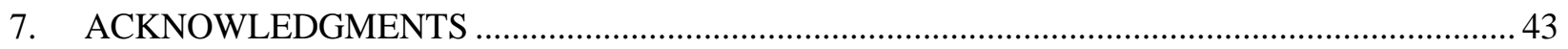

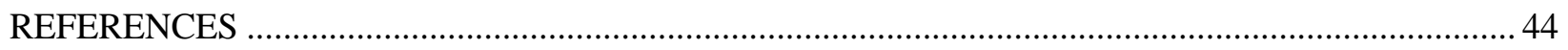


(This page intentionally left blank) 


\section{LIST OF FIGURES}

Figure 1. Helium-induced cracks in the weld HAZ of SS containing 8.3 appm He ................................ 2

Figure 2. Reference microstructure for 304C custom heat (10 wppm B-enriched, measured $~ 5.2$

appm He)

Figure 3. Reference microstructure for 304D custom heat (24 appm B-enriched, measured $~ 15.6$

appm He in another coupon with the same heat) .............................................................. 5

Figure 4. Scanning electron microscope (SEM) image and selected EDS maps for two small

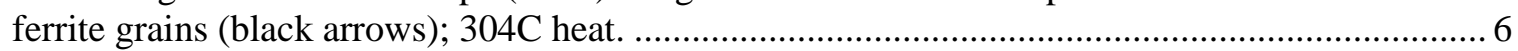

Figure 5. Typical appearance of the sliced surface after electropolishing. .......................................... 7

Figure 6. EDM system installed in LAMDA to manufacture specimens from radioactive material............ 8

Figure 7. Drawings (a) and appearance (b) of ultra-miniature SS-Teeny specimen.................................. 8

Figure 8. Grips for the K\&W tensile stage (left) and cnventional tensile grips (right) for the

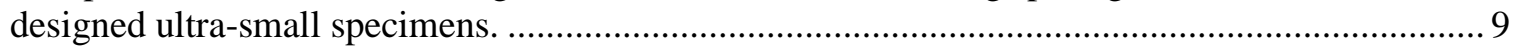

Figure 9. Visual appearance of the investigated friction stir weld coupon........................................... 10

Figure 10. The complexity and variations of the friction stir weld microstructure. ................................. 11

Figure 11. EBSD maps (IPF, IQ, Phase, and KAM) for the middle of the SZ ...................................... 12

Figure 12. EBSD maps (IPF, IQ, Phase, and KAM) for transition areas between TMAZ and SZ of

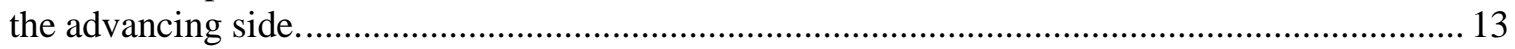

Figure 13. Large-area EBSD scan showing the transition between the SZ (at the right) and TMAZ

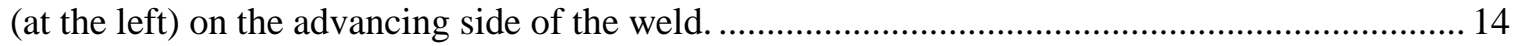

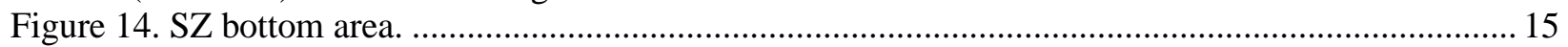

Figure 15. Preexisting pores in reference material (BM) and helium-induced damage in the

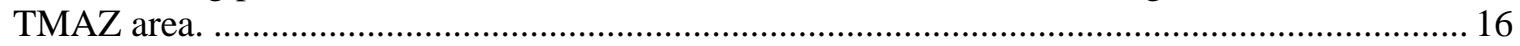

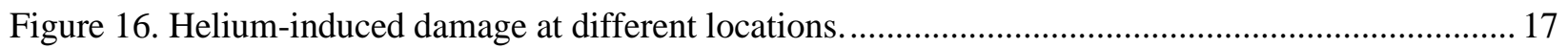

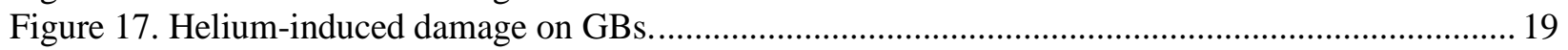

Figure 18. SE micrographs depict microstructure and He-induced damage for three different

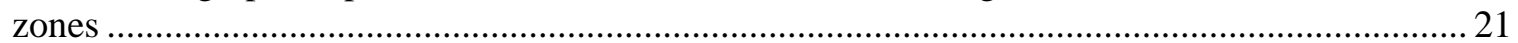

Figure 19. (111) and (220) pole figures, generated from the gauge area............................................. 22

Figure 20. Raw "load-displacement" tensile curve for 304C-6-14-1 sample (TMAZ). ........................... 23

Figure 21. Engineering stress versus engineering plastic strain $\left(\varepsilon-\varepsilon_{\text {elastic }}\right)$ for the three specimens

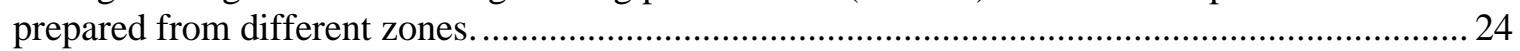

Figure 22. Microstructure after deformation at different strain levels..................................................2 25

Figure 23. GB maps generated from the EBSD data for \#304C-6-14-1 specimen................................. 26

Figure 24. Deformation texture at the last step of deformation for specimens ....................................... 27

Figure 25. Effect of deformation on the consequence on He bubbles represented different steps of

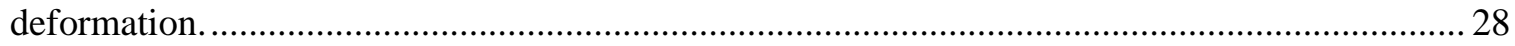

Figure 26. A visual appearance of the investigated 15.6 appm He FSW coupon (304D-5-14)................ 29

Figure 27. Microstructure of the friction stir weld with 15.6 appm He at key locations.......................... 30

Figure 28. Weldment with 15.6 appm He for the SZ middle at $~ 1 / 4$ of the depth................................... 31

Figure 29. Weldment with 15.6 appm He at the SZ middle line and middle of the weldment depth......... 32

Figure 30. SZ bottom area for 15.6 appm He coupon........................................................................ 33

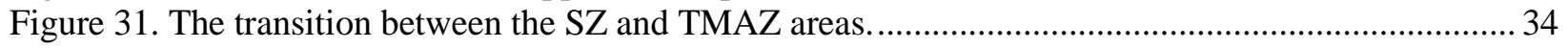

Figure 32. A typical microstructure of the SZ (15.6 appm He friction stir welded coupon [304D-

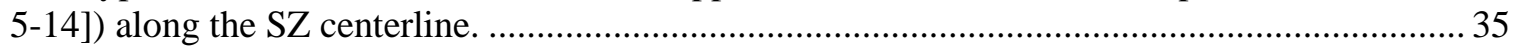

Figure 33. Compromised GBs in the TMAZ area of 304D-5-14 coupon.............................................. 36

Figure 34. Minor bubbles and a micro-crack in the TMAZ area of the 304D-5-14 coupon...................... 37

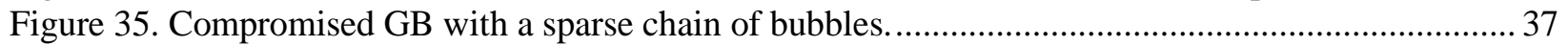

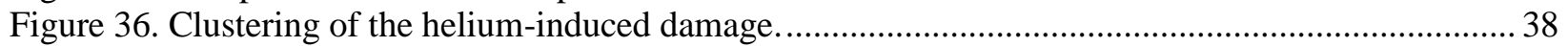

Figure 37. A cluster of helium bubbles near inclusion and along the GB. ............................................. 39 
Figure 38. A localized cluster of bubbles and a specific "halo"near two inclusions................................. 39

Figure 39. "Halo" and bubble cluster near inclusions.............................................................................4 40

Figure 40. Circle (or "halo") of bubbles associated with retained ferrite. ................................................. 40

Figure 41. Ferrite particle with anomalous pore density ........................................................................ 41

\section{LIST OF TABLES}

Table 1. Composition (wt. \%) of the investigated material [10] ............................................................. 4

Table 2. ID, source location, and reached strain level for the tested sample........................................ 20 


\section{ABBREVIATED TERMS}

$\begin{array}{ll}\text { 304L SS } & \text { 304L stainless steel } \\ \text { appm } & \text { atom parts per million } \\ \text { BM } & \text { base metal } \\ \text { BSE } & \text { backscatter electron image } \\ \text { dpa } & \text { displacement per atom } \\ \text { EBSD } & \text { electron backscatter diffraction } \\ \text { EDM } & \text { electrical discharge machine } \\ \text { EDS } & \text { energy-dispersive x-ray spectroscopy } \\ \text { EELS } & \text { electron energy loss spectroscopy } \\ \text { FSW } & \text { friction stir welding } \\ \text { GB } & \text { grain boundary } \\ \text { GTAW } & \text { gas-tungsten arc welding } \\ \text { HAB } & \text { high-angle grain boundary } \\ \text { HAZ } & \text { heat affected zone } \\ \text { HFIR } & \text { High Flux Isotope Reactor } \\ \text { IASCC } & \text { irradiation-assisted stress-corrosion cracking } \\ \text { IPF } & \text { inverse pole figure } \\ \text { IQ } & \text { image quality } \\ \text { K\&W } & \text { Kammrath \& Weiss (a vendor of the mechanical test equipment) } \\ \text { KAM } & \text { kernel average misorientation } \\ \text { LAB } & \text { low-angle grain boundary } \\ \text { LAMDA } & \text { Low Activation Materials Development and Analysis Laboratory } \\ \text { LWRS } & \text { Light Water Reactor Sustainability program } \\ \text { NPP } & \text { nuclear power plant } \\ \text { ORNL } & \text { Oak Ridge National Laboratory } \\ \text { rpm } & \text { rotation per minute } \\ \text { RLAB } & \text { random low-angle grain boundary } \\ \text { RHAB } & \text { random high-angle grain boundary } \\ \text { SE } & \text { secondary electron image. } \\ \text { SEM } & \text { scanning electron microscope/microscopy } \\ \text { SS } & \text { stainless steel } \\ \text { SZ } & \text { stir zone } \\ \text { TD } & \text { tensile direction } \\ \text { TMAZ } & \text { thermo-mechanically affected zone } \\ \text { wppm } & \text { weight parts per million } \\ & \end{array}$


(This page intentionally left blank) 


\section{EXECUTIVE SUMMARY}

This report describes new experimental results on the microstructure and mechanical performance of the friction stir welds made on neutron-irradiated steel with helium. The report focuses on helium-related issues, specifically, helium-induced degradation in the welded joint, aiming to repair irradiated components of nuclear power plants (NPPs). The friction stir welds analyzed here were produced at Oak Ridge National Laboratory previously, and limited characterization work was performed, mostly addressing the presence or absence of macroscopic cracks. The present work attempts to perform a more comprehensive study to assess microstructure conditions, grain size, plastic strain gradients, the morphology of the helium-induced damage, and deformation behavior.

Section 1 briefly describes issues associated with transmutation-induced helium and its impact on weldability. As an advanced welding approach, friction stir welding (FSW) is shown to be a promising solution for repairing irradiated parts and components. Section 2 describes the studied materials (i.e., custom steel heats with $\sim 5.2$ and $\sim 15.6$ atom parts per million [appm] He), experimental tools, and methods used to conduct the work, including an electric discharge machine (EDM) to manufacture ultrasmall specimens from prescribed locations on the friction stir weld.

Section 3 analyzes the microstructure of the friction stir welded coupon with $\sim 5.2$ appm He (custom "304C" heat) with a focus on grain morphology in the stir zone (SZ) and thermo-mechanically affected zone (TMAZ) and grain size gradients and changes across the coupon. It was shown that helium-induced damage in the friction stir welded joint is less pronounced compared to traditional fusion weld techniques. However, gradients in grain size caused by intense recrystallization in the SZ and plastic strains in the TMAZ are much higher than conventional weldments.

Section 4 provides preliminary results of the in situ mechanical tests performed on ultra-miniature tensile specimens manufactured from 5.2-appm He weldment. An accent was made on the evolution of heliuminduced features (e.g., bubble chains and tiny cracks) and their ability to grow and cause local fracture during loading. It was demonstrated that the preexisting helium-related micro-defects have limited ability to grow and lead to sudden fracture. Deformation mechanisms observed during in situ tests (mostly twinning and dislocation banding/channeling) were typical for 304L stainless steel (304L SS).

Section 5 describes results obtained for the friction stir welded coupon with $\sim 15.6$ appm He (custom "304D" heat). Microstructure and helium-induced features are discussed in detail. Some observed objects suggest strong inhomogeneity in the distribution of transmutation-induced helium. It was concluded that this particular heat might have a nonuniform distribution of boron (i.e., metallurgical issue).

Section 6 summarizes the work performed and suggests future research, including a re-irradiation experiment to assess the friction stir weld performance in a real NPP. Generalizing, the available results demonstrate immediate and substantial benefits of the FSW approach, compared to the traditional fusion welding techniques (e.g., gas tungsten arc welding), for joining helium-containing austenitic steels. No pronounced helium-induced cracking was observed in the investigated friction stir welded joints. 
(This page intentionally left blank) 


\section{INTRODUCTION}

\subsection{ACCUMULATION OF HELIUM IN THE IN-CORE MATERIALS AND ITS IMPACT ON WELDING}

Fusion welding is widely used in nuclear power plant (NPP) construction. Common welding techniques, such as gas tungsten arc welding (GTAW) and gas metal arc welding, are routinely employed to weld pristine, nonirradiated materials, providing high-quality joints. With years of development, those fusion welding techniques are reliable and predictable for nonirradiated and helium-free NPP metal components such as 300-series stainless steel (SS) components. Due to strict technical regulations and advanced design, modern NPPs are reliable and safe systems. Nevertheless, neutron irradiation and overall harsh inreactor environments (i.e., temperature, radiation, mechanical stress fields, elevated pressure, and potentially corrosive environment) compromise material performance. Over time, some parts and components may require repair or replacement that relies on welding techniques. Thus, repair and repair welding is essential to ensure the existing US reactor fleet's long-term viability, competitiveness, and safe lifetime extensions.

However, fusion repair welding of NPP-irradiated components must address one specific issue: heliuminduced degradation and/or cracking. Neutron fluxes stimulate transmutation reactions in the NPP core materials and lead to helium accumulation, mainly because of the transmutation of boron and nickel.

$$
\begin{gathered}
{ }^{10} \mathrm{~B}+n \rightarrow{ }^{7} \mathrm{Li}+{ }^{4} \mathrm{He} \\
{ }^{58} \mathrm{Ni}+n \rightarrow{ }^{59} \mathrm{Ni}+\gamma \\
{ }^{59} \mathrm{Ni}+n \rightarrow{ }^{56} \mathrm{Fe}+{ }^{4} \mathrm{He}
\end{gathered}
$$

Helium accumulation and helium-related issues are especially severe in water-moderated reactors, due to the "soft" neutron spectra, with a high fraction of thermal neutrons. Potentially, transmutation effects may be partially mitigated by using nickel-free steels; however, most, if not all, existing NPPs include Nicontaining 300-series SS as a major in-core component material. The presence of nickel makes helium accumulation unavoidable. Unfortunately, helium is practically insoluble in steel. With the high heat input in fusion welding, helium migrates at grain boundaries (GBs) and tends to form bubbles, drastically reducing the GB strength. Moreover, the local transient elevated temperatures during fusion welding result in tensile stresses in the weld and nearby areas. The stresses may be high enough to initiate crack formation on the helium-compromised GBs and lead to crack propagation in the heat affected zone (HAZ) and/or weld zone (i.e., helium-induced cracking).

Even 1-3 atom parts per million (appm) of helium can be enough to cause helium-induced cracking in welding. Austenitic steels with 5-15+ appm of helium are often considered nonweldable with today's fusion welding techniques. It may be assumed that helium accumulates at rates of roughly $0.2-1$ appm per

displacement per atom (dpa), and $\sim 1$ dpa usually means $\sim 1$ year of service for in-core components. The rates may be an order of magnitude lower for the peripheral components or higher in the core, but, generalizing, critical helium concentrations (above 1-3 appm) may be reached even for peripheral components within $\sim 10-20$ years. This time interval is much lower than the planned life span of typical NPPs (40 years), even without considering an extended operation to 60 or $80+$ years. Thus, heliumrelated issues prohibit fusion welding repair, and, without any doubt, this is inevitable during NPP operation.

For example, in 1986, the GTAW technique was used to repair the water leakage of a Savannah River National Laboratory reactor. Many cracks presented at the HAZ after repair welding attempts, and the cracks resulted in the reactor's permanent shutdown. The investigation showed that these were helium- 
induced cracks, and helium concentration in the repaired water tank wall was $\sim 3$ appm [1]. An example of a fusion weld cross-section with helium-induced cracks in the HAZ is shown in Figure 1 [2]; the helium content was $8.3 \mathrm{appm}$. Studies have shown that elevated temperatures and the appearance of tensile stress during fusion welding - more precisely, during cooling down after solidification - are two key factors in helium-induced crack formation and propagation [3].

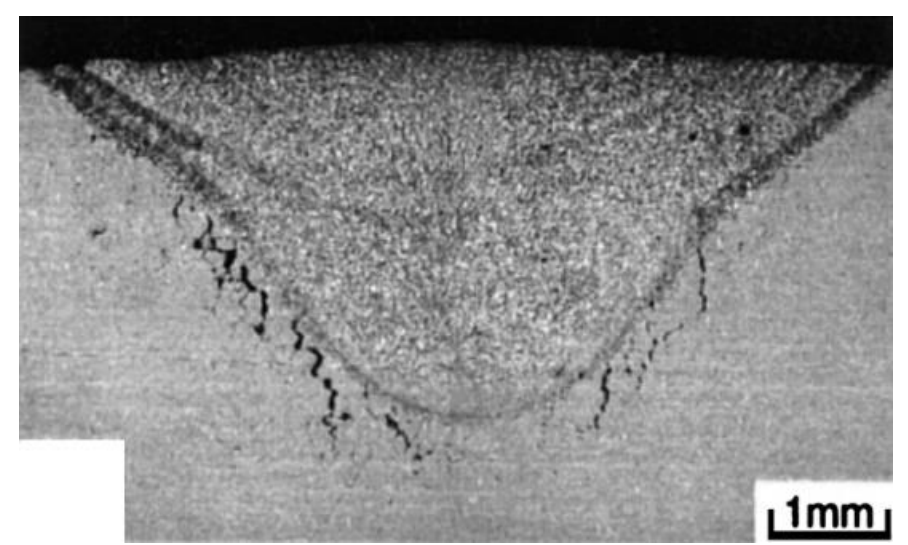

Figure 1. Helium-induced cracks in the weld HAZ of SS containing $8.3 \mathrm{appm}$ He [2]. Note many cracks exceed $1 \mathrm{~mm}$ in length, and the total length of macroscopic cracks is well above $\sim 5-6 \mathrm{~mm}$.

Thus, as discussed above, nickel is a common element in many SSs. Boron is an impurity that is difficult to avoid in commercial production; hence, helium accumulation is unavoidable. At some point, it will reach a critical level that compromises the material's weldability during a reactor's service life.

\subsection{FRICTION STIR WELDING AS A PROMISING SOLUTION}

Friction stir welding (FSW) is an advanced manufacturing technology [4,5] with peak temperatures much lower than the material bulk melting point (generally 0.6-0.8 melting temperature, $\mathrm{T}_{\mathrm{m}}$ ). During FSW, the material is heated by the friction between the welding tool and welded material and by plastic deformation of the material being welded. Heated material flows/deforms around the welding tool and forms a joint due to mechanical mixing and recrystallization [6]. Tool wear during high-temperature materials FSW is often only mentioned as a minor side effect[7].

In general, a friction stir weld contains four metallurgical zones: stir zone (SZ), thermo-mechanically affected zone (TMAZ), HAZ, and base metal (BM). The SZ is the material directly affected by the FSW tool, usually underneath the FSW tool. It experiences elevated temperature and large plastic deformation and is generally recrystallized during the cooling process. The TMAZ, located on both sides of the SZ, receives both high-temperature and plastic deformation, but the grain elongation is still seen after the FSW because of lower temperatures than those in the SZ. The HAZ is further out from the TMAZ; it receives a high temperature that affects the material microstructure/properties but does not exhibit plastic deformation. The zone in which material microstructure/mechanical properties are unaffected by the FSW temperature and plastic deformation is the BM. In a friction stir weld, the side where the FSW tool is rotating and traveling along the same direction is called the advancing side, and the side where the two directions are opposite to each other is called the retreating side.

FSW is arguably the most recent invention in welding technologies [6]. It has been widely studied and developed with different materials, from nonferrous metals to ferrous metals and steels to high-alloy refractory materials. In many applications, FSW has demonstrated outstanding weldability to form highquality joints. Compared to traditional welding approaches, lower peak temperatures and shorter time at 
elevated temperatures significantly reduce the intensity of diffusion-based processes, including helium migration. Lower temperatures may also reduce tensile thermal stresses and, in turn, cracking. These attributes make the FSW a potential candidate to weld irradiated material with high helium content.

\subsection{RECENT ACHIEVEMENTS ON IRRADIATED MATERIAL FSW}

Although promising, the FSW had not been used for joining irradiated materials until Oak Ridge National Laboratory's (ORNL's) team, including the present report co-authors, who also were the major contributors to FSW and characterization efforts, successfully demonstrated FSW on irradiated 304L SS for the first time in late $2017[6,8,9]$.

This development of irradiated 304L SS FSW and subsequent initial characterization $[6,8]$ was a joint effort of several organizations, programs, and projects, including the US Department of Energy (DOE) Light Water Reactor Sustainability (LWRS) Program. Within this effort, custom 304L SS specimens, with a controlled amount of boron, were irradiated at the High Flux Isotope Reactor (HFIR) at ORNL to receive a controlled amount of transmuted helium from boron. The irradiated 304L SS coupons were then friction stir welded at ORNL. Up to now, FSW has been successfully applied on three irradiated 304L SS coupons that contained $\sim 5, \sim 10$, and $\sim 20$ weight parts per million (wppm) of boron before irradiation, respectively. Preliminary characterization showed no macro helium-induced cracking observed in a metallographic specimen removed from the center of these joints [6,8,9]. Currently, the remaining welded specimens, as well as leftover coupon blocks, are stored at ORNL to support the current work and future investigations.

The present report attempts to continue the characterization of helium-containing friction stir welds, focusing on grain microstructure, plastic strain gradients, and helium-induced degradation. 


\section{MATERIALS AND EXPERIMENTAL METHODS}

\subsection{CUSTOM 304L SS COMPOSITION, FABRICATING, AND PROCESSING}

Custom 304L austenitic SS heats with boron additions before irradiation (Table 1) were manufactured for this work. The details on custom heat fabrication and processing can be found in [10] and references within. The controlled amount of boron in the 304L SS coupon was expected to transmute to helium during the neutron irradiation, thereby simulating irradiated structural SS conditions in nuclear reactors. The $304 \mathrm{~L}$ SS coupon dimensions were $76 \mathrm{~mm} \times 56 \mathrm{~mm} \times 8.9 \mathrm{~mm}$.

Table 1. Composition (wt. \%) of the investigated material [10]

\begin{tabular}{|c|c|c|c|c|c|c|c|c|c|c|c|c|c|}
\hline Type & $\begin{array}{c}\text { Heat } \\
\text { name }\end{array}$ & $\begin{array}{c}\text { B } \\
(\mathbf{w p p m})\end{array}$ & $\mathbf{F e}$ & $\mathbf{C}$ & $\mathbf{M n}$ & $\mathbf{S i}$ & $\mathbf{C r}$ & $\mathbf{N i}$ & $\mathbf{M o}$ & $\mathbf{C u}$ & $\mathbf{N}$ & $\mathbf{P}$ & $\mathbf{S}$ \\
\hline $\begin{array}{c}\text { Custom } \\
\text { B- }\end{array}$ & $304 \mathrm{C}$ & 10 & Bal. & 0.014 & 1.5 & 0.49 & 19.28 & 10.35 & 0.04 & 0.05 & 0.035 & $<0.001$ & 0.002 \\
\cline { 2 - 13 } \\
$\begin{array}{c}\text { enriched } \\
\text { 304L }\end{array}$ & $304 \mathrm{D}$ & 24 & Bal. & 0.01 & 1.53 & 0.49 & 19.33 & 10.41 & 0.04 & 0.05 & 0.035 & $<0.001$ & 0.002 \\
\hline
\end{tabular}
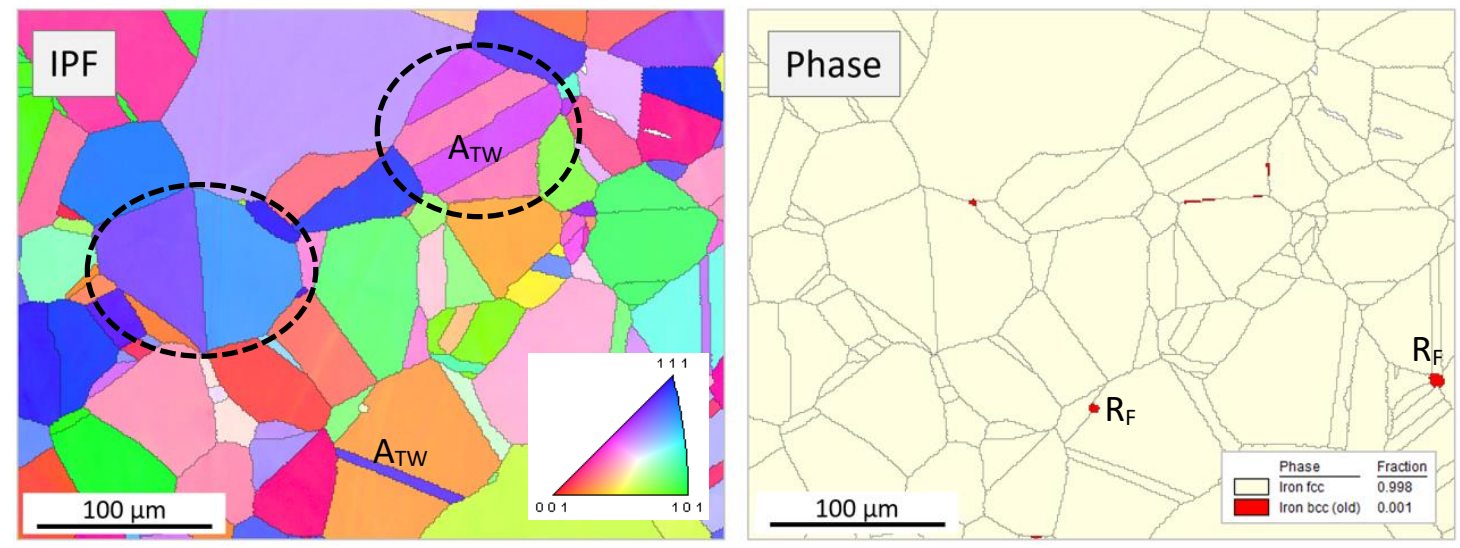

Figure 2. Reference microstructure for 304C custom heat (10 wppm B-enriched, measured 25.2 appm He): Electron backscatter diffraction (EBSD) inverse pole figure (IPF) and phase maps. One can see the annealed austenite structure with equiaxial grains (shown by dashed ovals), annealing twins (marked as "ATw"), and a small amount of retained ferrite $\left(R_{F}\right)$. The retained ferrite grains usually have a round or specific elongated shape. The amount of ferrite was found to be $<0.2 \%$. The EBSD step (pitch) size is $1 \mu \mathrm{m}$. All IPF maps within the document are colored horizontally, and the IPF color key is the same for all IPF maps. 

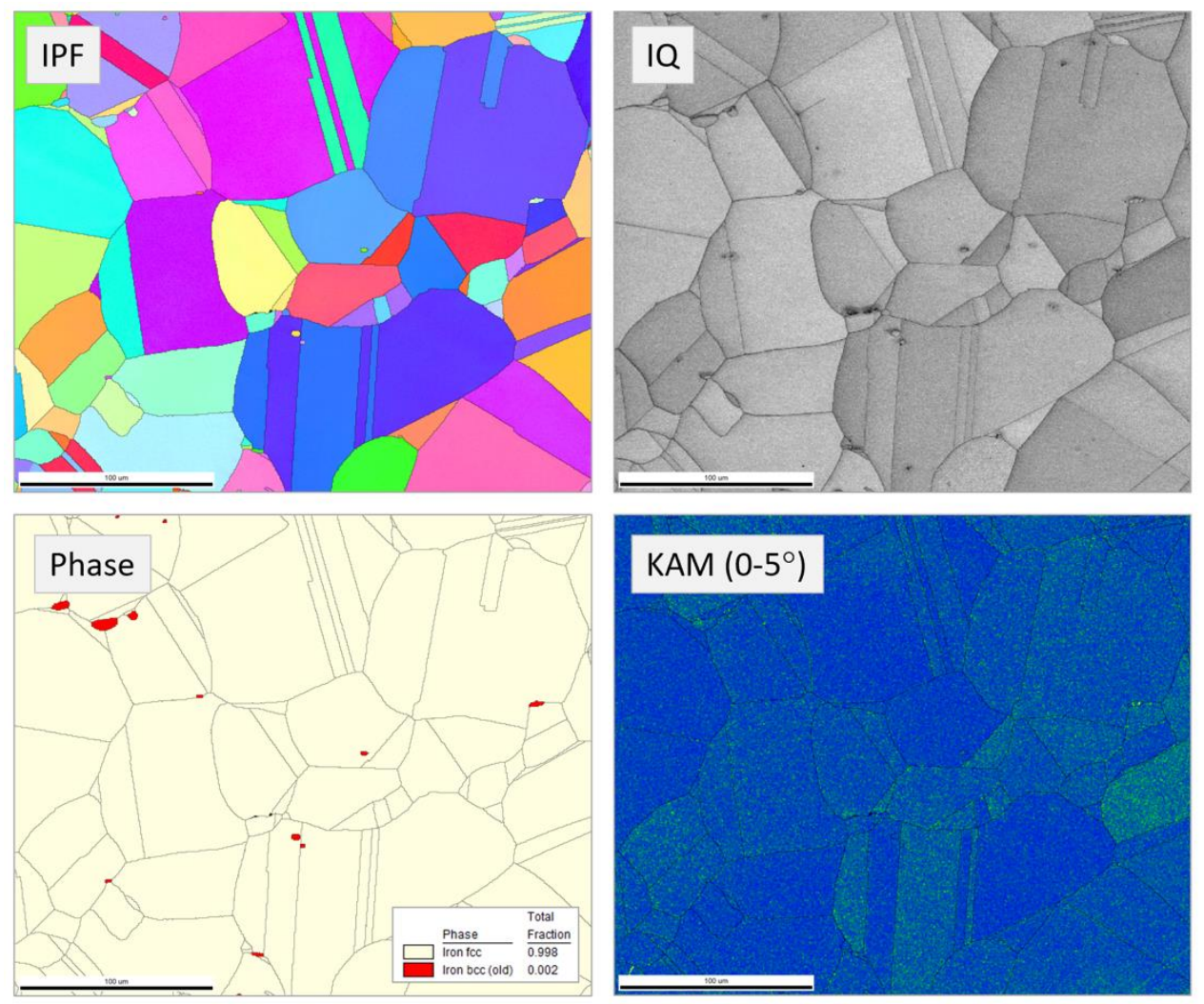

Figure 3. Reference microstructure for 304D custom heat ( 24 appm B-enriched, measured $\sim 15.6$ appm He in another coupon with the same heat): EBSD IPF, image quality (IQ), phase, and kernel average misorientation

(KAM) maps. One can see the annealed austenite structure with a minor amount of ferrite. Many ferrite grains have a specific elongated shape with a long axis oriented in the horizontal direction. The IQ map shows the reduced pattern quality around many ferritic grains (no such effect was observed in 304C heat); reduced

Kikuchi pattern quality may suggest element segregation effects. The KAM map reveals no plastic strain (fully annealed conditions). Amount of ferrite for this scan <0.2-0.3\%. Scan size: $300 \times 250 \mu \mathrm{m}$; EBSD step (pitch) size: $0.5 \mu \mathrm{m}$.

Figure 2 and Figure 3 show a typical microstructure of the studied materials (both 304C and 304D heats) after neutron irradiation: IPF map, showing color-coded lattice orientation information; IQ map, representing Kikuchi pattern quality; phase map, showing the distribution of identified phases; and KAM to provide information on lattice gradients and dislocation densities. EBSD data analysis and representation are widely discussed in the literature (see $[11,12]$ and references within). One can see a well-annealed austenite structure with multiple annealing twins. The analysis showed no pronounced texture in the austenitic matrix. The structure presents a limited amount of retained ferrite (much below $1 \%$ ), with some insignificant variations between locations and heats. The retained ferrite presence is typical for many 300 -series steels and is not a concern for the present discussion. Ferrite grains sometimes appear as bands or chains elongated in one direction and are most likely due to the former hot rolling direction. The energy-dispersive x-ray spectroscopy (EDS) scans (Figure 4) reveal that the retained ferrite grains are slightly enriched in chromium and depleted in nickel, typical for retained ferrite. 

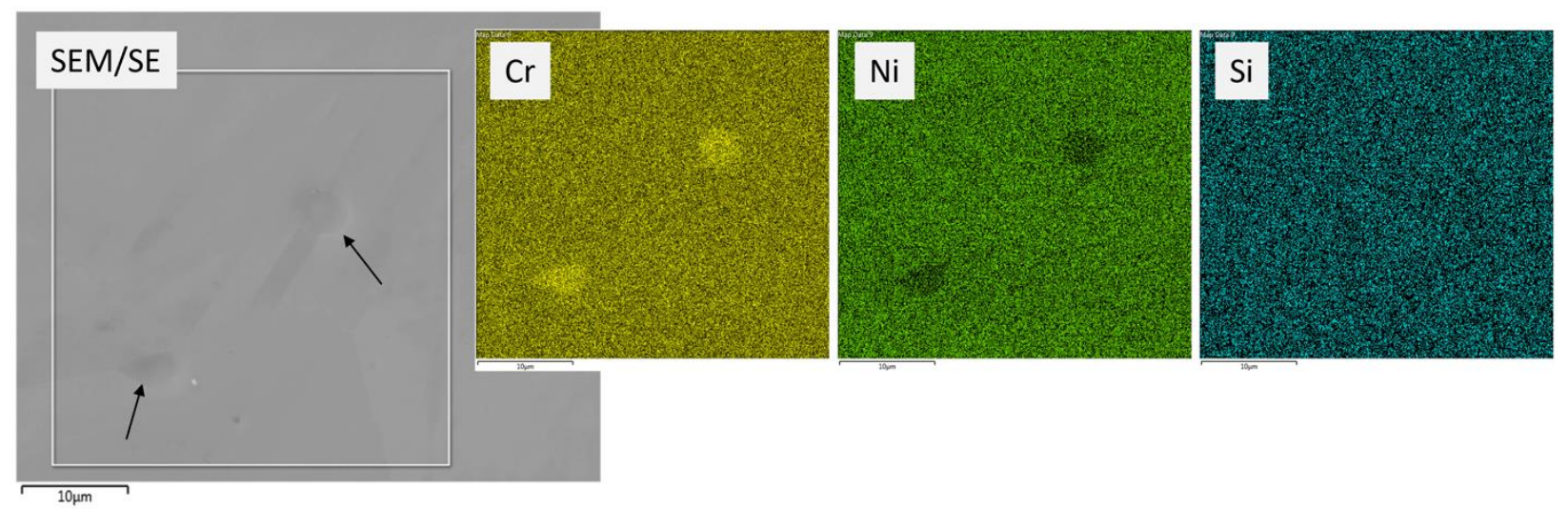

Figure 4. Scanning electron microscope (SEM) image and selected EDS maps for two small ferrite grains (black arrows); 304C heat. Ferrite grains are believed to be a retained ferrite that survived the material processing. One may see enrichment in chromium and depletion in nickel. No visible changes in other elements (silicon map is shown as an example) were observed. Note that routine SEM/EDS analysis cannot capture minor amounts of light elements like boron.

\subsection{IRRADIATION}

All 304L SS coupons with different levels of boron were irradiated at HFIR for three operation cycles (22-26 days/cycle), with a total fluence in the range of $4.5 \times 10^{20}$ to $1.3 \times 10^{21} \mathrm{n} / \mathrm{cm}^{2}$. The irradiated SS304 steel blocks were cooled down for over 2 years before welding experiments. Additional details are reported in [10].

\subsection{FRICTION STIR WELDING}

The FSW was performed on the irradiated 304L SS coupon with an unirradiated 304L SS tab at each end of the irradiated coupon. As mentioned above, the irradiated 304L SS coupon dimensions were 76.2 $\mathrm{mm} \times 55.9 \mathrm{~mm} \times 8.9 \mathrm{~mm}$, and the tab dimensions were $38.1 \mathrm{~mm} \times 55.9 \mathrm{~mm} \times 8.9 \mathrm{~mm}$. A polycrystalline cubic boron nitride tool was used in FSW, and the FSW started in the beginning tab, went through the irradiated coupon along the length $(55.9 \mathrm{~mm})$ direction, and stopped in the end tab. FSW parameters were $400 \mathrm{rpm}$ rotation rate, $50.8 \mathrm{~mm} / \mathrm{min}$ welding speed with position control mode, and argon cover gas $[8,10]$.

\subsection{COUPON CUTTING AND PREPARATION}

After FSW of the 304L SS coupons, metallographic specimens (i.e., thin slices) were cut from the FSW in a hot cell using a bandsaw. The center of the metallographic specimen was aligned with the center of the friction stir weld, and each metallographic specimen contained SZ, TMAZ, HAZ, and BM. The slices were $30.5 \mathrm{~mm} \times 8.9 \mathrm{~mm} \times 2.5 \mathrm{~mm}$. The friction stir weld was located in the middle of the $30.5 \mathrm{~mm}$ long slice. The slices were transferred to ORNL's Low Activation Materials Development and Analysis (LAMDA) facility for further preparation and analysis.

The selected thin slices were epoxy-mounted, mechanically ground, and polished using standard metallography procedures. After several trials, electropolishing was selected as the final preparation step. Standard Struer A2 solution (approved for use in LAMDA) was used, the voltage was 30V DC, and electropolishing duration varied from 5 to $\sim 12 \mathrm{sec}$ depending on the surface conditions. Compared to the colloidal silica polishing, the electropolishing process avoids any mechanical contact with the prepared surface and provides a clean metallic surface free of strain (Figure 5). 


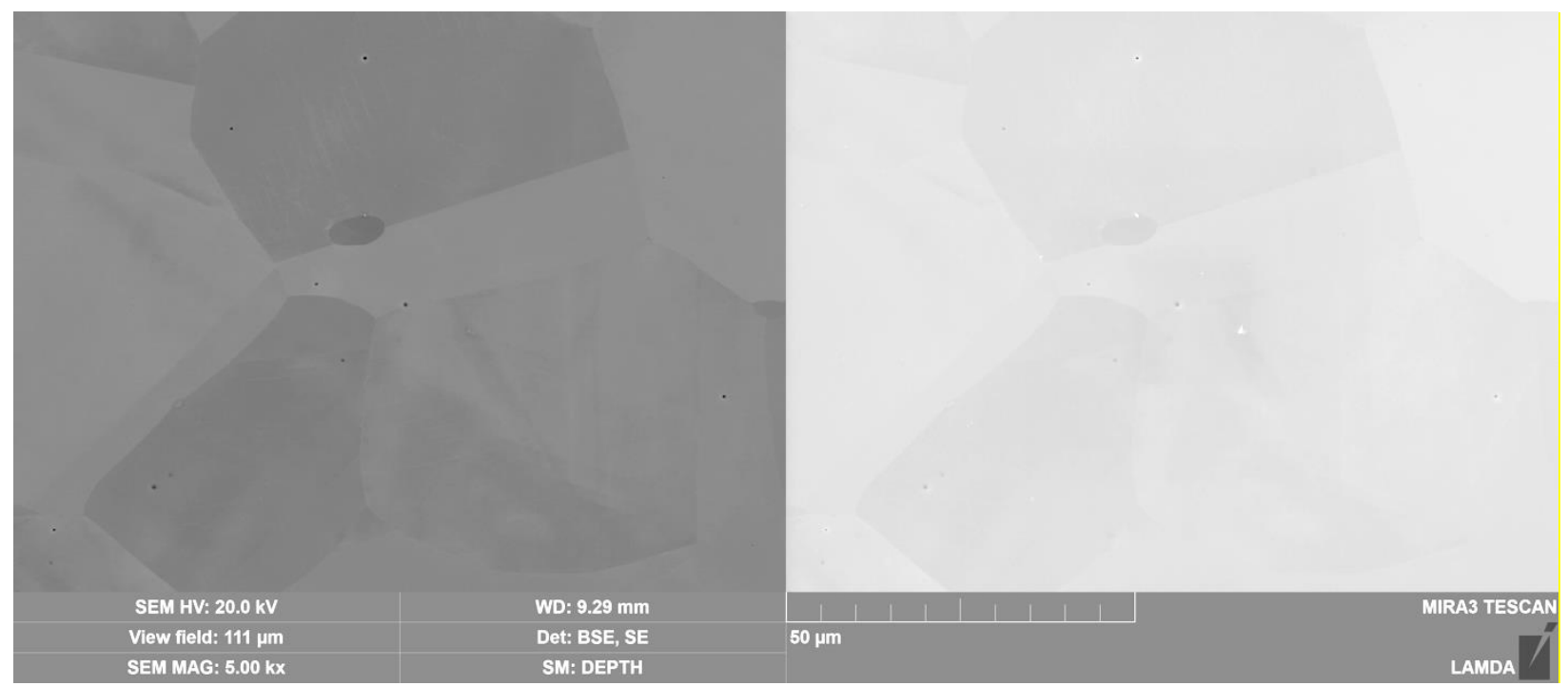

Figure 5. Typical appearance of the sliced surface after electropolishing. 304C heat, reference location (out of FSW). One can see a clean, flat metal surface with very few scattered nonmetallic inclusions of metallurgical origin. (Left) backscatter electron image (BSE) detector; (right) Secondary electron (SE) image detector $\left(0^{\circ}\right.$ tilt).

\subsection{MICROSTRUCTURE ANALYSIS}

A TESCAN MIRA3 SEM was used to conduct general microstructure analysis and EBSD and EDS measurements. The SEM is equipped with an advanced Oxford Symmetry EBSD detector (resolution $1244 \times 1024$ pixels, indexing rate up to $\sim 200 \mathrm{~Hz}$ in full-frame mode and $\sim 3.5 \mathrm{kHz}$ in $8 \times 8$ binning mode) and Oxford EDS detector. The specimen surface was surveyed using SE image and BSE detectors. The BSE detector was more informative, as it also provided information on grain morphology and plastic strain level (due to the lattice orientation contrast).

The SEM also allowed installing and using a miniature Kammrath \& Weiss (K\&W) 5-kN tensile frame for in situ mechanical testing $[13,14]$. This capability is important for the present work (see Section 5).

\subsection{TARGETED TENSILE SPECIMEN MANUFACTURING AND TESTING}

Once the microstructure analysis was completed, the specimen was useful for other purposes. Evaluating mechanical performance, deformation, and fracture mechanisms were especially important to ensure the absence of helium-induced embrittlement. The TMAZ area was of special interest (see below).

Miniature tensile specimens of the "SS-Teeny" geometry - a custom specimen geometry for mechanical testing of irradiated metals and alloys, as discussed below-were manufactured using the EDM system (Figure 6) installed in the LAMDA hot area. The system allows for handling, processing, and cutting the irradiated materials involved in this and other projects. The AgieCharmilles CUT 200 Sp commercial system was purchased $\sim 3$ years ago and allowed for multiple wire diameters, providing an accuracy level up to $3-5 \mu \mathrm{m}$. Cutting is performed on specimens fully submerged in water, which excludes any possibility of overheating. 


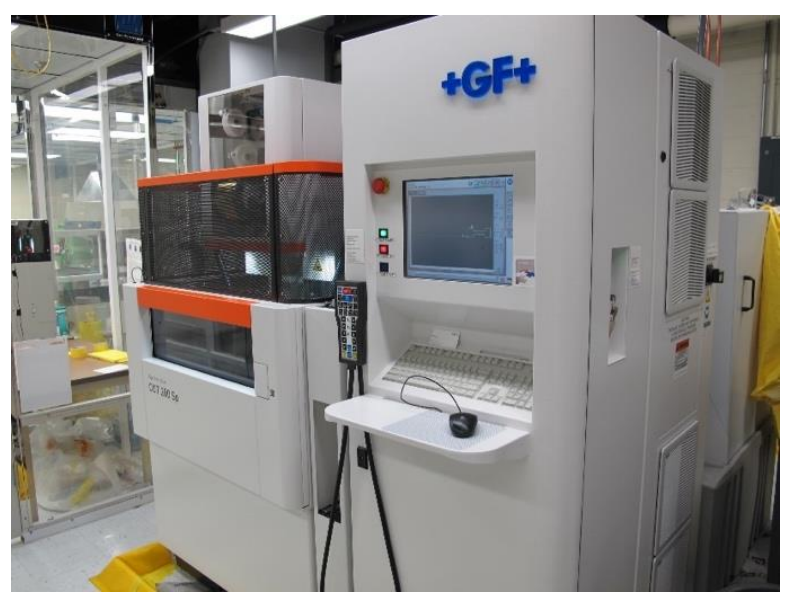

Figure 6. EDM system installed in LAMDA to manufacture specimens from radioactive material.

SS-Teeny specimen (Figure 7) has a gauge length of $1.5 \mathrm{~mm}$ and width and thickness of $0.6 \mathrm{~mm}$. The total specimen length $(5 \mathrm{~mm})$ allows researchers to use the Minimet polisher for mechanical grinding and polishing (down to $\sim 1 \mu \mathrm{m}$ diamond sandpaper), making preparation faster and more reliable. (Note the Minimet is challenging to use if specimen length exceeds $\sim 11-12 \mathrm{~mm}$ ).

The gauge dimensions provided a length-to-width ratio of 2.5, which is sufficient to avoid the impact of the specimen shoulders and limited gauge length on the necking processes. The geometry also meets the common requirement of at least 5 grains across the smallest dimension for typical austenitic steels with a grain size of $60-80 \mu \mathrm{m}$.
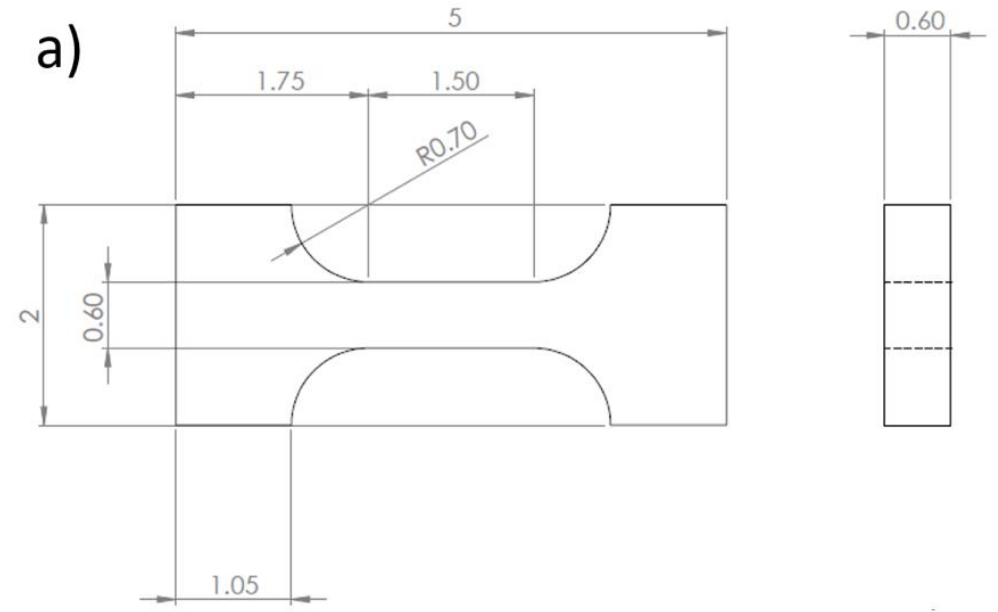

b)

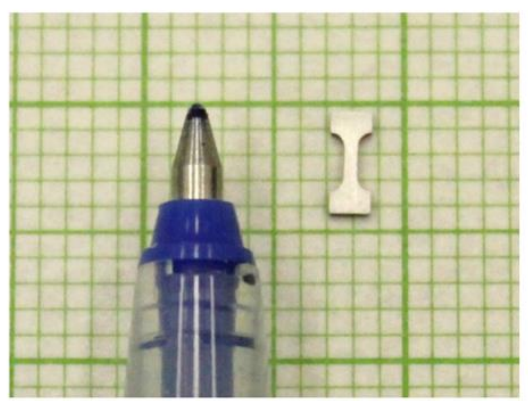

Figure 7. Drawings (a) and appearance (b) of ultra-miniature SS-Teeny specimen. Dimensions are in mm. A pen is used for scale.

The SS-Teeny geometry was designed to limit the consumption of source material. Manufacturing of the SS-Teeny specimen consumes $\sim 2.5 \times \sim 5.5 \mathrm{~mm}$ space $\left(\sim 14 \mathrm{~mm}^{2}\right)$, including extra margins for electric discharge machine (EDM) cutting, and is much smaller than the $\sim 4 \times 7.5 \mathrm{~mm}\left(\sim 30 \mathrm{~mm}^{2}\right)$ space used in earlier work [14]. Limited material consumption may be important for specific applications such as targeted specimen manufacturing from friction stir weld slices. Within the current project, the SS-Teeny specimens had activity levels $\sim 5-7 \mathrm{mR} / \mathrm{hr}$ at $1 \mathrm{ft}$ or less, which was beneficial due to the reduced activity. 
Grips (Figure 8) were designed for both in-SEM and out-of-SEM (i.e., conventional tensile) testing to perform mechanical tests with SS-Teeny specimens.
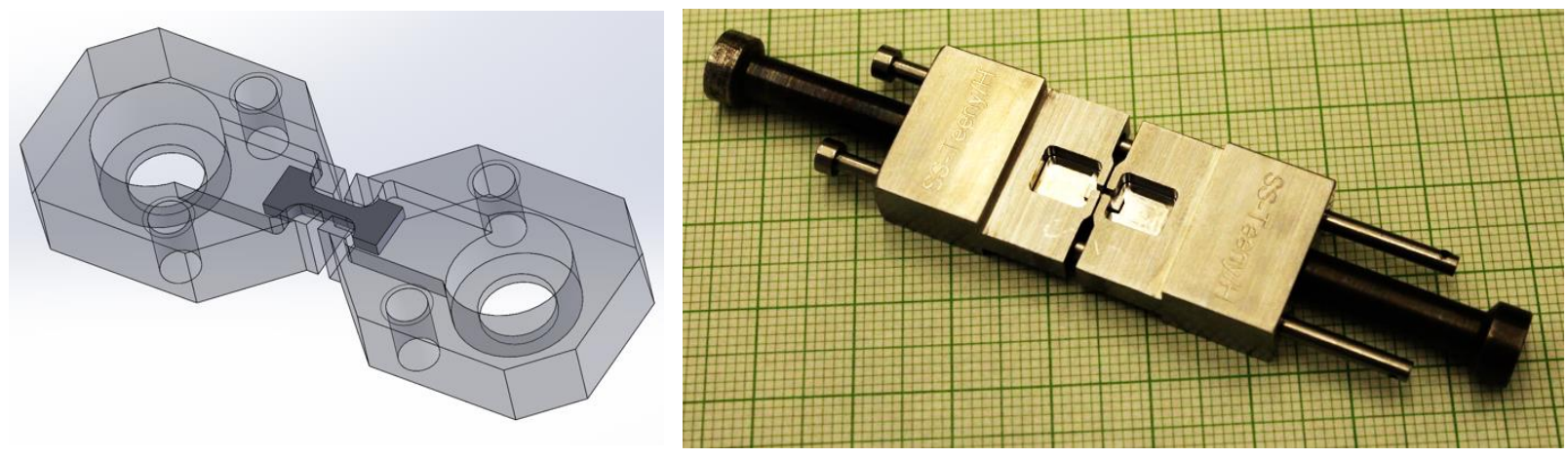

Figure 8. Grips for the $\mathrm{K} \& W$ tensile stage (left) and cnventional tensile grips (right) for the designed ultrasmall specimens. 


\section{FRICTION STIR WELD WITH 5.2 appm He (304C HEAT)}

\subsection{APPEARANCE OF THE FSW COUPON}

Figure 9 shows the visual appearance of the friction stir weld coupon (slice). Again, the left side of the coupon is the advancing side, and the right side is the retreating side. One can see a solid, metallic surface, free of macroscopic (millimeter or so in length) cracks or voids.

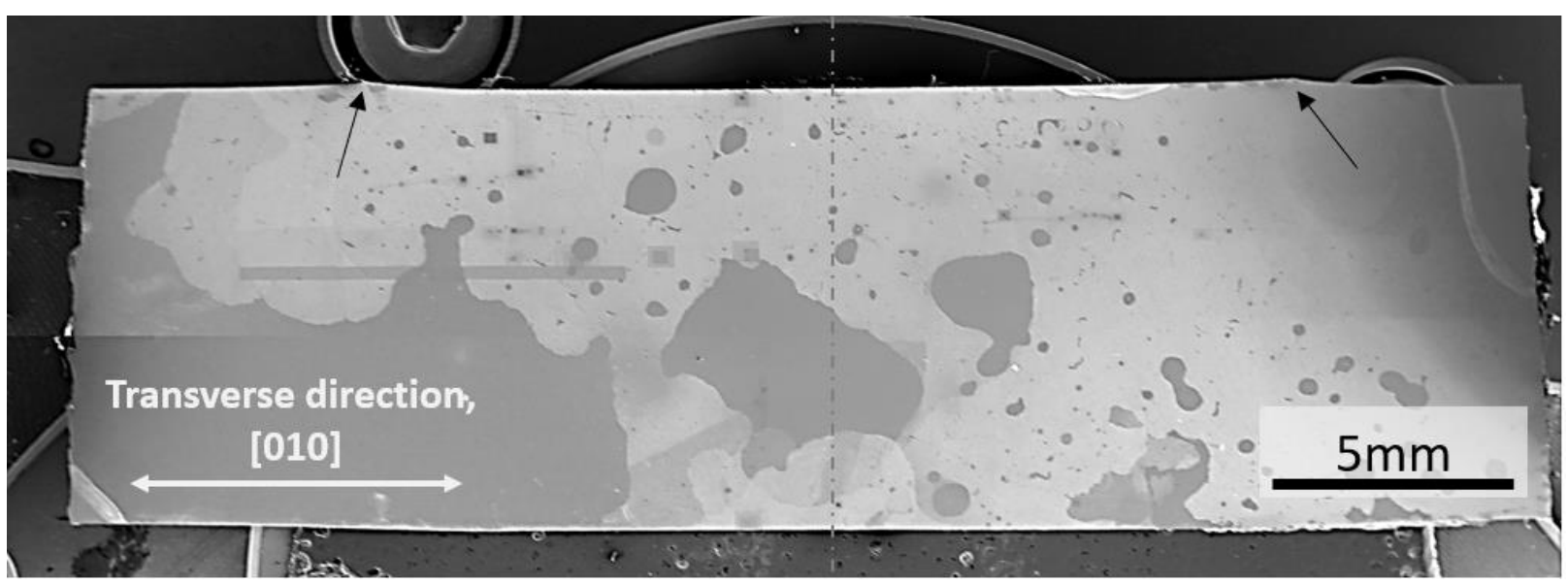

Figure 9. Visual appearance of the investigated friction stir weld coupon. One may see specific features such as the FSW tool undercut (black arrows). Brightness and contrast were adjusted to reveal carbon footprints after the EBSD scans. The coupon does not reveal any macroscopic defects ( millimeters in size). However,

the surface has some variations in color related to electropolishing and rectangle-like carbon spots after EBSD scanning. Note the SEM image shows some distortion due to the low magnification and large field of view.

\subsection{MICROSTRUCTURE OF THE KEY AREAS}

Figure 10 presents the complexity of the friction stir weld microstructure. Only IPF maps are shown, and additional details will be discussed below. The friction stir weld shows a high degree of microstructure variation. The annealed austenite (see the reference IPF map and Figure 2) experiences strong deformation in the TMAZ. Dimensions of the area subjected to the thermal impact are difficult to estimate, but the width of the TMAZ is $\sim 1.5-2 \mathrm{~mm}$. As a result, the degree of plastic strain increases towards the SZ. The boundary between the TMAZ and SZ (see the SZ Left Edge map) shows a mix of strongly deformed austenite grains with pronounced lattice gradients and newly formed recrystallized grains. The SZ interior reveals equiaxial grains, smaller than reference steel, sometimes with curled and twisted GBs. Although detailed, quantitative grain size analysis was out of the present work scope, qualitative analyses (Figure 10) revealed that the grain size tended to be smaller toward the SZ edges and slightly larger in the SZ middle and top. Grain size gradients inside the SZ are probably due to longer times at high temperature and slower cooling rates in FSW. The smallest grains were observed at the SZ bottom. This area was much smaller, with grains a few microns in size. The FSW tool pin tip has a smaller diameter; hence it generated the least heat input at the SZ bottom in FSW and led to ultra-small grain structures after FSW. 


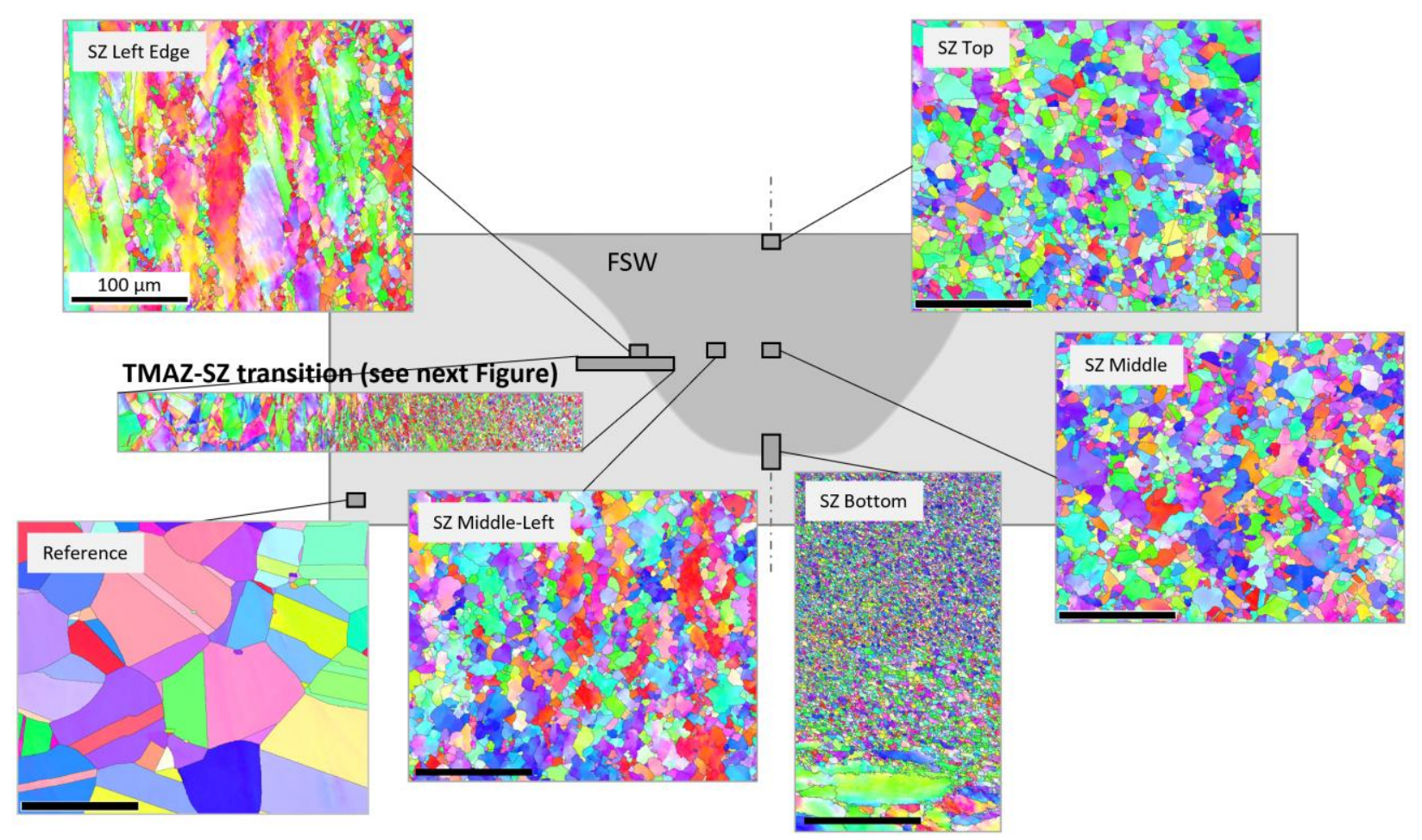

Figure 10. The complexity and variations of the friction stir weld microstructure. The EBSD IPF images are given for key locations. The scale bar (magnification) is the same for all areas $(=100 \mu \mathrm{m})$, except the stitched TMAZ-SZ map. The reference microstructure (different dataset, not Figure 2) is shown for comparison.

Whereas the parent material was mostly texture-free, the friction stir weld shows some degree of texture. The texture is most pronounced along the SZ edge (see Figure 10, the SZ Left Edge map); qualitatively, one can see "green" and "red" colors dominating the IPF map. Most likely, this is due to the overlapping of strong strain-induced texture with some preferential orientation of recrystallized grains. SZ areas close to the edge may show small spots with dominating "red" color (001-orientation with respect to the horizontal direction). More work is necessary to quantify texturing; whereas the whole SZ appears weakly textured, small spots inside the SZ have some texture due to the local condition variations. The texture becomes negligible inside the SZ middle (no dominating color in the whole IPF map).

Based on the results shown in Figure 10, the FSW process generates a very complex structure with gradients in grain size, plastic strain level, and, to some degree, texturing. No macroscopic (a millimeter or fraction of millimeter) defects were observed, suggesting low brittle fracture risks due to the critical defects. One can expect promising mechanical performance; however, the radiation response of such a compound object may be very complex, especially taking into account effects like irradiation-assisted stress corrosion cracking (IASCC).

\subsubsection{Weld SZ}

Figure 11 represents a typical SZ structure with different scanned locations at the SZ top, middle, and two sides, which show very similar microstructure with comparable grain sizes. For these reasons, only the microstructure at one location (the SZ center) will be discussed in detail. As follows from the image, the microstructure exhibits a mix of small and equiaxed grains, below $\sim 10-20 \mu \mathrm{m}$ in size, with roughly shaped, twisted grains of $\sim 40-50+\mu \mathrm{m}$. The microstructure is practically ferrite-free, the preexisting 
retained ferrite fully disappeared. The conditions (i.e., peak temperature and time at elevated temperatures) were not favorable to cause massive new phase formation.

Analyzing the KAM map, one can see multiple in-grain, low-angle grain boundaries (LABs), suggesting high-temperature deformation and partial recrystallization. Visually, KAM varies inside grains, showing grains with a uniform "blue" color (mostly recrystallized) and grains with a mix of "green" and "blue" colors (partially recrystallized). The KAM variations suggest an elevated density of dislocations in the structure typically seen in the SZ after FSW [4].
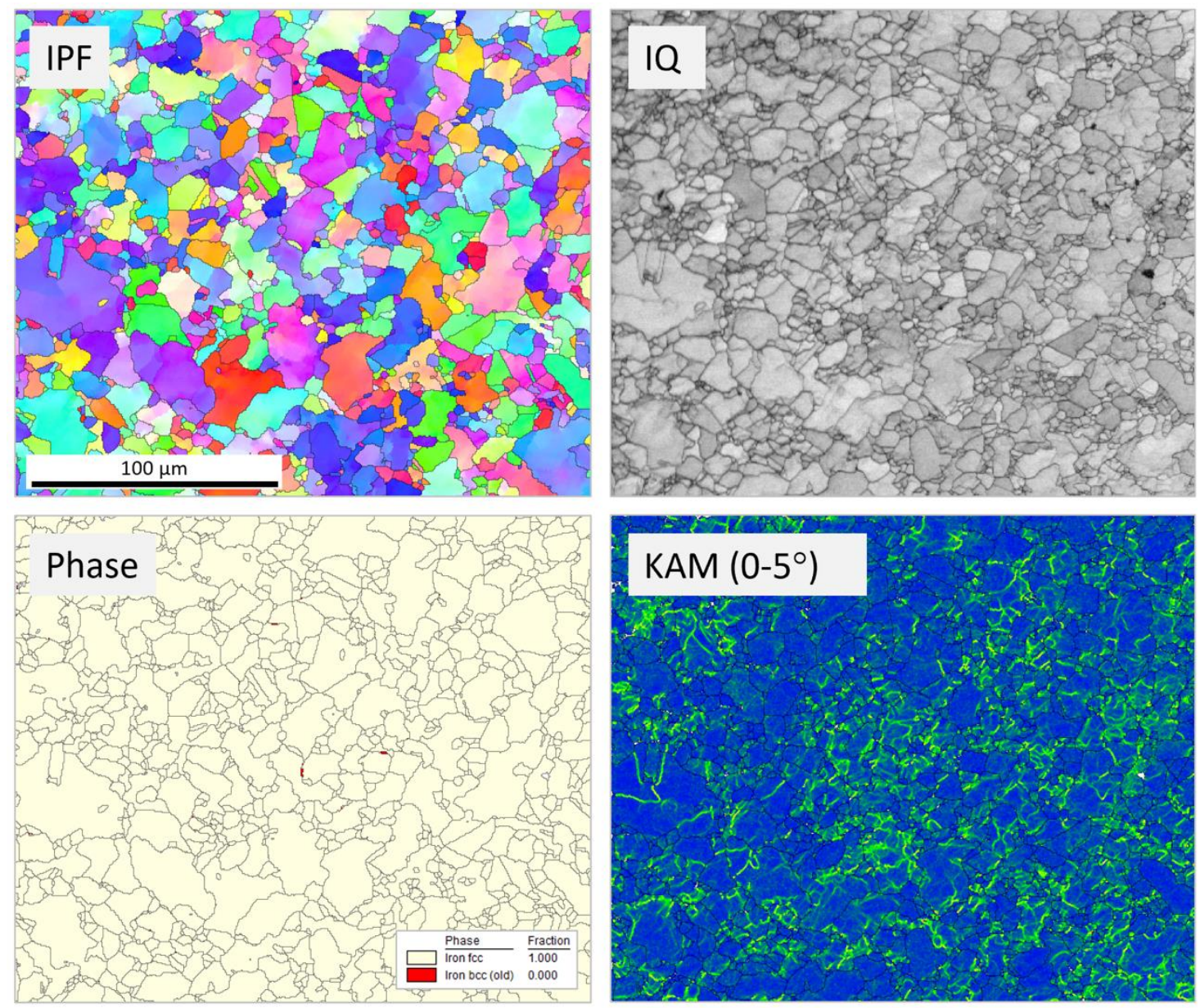

Figure 11. EBSD maps (IPF, IQ, Phase, and KAM) for the middle of the SZ. One can see a mix of small rounded and large rough shape grains. Color in-grain gradients suggest some plastic level of deformation. Note the curled or twisted shape of many grains. Practically no ferrite $(<0.1 \%)$ was observed in the SZ (only a few very tiny grains were observed). EBSD step (pitch) size was $1 \mu \mathrm{m}$.

\subsubsection{TMAZ to SZ Transition on the Weld Advancing Side}

Figure 12 shows the transition area between the TMAZ and SZ on the weld advancing side. This scan was positioned to highlight specific features existing only on the SZ edge. The transition area's width is $\sim 100 \mu \mathrm{m}$ and may vary slightly depending on the exact location. One may see strongly deformed grains at the left inside the TMAZ. Some of these deformed grains have specific chains or "necklaces" along GBs, consisting of much smaller grains. 
Large grains in the middle of the scan (e.g., $G_{1}$ and $G_{2}$ in Figure 12 ) have a very specific in-grain structure: blocky, rectangular-like in-grain boundaries (see the KAM map inset in Figure 12) that are likely the result of co-acting high-temperature deformation and partial recrystallization. In addition, the structure exhibits strong spatial gradients. For example, after a small shift at $\sim 50-70 \mu \mathrm{m}$ at the right from $\mathrm{G}_{2}$, small equiaxial grains are separated by high-angle boundaries.

The retained ferrite survived in the transition area, but the ferrite grains have a needle-like shape and, likely, a plate-like shape found normal to the image plane. The grains are oriented in the vertical direction, reflecting strong plastic strain during the FSW process. The ferrite grains disappear close to the recrystallization boundary and inside the SZ area.
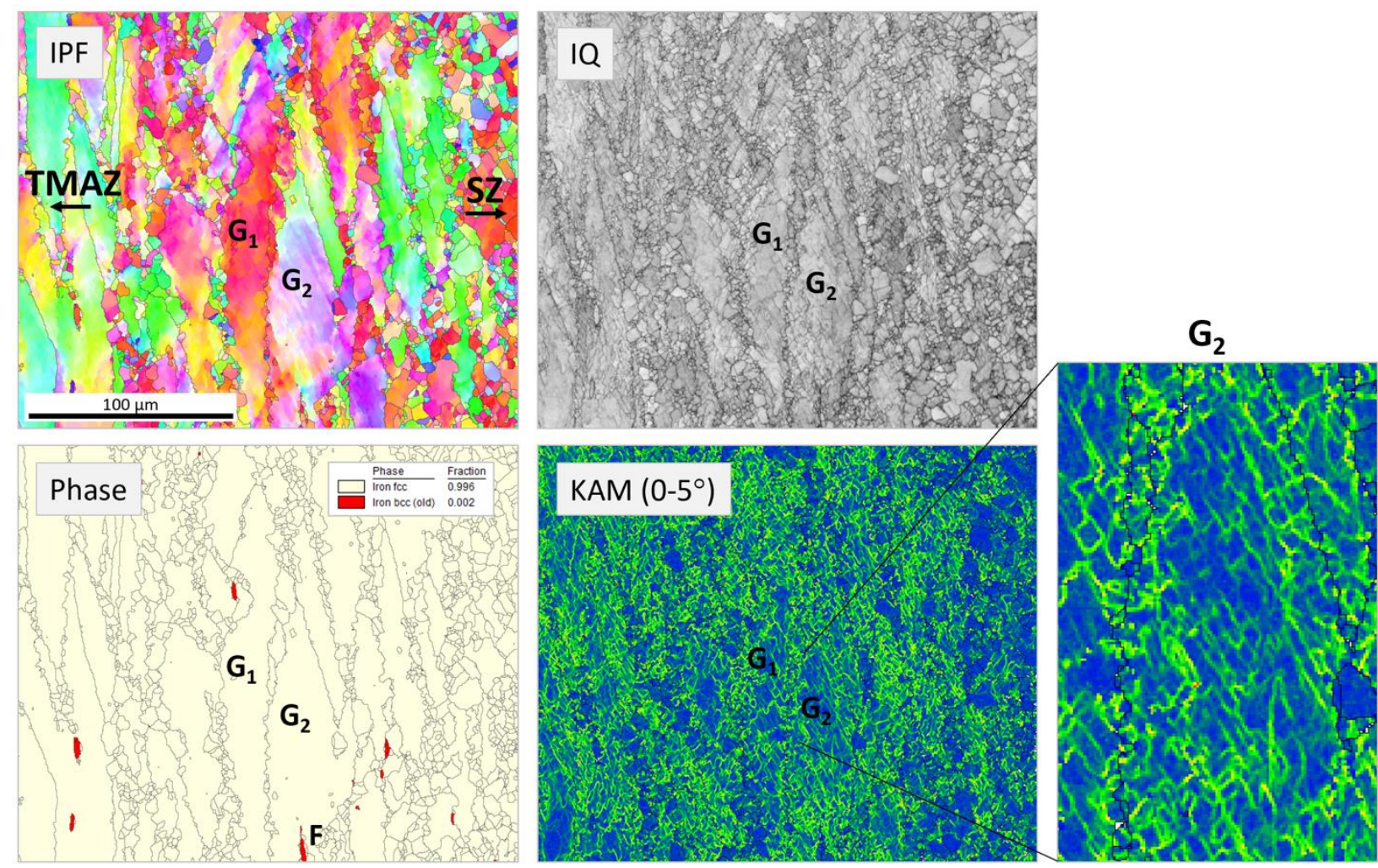

Figure 12. EBSD maps (IPF, IQ, Phase, and KAM) for transition areas between TMAZ and SZ of the advancing side. One can see a sharp change in microstructure between TMAZ and SZ (see details in the text) EBSD step (pitch) size: $1 \mu \mathrm{m}$. The inset at the bottom right shows an enlarged KAM map to highlight specific "blocky" shapes of in-grain boundaries.

Figure 13 shows a much larger TMAZ-SZ transition area (Figure 12) approximately in the middle. One can see striking changes in the grain morphology inside the TMAZ area. The plastic strain level, defined as the EBSD KAM parameter, reaches a maximum at $\sim 1 \mathrm{~mm}$ position along the $\mathrm{X}$-axis (i.e., the exact TMAZ-SZ transition) and decreases as it moves toward the SZ center. According to the KAM profile, the width of the mechanically affected portion of TMAZ is $\sim 1-1.5 \mathrm{~mm}$.

The appearance and character of the in-grain misorientation gradients and slip lines are typical for nonirradiated austenitic steel. In addition, no signs of dislocation channels or radiation-induced strain localization were observed in the TMAZ. This suggests the radiation-induced defects disappeared 
(i.e., experienced full or almost full annealing) before plastic deformation occurred. In other words, the thermal field preceded plastic deformation.

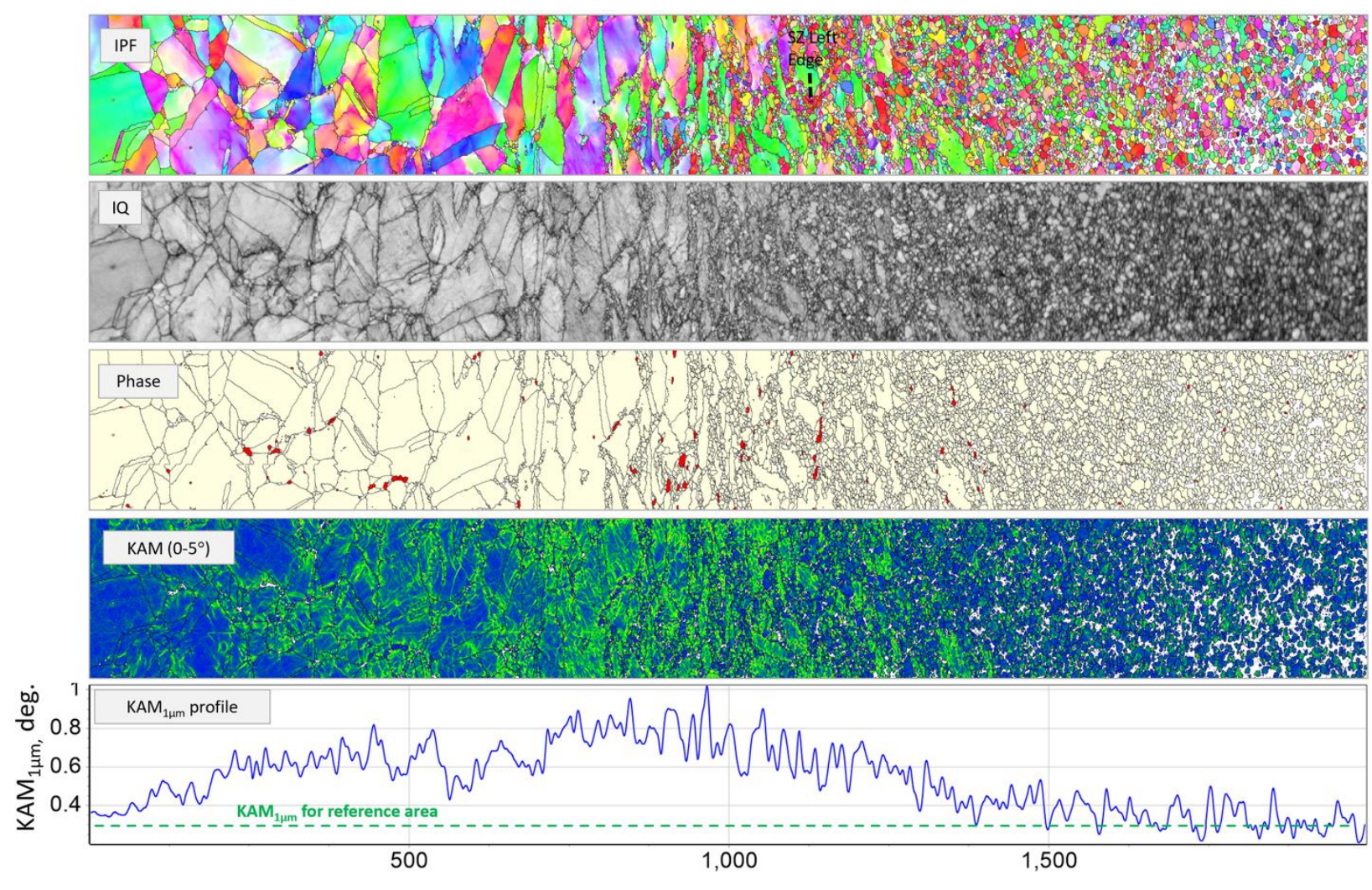

Figure 13. Large-area EBSD scan showing the transition between the SZ (at the right) and TMAZ (at the left) on the advancing side of the weld. 5.2 appm He coupon. One can see microstructure and plastic strain gradients (see Figure 10 for scan location).

\subsubsection{Bottom of the SZ}

Figure 14 shows a striking example of grain size gradients. The SZ bottom area has a grain size of $\sim 3-5$ $\mu \mathrm{m}$, suggesting elevated local strength levels, even after removing radiation-induced defects. The fine grain size at the bottom of the SZ was caused by the relatively low heat generation of the FSW tool pin tip. The SZ bottom area also experienced relatively low peak temperatures and a shorter time at high temperatures than other parts of the SZ. One can also see a very sharp transition from fine grains to a strongly deformed parent material structure, the TMAZ, at the bottom of the weld. 

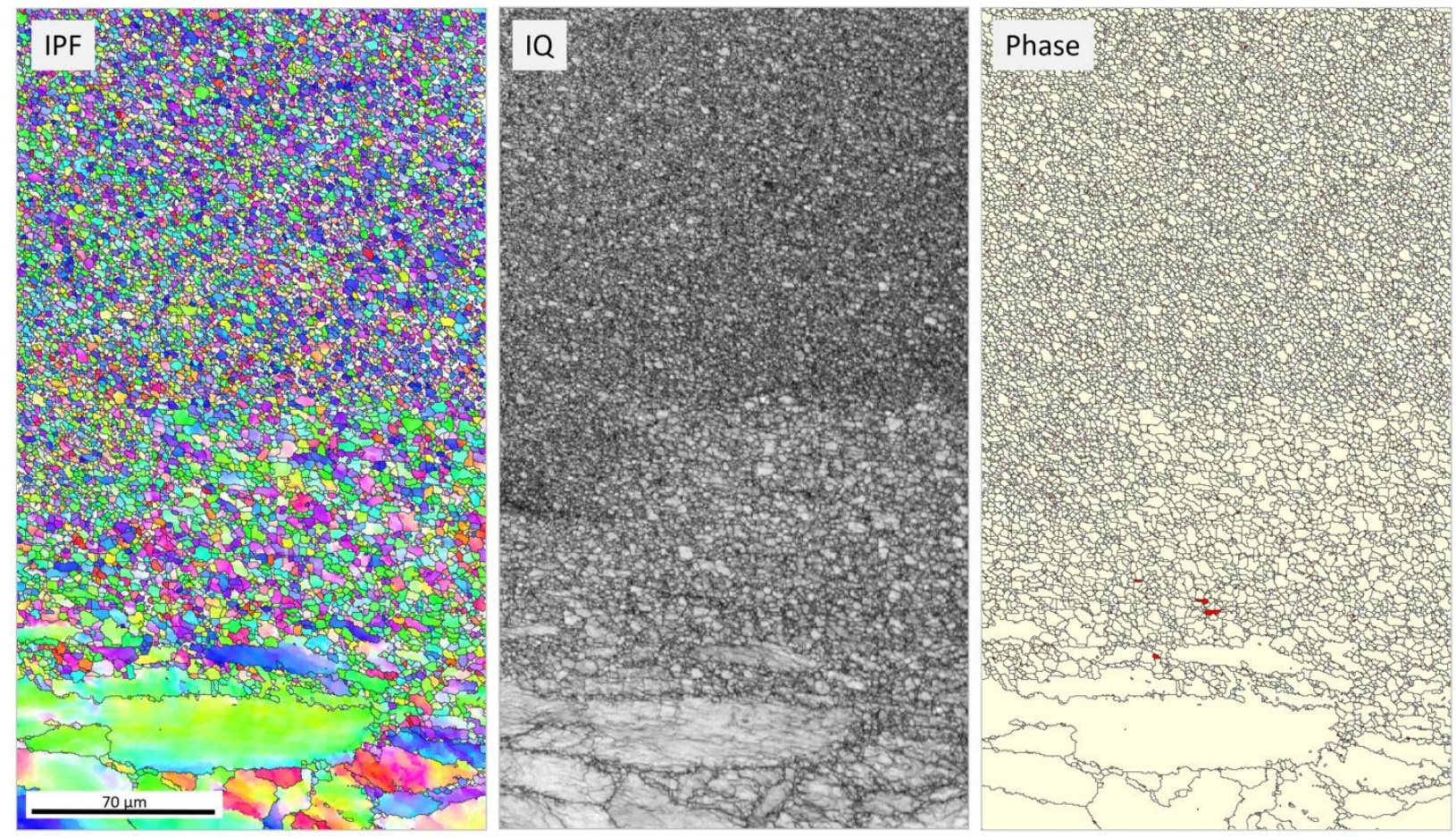

Figure 14. SZ bottom area. EBSD maps show transition between SZ and TMAZ directly at the bottom of the weld, Figure 10). One can see a very small grain size in $\mathrm{SZ}$ and a sharp (tens of microns) transition between TMAZ and SZ.

\subsection{HELIUM-INDUCED MICROSTRUCTURE FEATURES}

When common fusion-based welding techniques are used, welding-induced cracking in the HAZ is a long-term issue for neutron-irradiated materials containing helium [1,2,15]. As a result, helium-induced cracks may appear in the weld zone or HAZ, either on the surface or in the specimen interior, or both (see Figure 1). The material investigated in this report had a helium level much above the value, causing cracking [1]. Although no macroscopic cracks were found, it is important to evaluate any possible microstructure damage associated with higher helium levels.

\subsubsection{SEM Observations of Helium-induced GB Damage}

Figure 15 shows the microstructure of reference (BM) and TMAZ areas. The SEM image contrast was adjusted to highlight the pores and possible bubbles, cracks, and other defects in the structure. One can see that GBs in the reference area are clean, without precipitates or particles of any kind. Minor pores were present at the surface because inclusions were removed or etched away during the specimen preparation.

Figure 15 provides an example of how the preexisting features appear in the reference material (BM) and provides a method to identify helium-induced damage with a sufficient degree of reliability. As the pores appear at the surface during polishing, they lose helium, and the nature of the pore may be established only via indirect attributes (e.g., morphology, shape, proximity to the GB and other pores). Potentially, helium in confined micro-voids may be detected directly using techniques like electron energy loss spectroscopy (EELS) [15]; however, exploring this topic requires specially focused and time-consuming work. 
Helium-induced features (compare the top two panels in Figure 15) appear distinctly different from metallurgical defects and minor inclusions. First, the TMAZ area clearly shows much larger pores or bubbles. Second, the orientation contrast in BSE images demonstrates that these defects appeared, in most cases, along GBs. Often, the bubbles have an elongated shape and form specific chains or "necklaces" along GBs. Third, in some cases, the bubbles tend to merge into micro-cracks, such as the $\sim 10 \mu \mathrm{m}$ long crack shown in the image.

After visual analysis of the collected images, this area appeared to be one of the most damaged TMAZs on the retreating side, with the highest density of the observed helium-related issues. The BSE image with lower magnification reveals several "chains" of helium bubbles, in all cases along GBs. The largest continuous defect (worm-like crack) did not exceed $\sim 12-15 \mu \mathrm{m}$ in length and with a $\sim 1-2 \mu \mathrm{m}$ opening in width. Other areas, if imaged at comparable magnification, contained a smaller density of bubbles and pores.

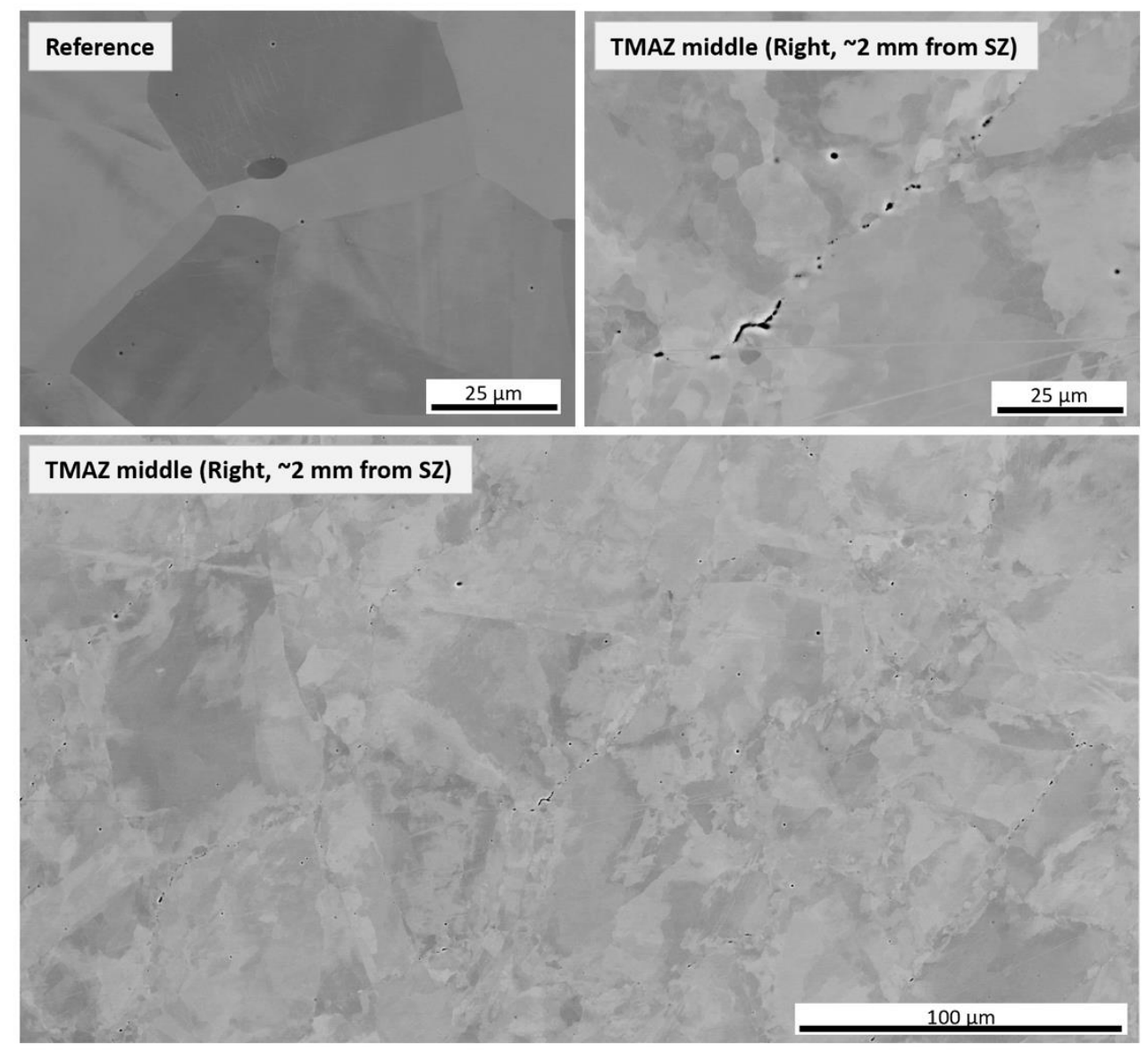

Figure 15. Preexisting pores in reference material (BM) and helium-induced damage in the TMAZ area. $\sim 2 \mathrm{~mm}$ from the SZ boundary on the retreating side at the right, see Figure 9. SEM BSE images. The same area of the friction stir weld specimen is shown at two different magnifications. Note the brightness/contrast was digitally corrected to highlight the microstructure features and improve the readability of the printed copy. 
It is assumed that all of these defects are minor (i.e., below the critical size able to cause sudden fracture under loading). Conventional welding techniques, as a rule, exhibit more severe damage and with a much higher defect density and size (in millimeters in many cases, see Figure 1).

Figure 16 shows the appearance of helium-induced damage at different locations in the SZ and HAZ. The SEM BSE images were recorded at approximately the same depth (around half of the SZ depth) but at different distances from the SZ and TMAZ boundaries. Inside the SZ, one can see multiple pores/bubbles with the size of $\sim 1-1.5 \mu \mathrm{m}$, as well as short pore chains oriented along GBs. Often, the single pore or pore chains appeared away from GBs, likely reflecting the GB migration during recrystallization. GBs migrate during recrystallization, but the pores/bubbles should retain their positions.

In some cases, the bubbles and pores had elongated, triangle-like, or wedge-like shapes, reflecting high plastic straining. However, from a practical point of view, the most important result is the high quality of newly formed GBs in the SZ and the finding that most do not have bubbles, which suggests good mechanical performance.
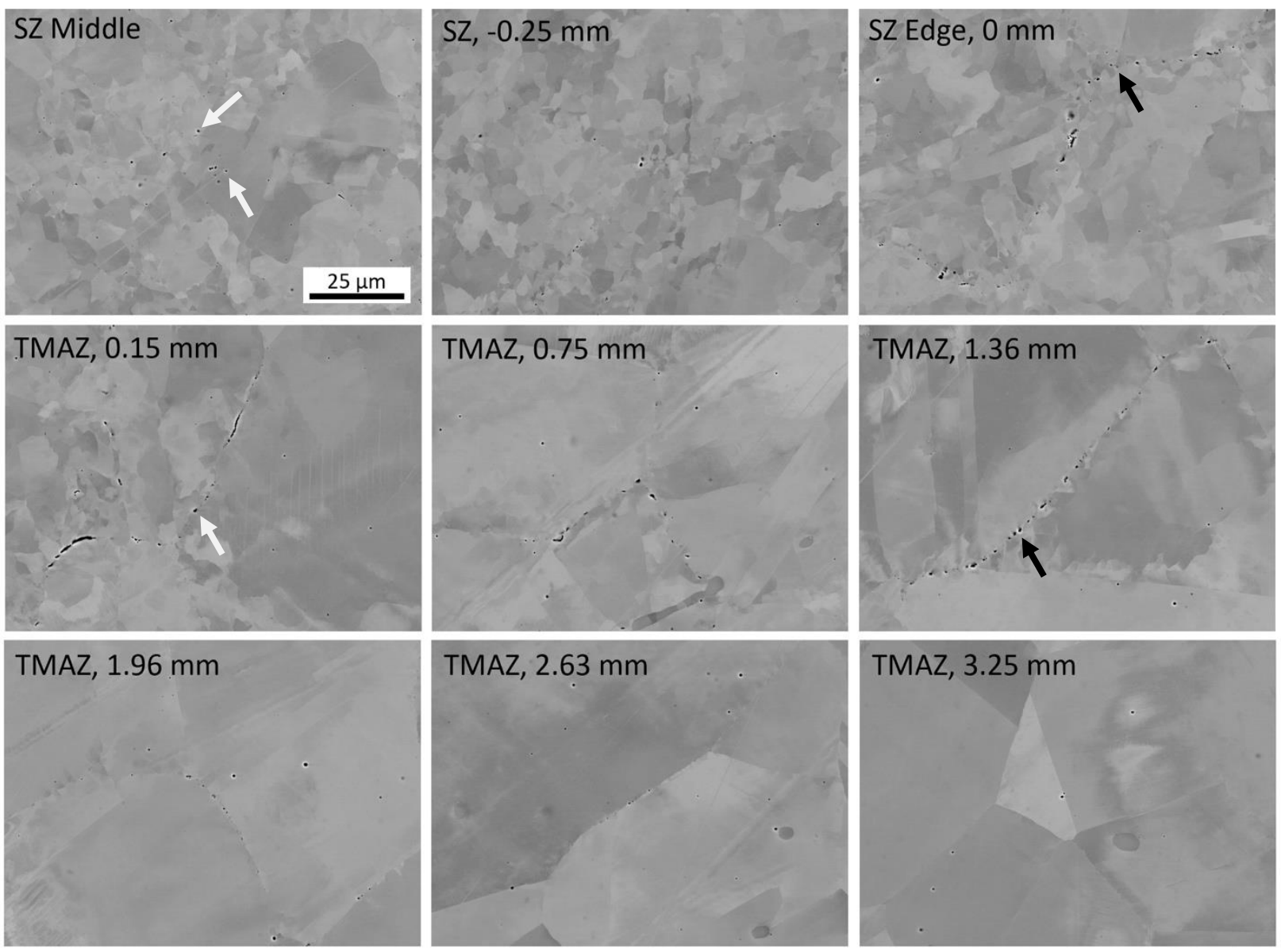

Figure 16. Helium-induced damage at different locations. The numbers show distance (in millimeters) from the SZ edge; negative value shows location inside the SZ. White arrows indicate single bubbles; black arrows indicate the bubble chains. SEM BSE detector images. The top row shows the SZ area (SZ middle [top left panel] approximately corresponds to the weldment center line in Figure 10); the middle and bottom rows represent a typical TMAZ structure. Scale bar (magnification) is the same for all images. Grain size and morphology may be deducted from orientation contrast. 
The degree of damage in the TMAZ area strongly depends on the distance from the SZ edge with pore chains and short $\sim 5-15 \mu \mathrm{m}$ cracks observed within $\sim 1.5 \mathrm{~mm}$ range from the SZ edge (see Figure 16, middle row). These defects, with rare exceptions, were associated with preexisting GBs.

Helium bubbles and pores present at $\sim 2 \mathrm{~mm}$ distance, and one can find single, negligible defects at $\sim 2.5$ $\mathrm{mm}$. No obvious helium-induced defects were presented at distances large than $\sim 2.5-3 \mathrm{~mm}$ from the SZ. The vast majority of the observed features could be classified as metallurgical inclusions (see Figure 16, bottom row).

Interestingly, the SZ Edge area cannot be described as having the largest degree of helium-induced damage. Qualitatively, the largest density of defects presented at $\sim 0.5-1 \mathrm{~mm}$ from the SZ edge. The lower density of defects directly near the SZ edge location may be explained by the high dislocation density because dislocations, being helium trap sites, slow down or prevent helium migration at the GB. Continuous plastic strain may also delay the bubble growth or lead to the fragmentation of the already formed bubbles.

In all cases, the observed defects' density and size were much smaller than the HAZ damage caused by GTAW or laser beam welding [2]. Another explanation for the smaller density and size could be the lower peak temperatures during the solid-phase FSW process, compared to the fusion welding techniques, in which peak temperatures exceed the material melting point. In addition, elevated dislocation densities due to plastic deformation may play a beneficial role, serving as helium trapping sites [2].

Interestingly, preexisting defects caused by material processing may be cured by elevated temperature and pressure. FSW is a thermo-mechanical process, and as such, it introduces and maintains high pressure during the FSW. Studies have shown that material defects can be repaired by FSW [16]. It is important to emphasize that the width of the defect-populated area (from SZ boundary to $\sim 2 \mathrm{~mm}$ ) appears to be larger, compared to the welding techniques with low energy contribution; thus, in [17], only 100-200 $\mu \mathrm{m}$ degraded (cracked) HAZ area was reported.

\subsubsection{Crystallography Analysis of Helium-induced Degradation}

Figure 17 shows an image of the damaged area with several compromised GBs and the corresponding EBSD dataset. This location was selected because it contains multiple degraded GBs (enough statistics in one single scan) and is located in the TMAZ close to the SZ edge, which experienced the largest temperature jump and plastic strain. In the SEM image, one can see several damaged GBs, enumerated as $\# 1, \# 2, \ldots \# 6$. The \#1 GB contains several clusters of helium bubbles; \#2 shows a short, $\sim 12 \mu \mathrm{m}$ crack and a few isolated bubbles. One $\sim 20 \mu \mathrm{m}$ crack, according to EBSD results, contains three visible GBs (\#3, \#4, \#5), and, finally, minor deterioration present at GB \#6. Other GBs contain no or only minor heliumrelated degradation, although one may deduce the position of these GBs in the SEM image.

EBSD results suggest that all GBs with observed degradation belong to the random high-angle boundary (RHAB) type black color in the GB map (Figure 17(b)). In addition, the IPF map indicates misorientation angle values exceeding $20^{\circ}$ (Figure $17(\mathrm{c})$ ). Note that due to the pronounced in-grain lattice gradients, these are estimated values, with an accuracy of a few degrees.

Special GBs, like $\sum 3$, did not appear in the GB map (Figure 17(b)) if one targets "perfect" $\sum 3$ boundaries (i.e., with minor or no deviation from theoretical $60^{\circ}$ rotation about the 111 -axis). However, multiple "imperfect" $\sum 3$ GBs were present in the field of view. Significant plastic strain led to a strong $\left(5^{\circ}\right.$ or larger) deviation from the common twin boundaries $\left(60^{\circ}\right.$ rotation about 111-axis). Instead of being imperfect, the observed $\sum 3$ did not show signs of helium-induced degradation. 

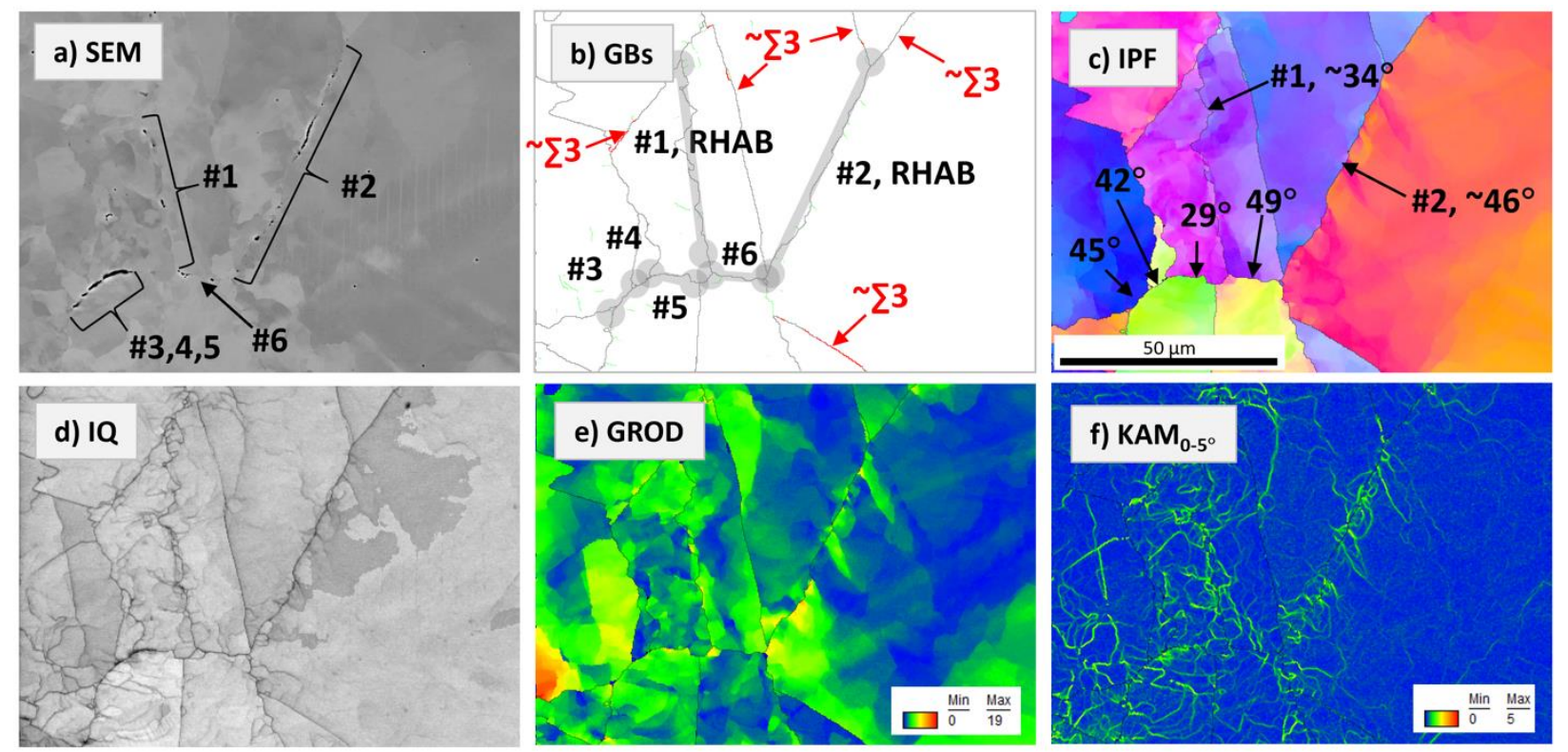

Figure 17. Helium-induced damage on GBs. (a) SEM/BSE image of the TMAZ ( $0.15 \mathrm{~mm}$ from SZ boundary) with identified GB damage; (b) EBSD-retrieved GB network map; (c) IPF map, showing the misorientation of GBs \#1-\#6; (d, e, f) additional EBSD maps showing pattern quality (IQ map) and misorientation parameters. Scale bar is the same for all images. The SEM image was recorded at the $0^{\circ}$ tilt, whereas EBSD scans were performed at $70^{\circ}$ tilt. EBSD step (pitch) is $250 \mathrm{~nm}$. 


\section{DEFORMATION MECHANISMS IN THE FRICTION STIR WELDED COUPON WITH 5.2 APPM HE}

\subsection{LIST OF TESTED SPECIMENS}

The presence of helium-induced damage — bubbles, chains of bubbles, and micro-cracks - may compromise the material's performance, even if only a small fraction of all GBs are affected. To ensure the mechanical property level and identify the deformation mechanisms, small tensile samples (Figure 7) were manufactured from the three different zones of friction stir weldment with $\sim 5$ appm He. The reference specimen was cut from the coupon's edge. The material at this location experienced irradiation and, probably, some heat impact during FSW but apparently was not be sufficient to affect the microstructure and mechanical properties at this location. No plastic strain occurred at this location. The reference specimen was intended to provide baseline information regarding deformation mechanisms. The SZ middle and TMAZ specimens in Figure 18 had some degree of helium-induced damage in the form of scattered bubbles, bubble chains, and micro-cracks (Figure 16). The mechanical response of these specimens would answer how critical the damage degree is concerning the material performance.

Table 2. ID, source location, and reached strain level for the tested sample.

\begin{tabular}{|c|c|c|l|}
\hline ID & Source location & Presence of He bubbles & Reached strain level \\
\hline 304C-6-14-15 & Reference & Not observed & Deformed up to $\sim 25 \%$ \\
\hline 304C-6-14-7 & SZ middle & $\begin{array}{c}\text { Low fraction; scattered } \\
\text { inside grains and at GBs }\end{array}$ & Deformed up to $\sim 25 \%$ \\
\hline 304C-6-14-1 & $\begin{array}{c}\text { Higher fraction; mostly as } \\
\text { bubble chains along GBs, } \\
\text { sometimes scattered in } \\
\text { grains }\end{array}$ & Deformed up to $~ 25 \%$ \\
\hline
\end{tabular}

The SEM/EBSD in situ tensile experiments, described Section 2.5 , were conducted to reveal and quantify deformation phenomena, as well as fracture mechanisms if they occur during the test. During the in situ experiments, the EBSD data and SEM images of the microstructure were recorded at different strain levels. Detailed information regarding the tested samples is included in Table 2.

\subsection{PRE-DEFORMED MICROSTRUCTURE AND TEXTURE}

Before the deformation, the general microstructure and specific features were analyzed for the manufactured miniature tensile samples, as seen in Figure 18. Small cavities were observed in the reference specimen and identified as metallurgical defects and inclusions, as shown in Figure 18(a). These pores were located, as a rule, in the grain body rather than at GBs. Multiple small pores/voids, likely He bubbles (Figure 18(b)) were observed in the specimen that was selected from the SZ middle. The size and number of the pores/voids per unit area were much larger compared to the reference location. Microstructure from the TMAZ area (Figure 18(c)) shows relatively larger bubbles than the SZ and reference objects, and most of them appeared along GBs.

The pre-deformed tensile direction (TD) IPF maps and GB maps were generated from the EBSD data (Figure 18). Figure 18(d), 18(e), and 18(f) show the TD IPF maps. GB maps presented in Figure 18(g), 18(h), and 18(i) are from the reference SZ middle and TMAZ, respectively. Finer grain sizes appear on the SZ middle, predicting higher strength and ductility. The sample from the TMAZ shows the lattice gradients (i.e., color changes in the IPF map), reflecting the presence of plastic strain caused by the FSW 
process. SZ middle sample shows much weaker lattice gradients, reflecting that the recrystallization process occurred in the SZ area.

The SZ middle sample has a higher fraction of the random low-angle grain boundaries (RLABs) than the reference and TMAZ samples. During the loading, these LABs play a role in obstructing the motion of dislocations and increasing the alloy's strength. However, the reference sample contains mainly RHABs and twin boundaries.
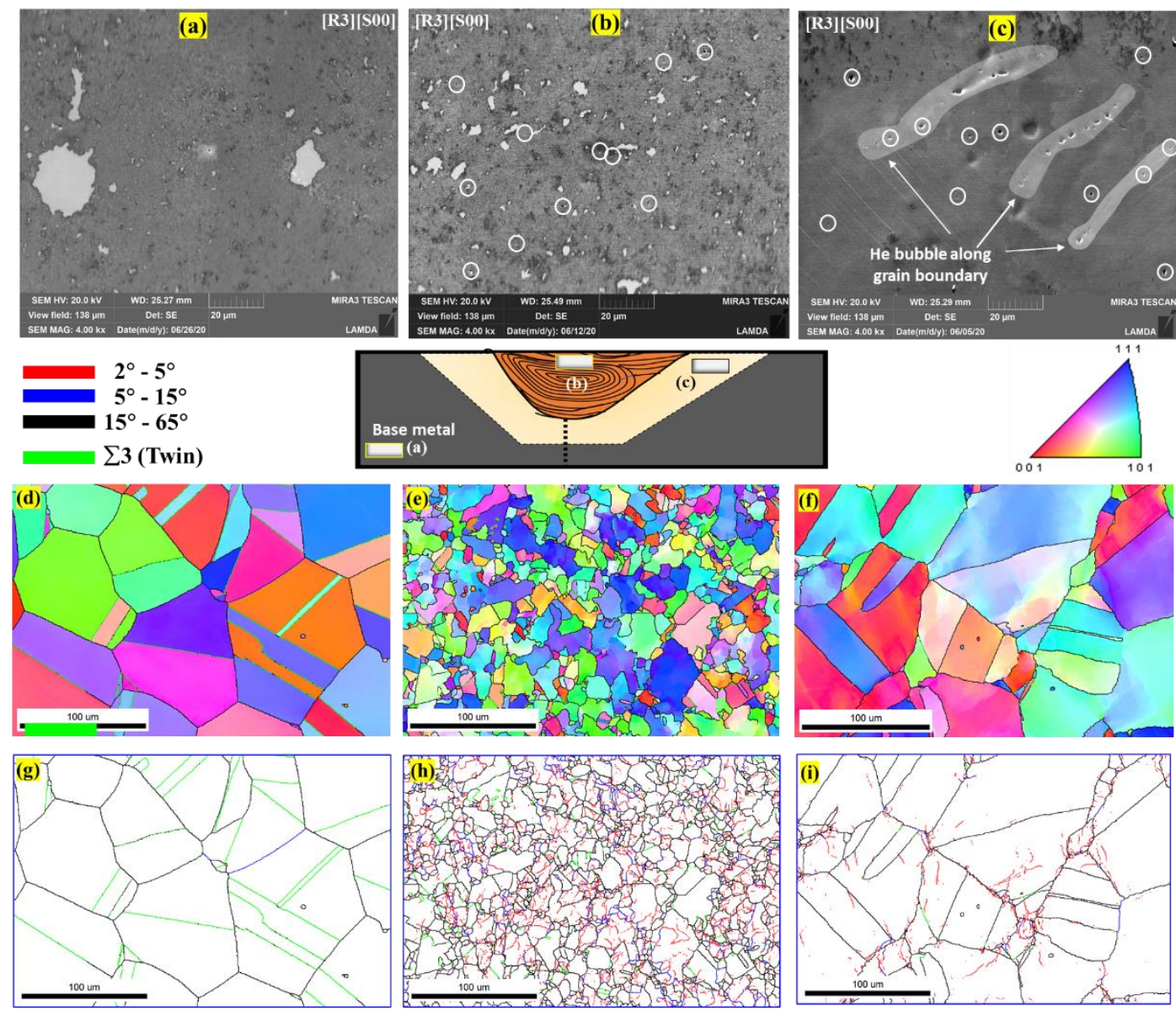

Figure 18. SE micrographs depict microstructure and He-induced damage for three different zones: (a) reference, (b) SZ middle, and (c) TMAZ. EBSD-generated maps depicting the (d) TD IPF map of reference, (e) TD IPF map of SZ middle, (f) TD IPF map of TMAZ, (g) GB map of reference, (h) GB map of SZ middle, and (i) GB map of TMAZ.

EBSD data were recorded from the whole gauge of the miniature tensile specimens before the deformation to evaluate the texture. The (111) and (220) pole figures (Figure 19) were generated using specialized EBSD data analysis software, TSL OIM (https://www.edax.com/products/ebsd).

As one can see, the reference sample exhibits weak, if any, texturing up to $\sim 2-2.5 \times$ random, which is an expected result for annealed austenite. The SZ middle sample has a slightly stronger crystallographic texture, up to $\sim 3.45 \times$ random, transitioning toward a fiber-like texture. Due to plastic deformation and recrystallization, the whole $\mathrm{SZ}$ area has a complex structure with multiple small regions with varying textures. Furthermore, the change of the location to the TMAZ suggests a weakly deformed austenite with 
grain sizes comparable to the reference sample. The major difference between the reference and TMAZ locations is the presence of plastic strain.

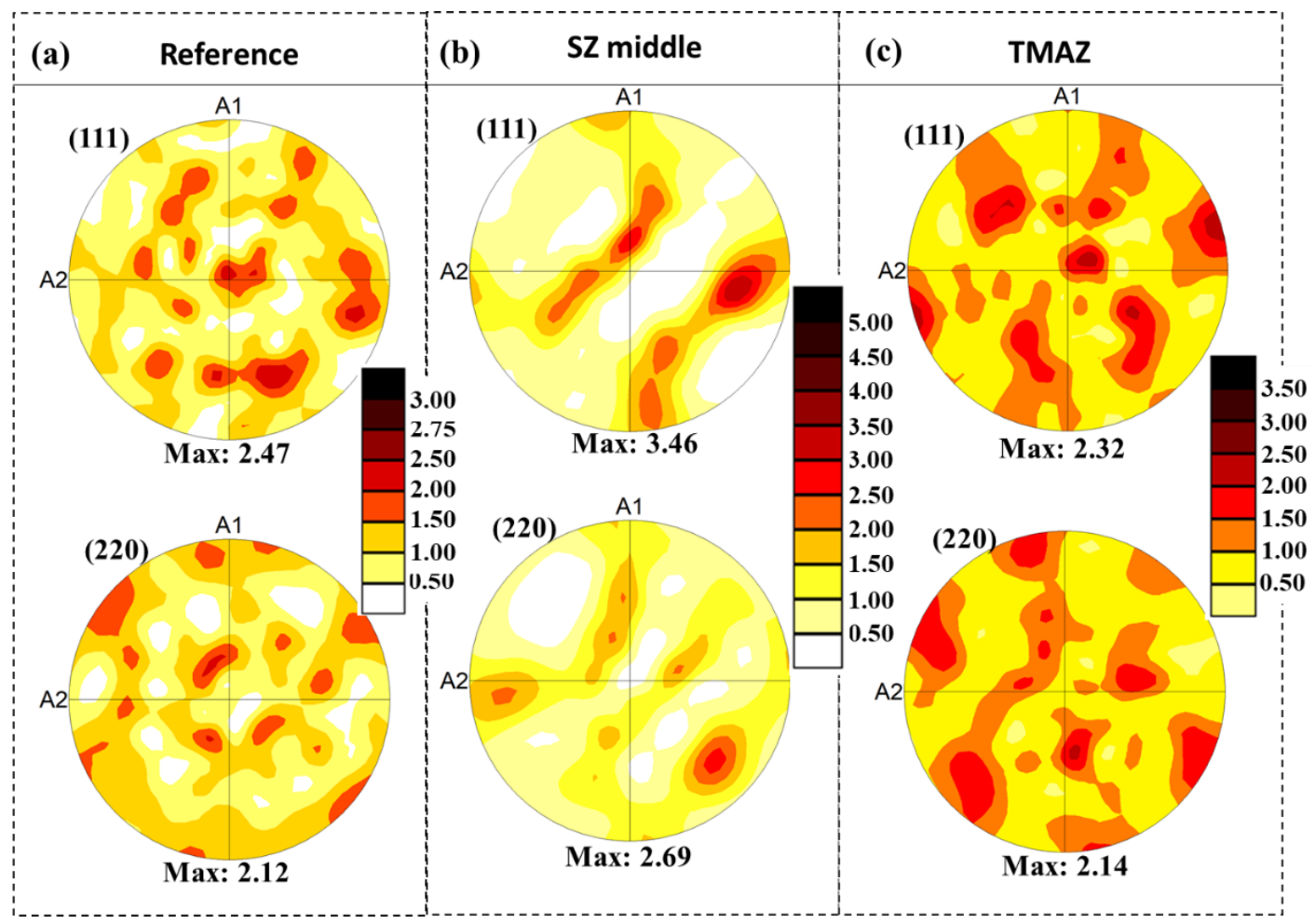

Figure 19. (111) and (220) pole figures, generated from the gauge area. (a) Reference region, (b) SZ specimen, and (c) TMAZ.

\subsection{TENSILE BEHAVIOR OF SPECIMENS FROM DIFFERENT METALLURGICAL ZONES}

A typical raw (unprocessed) load-displacement curve is presented in Figure 20. This specimen (TMAZ area) revealed pronounced strain hardening. Moreover, no necking developed, and no signs of fracture or embrittlement were observed for displacements up to $\sim 600-700 \mu \mathrm{m}$ (roughly $\sim 25 \%$ of strain). The experimental curve shows some force drops, which correspond to the strain interruptions to perform EBSD scanning. Ten deformation steps were performed on this particular specimen, providing sufficient statistics. 


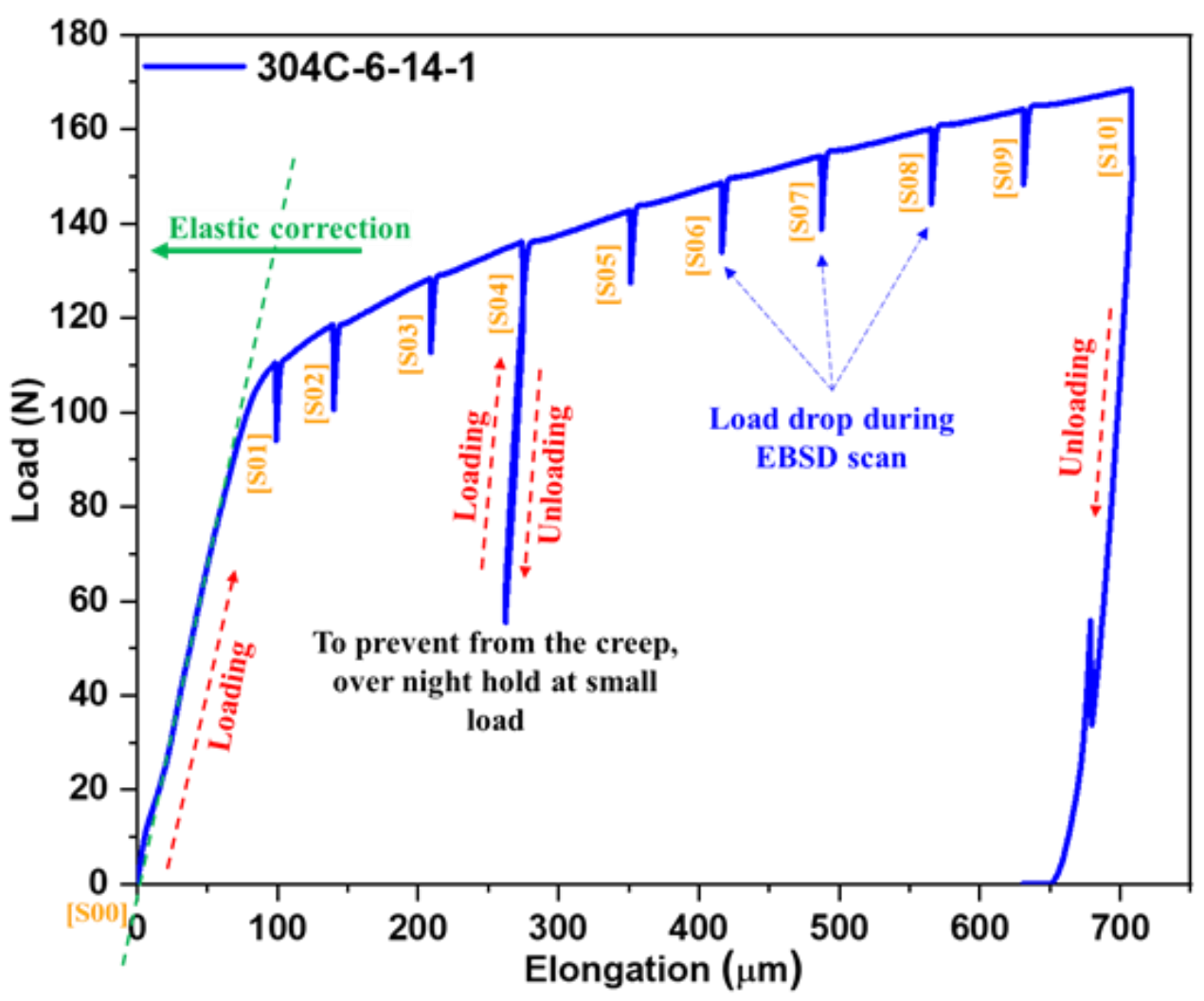

Figure 20. Raw "load-displacement” tensile curve for 304C-6-14-1 sample (TMAZ).

All three specimens were deformed to $25 \%$, ensuring the absence of embrittlement or sudden, unexpected fracture. The engineering stress-engineering plastic strain curves for all samples are shown in Figure 21. Again, one can see the reference specimen had the highest strength, as the material at this location experienced hardening during irradiation in the HFIR and weak, if any, thermal impact during the FSW process.

The SZ middle sample showed a moderate level of strength. As expected, radiation-induced defects were fully annealed during the FSW process. The strength increase may be attributed to the smaller grain size and limited degree texturing. The TMAZ sample shows a lower strength compared to the reference and SF samples. This may be attributed to a strong heat impact and annealing of radiation-induced damage. Simultaneously, the plastic strain was not sufficient to compensate for the defect annealing. In all cases, the yield stress was slightly above a value one would expect for a typical annealed 304L steel ( 240$260 \mathrm{MPa}$ ).

It is important to emphasize that no crack formation or sudden fracture was observed in the tested specimens up to $\sim 25 \%$ elongation. Furthermore, the He bubbles presented in the structure of TMAZ and SZ samples did not lead to severe embrittlement. However, more statistics (i.e., additional tests) are necessary, as well as fractography analysis. 


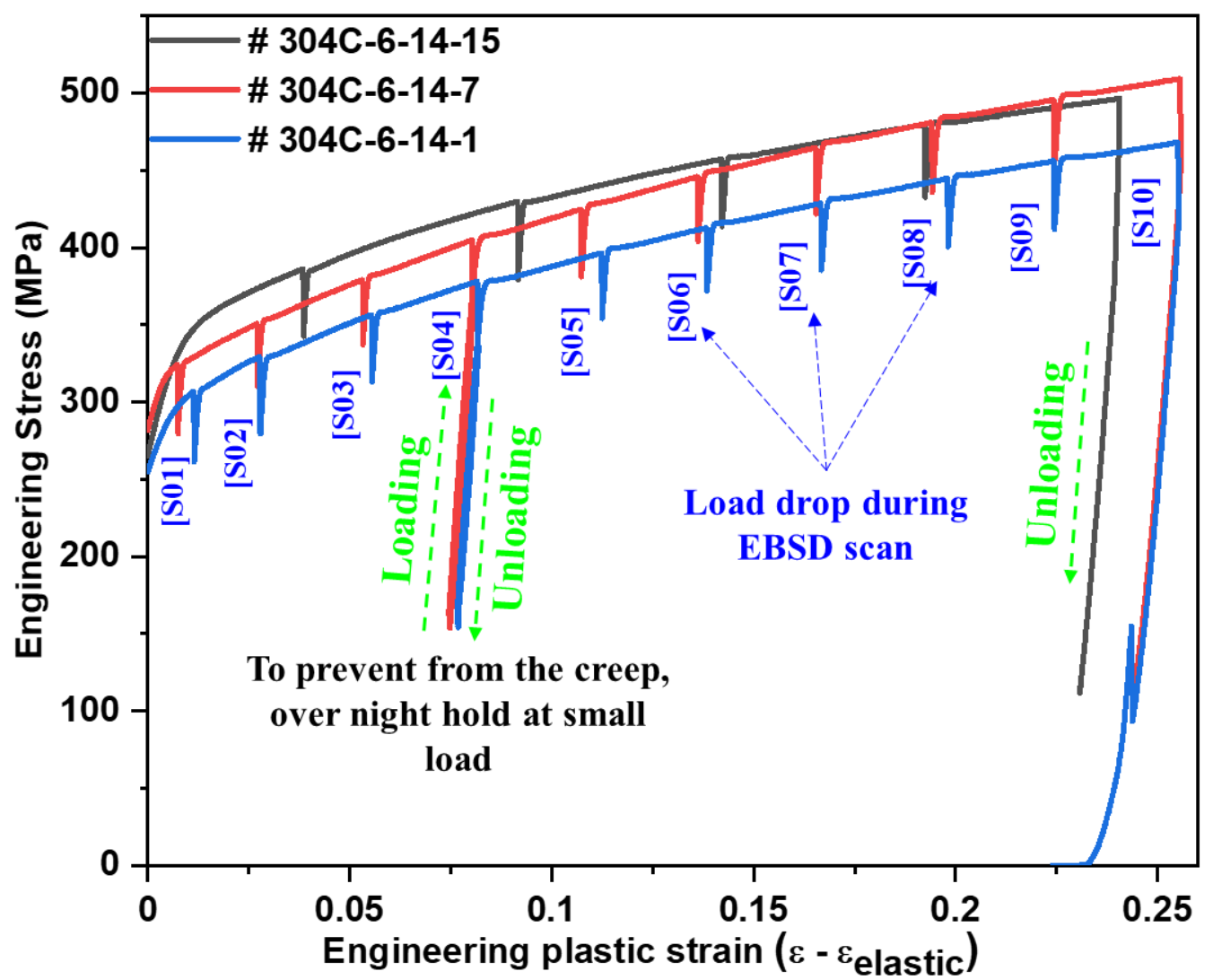

Figure 21. Engineering stress versus engineering plastic strain $(\varepsilon-\varepsilon$ elastic) for the three specimens prepared from different zones.

\subsection{STRAIN-INDUCED PROCESSES AND ACTIVE DEFORMATION MECHANISMS}

Austenitic steels may show different deformation mechanisms, including the formation of lattice gradients, changes in the GB character, evaluation of the crystallographic texture, twinning, phase instability, and the formation of cracks and pores. The presence of helium-induced damage, however, may enhance or suppress any of these processes. In situ mechanical testing - tracking and observing the same location at different levels of strains - is one of the most suitable tools to examine those processes. This section discusses only the most interesting and important results; data analysis and processing are still in progress, and full datasets will be discussed in separate, focused manuscripts.

\subsubsection{Local misorientation change and lattice gradients formation}

Helium-induced damage and GB degradation were the most pronounced in the TMAZ specimen. Figure 22(a) and Figure 22(b) show the chain of helium bubbles along the GB, and this chain was of high priority. The region of interest (Figure 22(c)) included numerous grains surrounding the compromised boundary to provide sufficient statistics. Figure 22(c), Figure 22(d), Figure 22(e) show this region at different deformation steps (i.e., strain levels), corresponding to S01, S06, and S10 in Figure 21. One can see that the compromised GB with helium bubbles served as a source of multiple slip lines, and, at some strain level, strain-induced twins appeared close to this boundary. 
Analysis of the IPF maps showed lattice rotation and formation of the in-grain misorientation gradients. Both phenomena are well known for nonirradiated 300-series steels. Qualitatively, helium bubbles did not influence lattice rotation processes; however, they did enhance the local twinning.
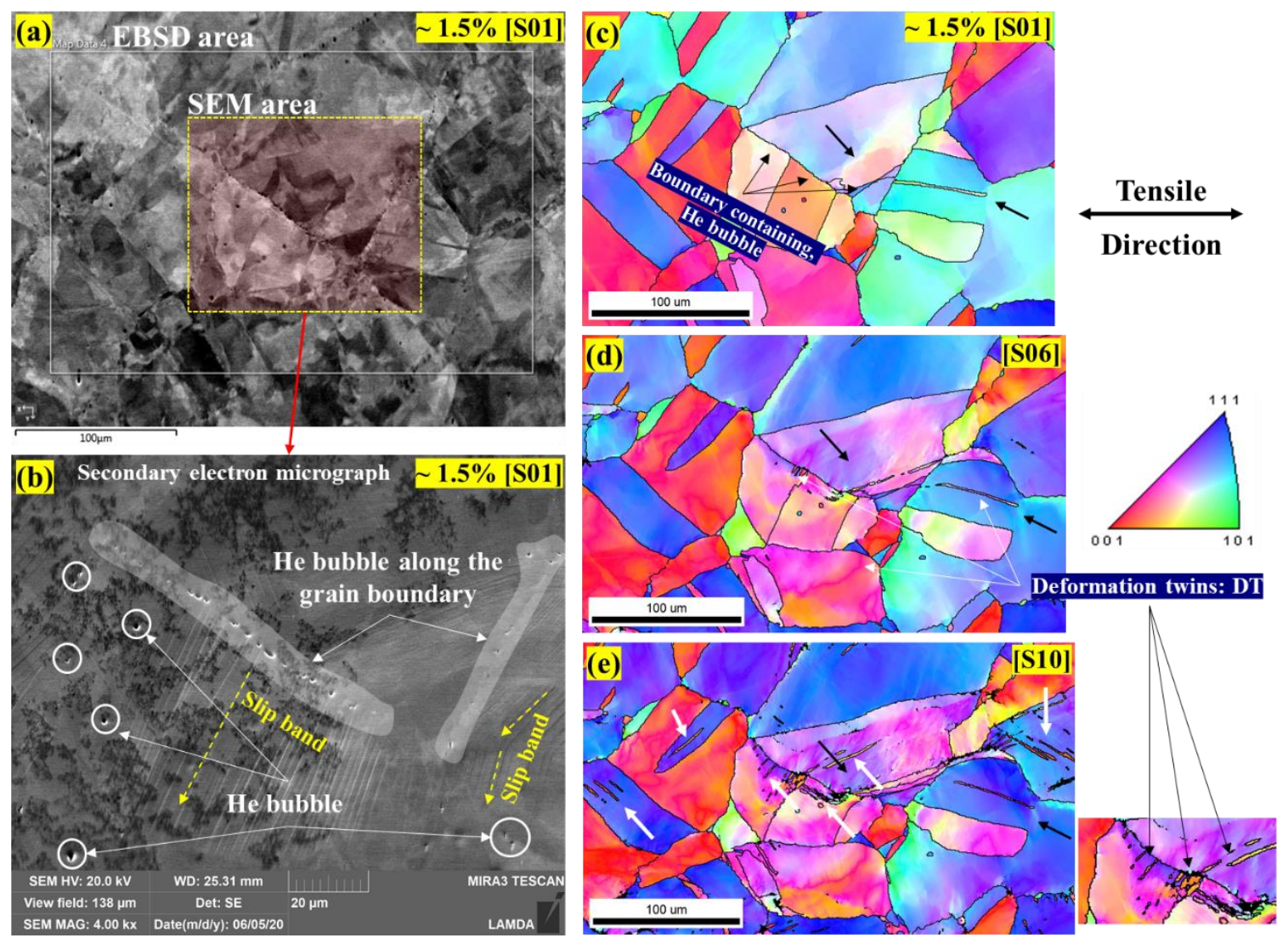

Figure 22. Microstructure after deformation at different strain levels. TMAZ specimen. (a) Magnified SEM micrograph depicting the window of SEM image and EBSD data acquisition; (b) secondary electron SEM micrograph showing the distribution of He bubbles and slip bands; (c) TD IPF map depicting the formation of lattice gradient; (d) TD IPF map depicting the formation of twin from the GB containing He bubbles; (e)

TD IPF map at the step of [S10] showing the bulging of the GB near the He bubble and formation of deformation twins.

\subsubsection{Grain Boundary Evolution and Formation of In-grain Boundaries}

Usually, GBs act as barriers in the path of dislocation motion and can influence mechanical behavior. During the deformation, the GB character often changes, influencing alloy performance. Figure 23 shows GB evolution in the TMAZ specimen. As strain increases, the fraction of in-grain LABs increases as well. Interestingly, the largest increase in LAB density can be seen close to the GB with helium bubbles. Since LABs form by the arrangements of the dislocations, one could speculate that helium bubbles serve as stress localization points and lead to higher local dislocation densities than typical, nondamaged GBs. 
(a) $[\mathbf{R 4}][\mathbf{S 0 0}]$

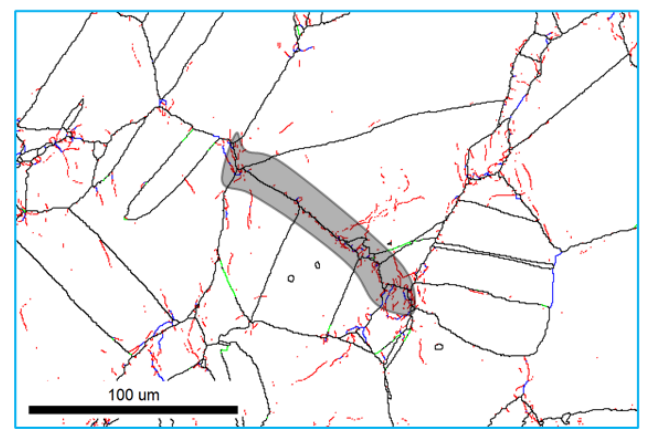

(c) $[\mathbf{R 4}][\mathbf{S 0 6}]$

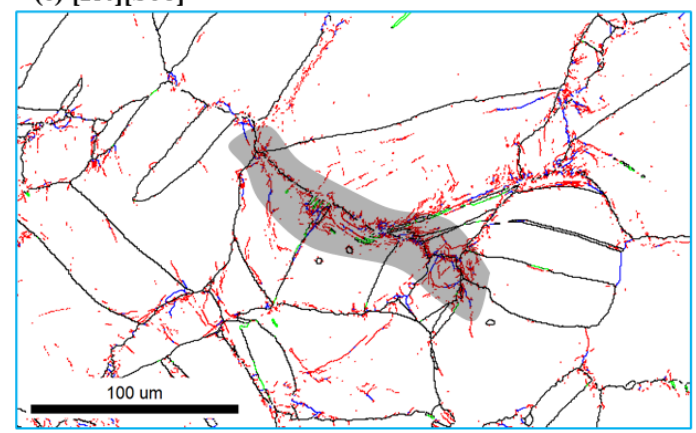

(e)

\begin{tabular}{crrrr}
\hline Grain boundaries in \% & {$[$ S00] } & {$[$ S01] } & {$[$ [S06] } & {$[$ [S10] } \\
\hline $2^{\circ}-5^{\circ}$ & 29.1 & 28.8 & 47.0 & 58.0 \\
$5^{\circ}-15^{\circ}$ & 5.5 & 5.3 & 7.9 & 10.3 \\
$15^{\circ}-65^{\circ}+\sum 3$ & 65.4 & 65.9 & 45.0 & 31.6 \\
$\sum 3$ (Twin) & 1.7 & 1.7 & 2.4 & 5.0 \\
\hline
\end{tabular}

(b) $[\mathrm{R4}][\mathrm{S} 01]$

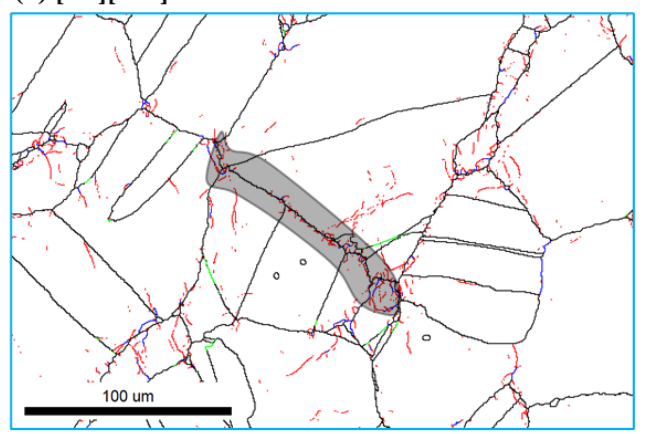

(d) $[\mathrm{R4}][\mathrm{S} 10]$

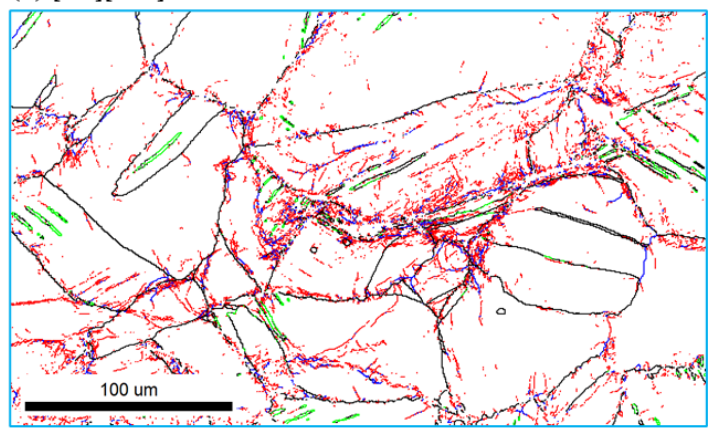

Figure 23. GB maps generated from the EBSD data for \#304C-6-14-1 specimen. The maps shows the distribution of the LAB, medium-angle grain boundary, high-angle grain boundary (HAB), and twin boundary $\left(\sum 3\right)$ for the deformation steps of (a) S00, (b) S01, (c) S06, and (d) S10.

\subsubsection{Deformation-induced Texture Evolution}

The bulk texture after FSW is presented in Figure 19; whereas the reference and TMAZ specimens were mostly texture-free, some texture was presented in the SZ specimen. Figure 24 shows the postdeformation texture, (111) and (220) pole figures, in the investigated specimens. 


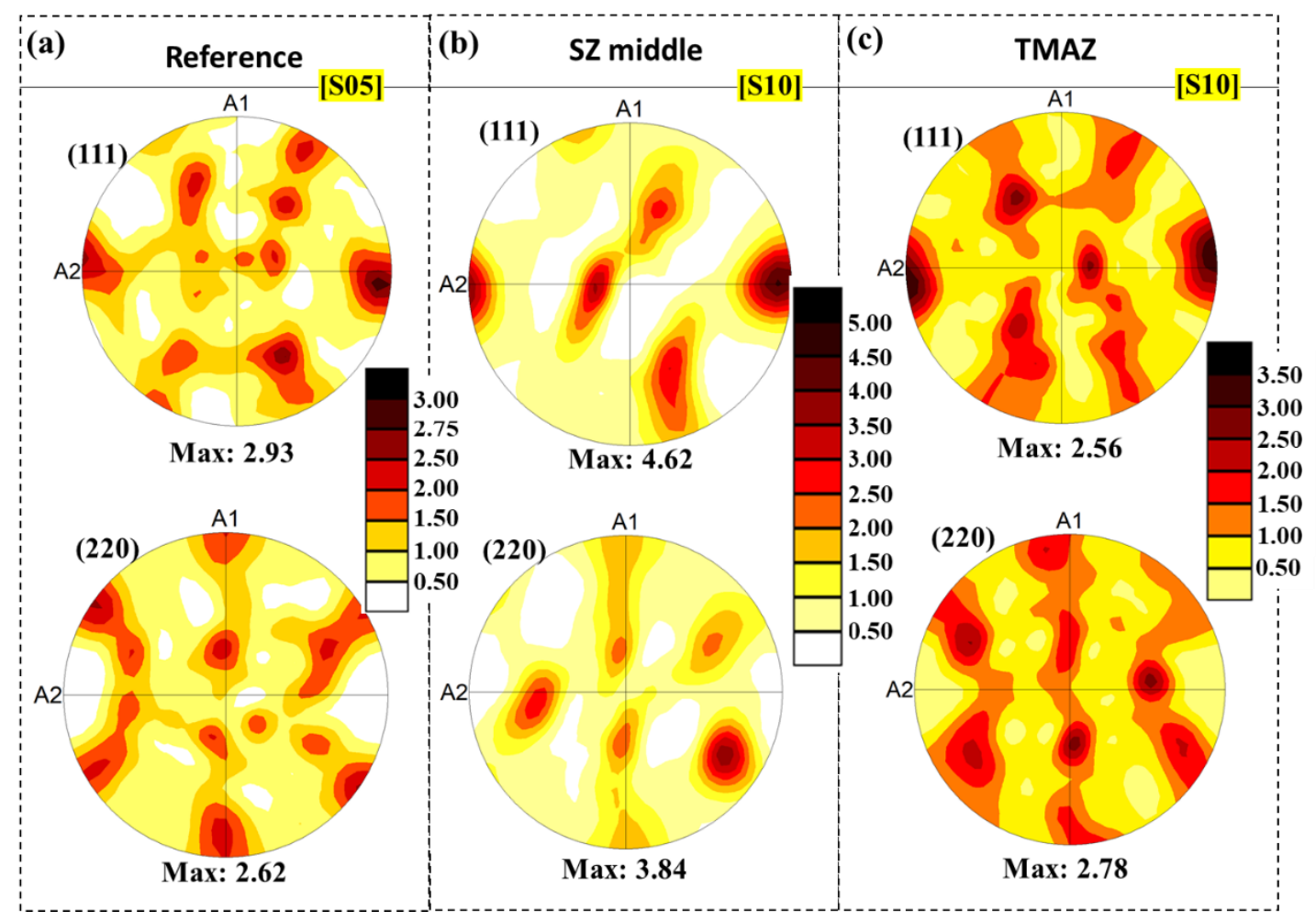

Figure 24. Deformation texture at the last step of deformation for specimens: (a) 304C-6-14-15, (b) 304C-614-7, and (c) 304C-6-14-1, depicting the crystallographic orientation change.

During deformation, the polycrystalline materials with face-centered cubic (fcc)-lattice will demonstrate lattice rotation and texture formation. In general, grains in fcc-material will show orientation change towards the (111) and (001) corners of the IPF unit triangle regarding the tensile axis. The pole figures in Figure 24 show this kind of behavior for the reference and TMAZ specimens. The SZ object increases texture intensity, but lattice rotation is not as pronounced as in the reference and TMAZ specimens. It may be explained by much smaller grain size and some weak preexisting texture. As expected, texturing will become more pronounced with plastic strain increase.

\subsection{IMPACT OF HELIUM-INDUCED DAMAGE ON MATERIAL PERFORMANCE}

Pronounced helium-induced degradation of GBs was observed only in the TMAZ specimen; the SZ specimen showed only some rare, scattered bubbles, usually appearing far from GBs. The reference object, as mentioned above, did not contain any notable helium-induced features.

The helium bubbles in the TMAZ specimen often formed chains along GBs, and there was a concern that these chains or even single bubbles may serve as crack nucleation sites. In situ mechanical testing and tracking of a degraded GB is a good option to explore this possibility and identify the phenomena related to the helium bubble chain. Figure 25 shows the compromised GB (i.e., a GB containing a chain of helium bubbles, with many other bubbles likely lying below the surface) to react to different strain levels. For example, a small plastic strain, S01, led to the appearance of multiple slip lines originating directly from the bubbles (Figure 25(a)). 

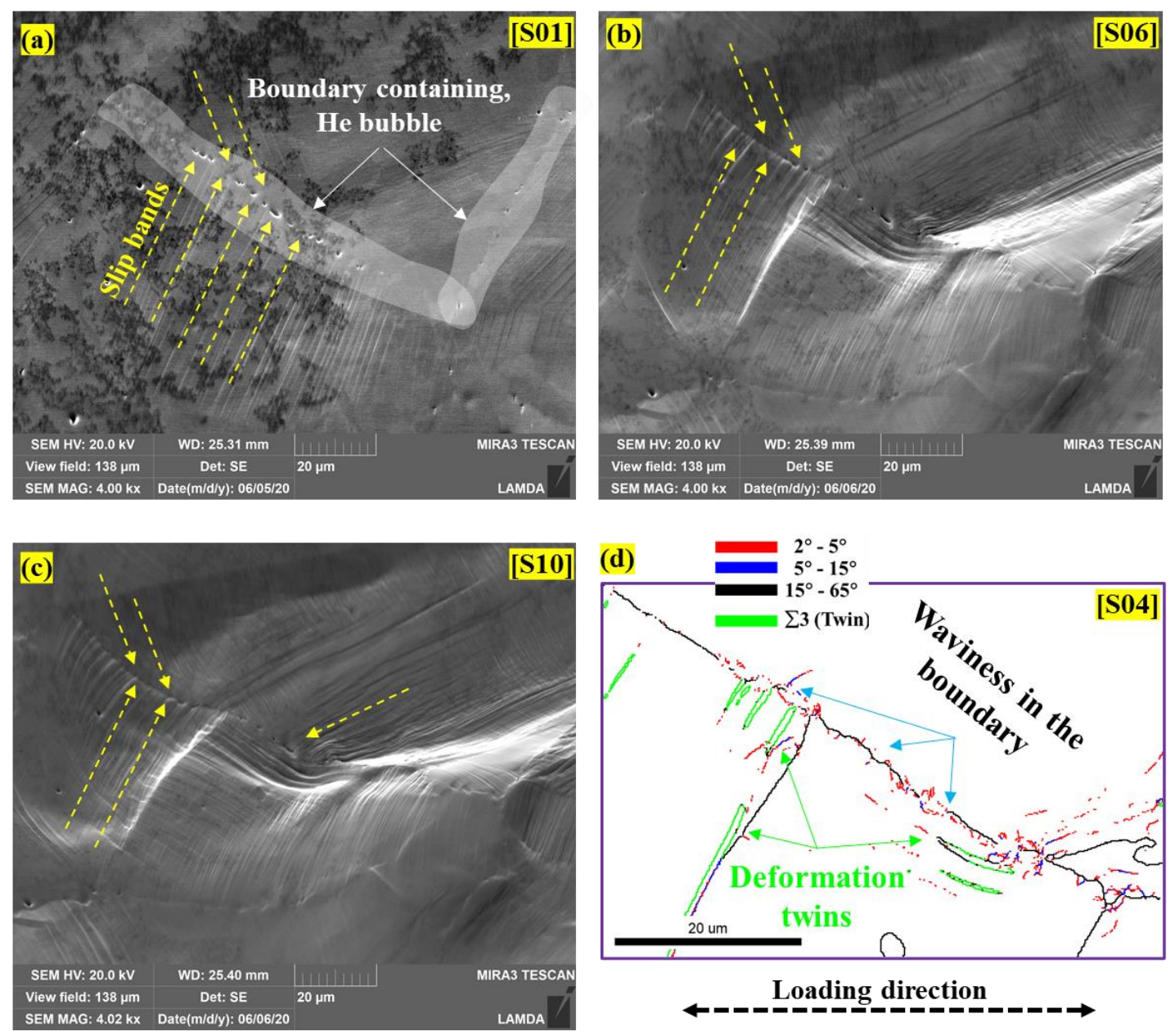

Figure 25. Effect of deformation on the consequence on He bubbles represented different steps of deformation. (a) [S01], (b) [S06], and (c) [S10]; (d) GB map generated from the EBSD data recorded at identical location phenomena around the GB containing He bubbles.

As plastic strain increased, the slip lines became more and more pronounced (Figure 25(b), Figure 25(d)), leading to the well-developed surface morphology. At some point (Figure 25(d), S04), strain-induced twins appeared near the compromised GB and grew into the grain body. The twin appearance suggests high local stresses in the compromised GB vicinity.

Instead of the elevated local stresses and high local strains at the compromised GB, no bubble coalescence was observed. Moreover, the compromised GB did not tend to serve as a crack nucleation location during the in situ testing. This result demonstrates that the compromised GB is stable up to $25 \%$ of deformation even in the presence of He bubbles and pores.

Several regions of interest, each containing at least one well-defined compromised GB, were tracked during the in situ testing, and no cracking was observed in any of them. A more detailed analysis will be reported in a future document. The most important result for the present report is the reasonable mechanical integrity of the tested specimen and the absence of obvious helium-induced embrittlement. 


\section{FRICTION STIR WELD WITH 15.6 APPM HE}

\subsection{VISUAL APPEARANCE OF THE 15.6-APPM HE FSW COUPON}

Figure 26 shows the visual appearance of the friction stir weld coupon. The weldment was performed on the "304D" custom heat with $~ 15.6$ appm He after irradiation. The SEM image brightness and contrast were adjusted to highlight possible defects, cracks, and discontinuities in the structure. As expected, macroscopic defects (a millimeter in length or so) would be easily detected at given conditions. However, analyzing the image, one can see a solid metallic surface without any visible cracks or voids.

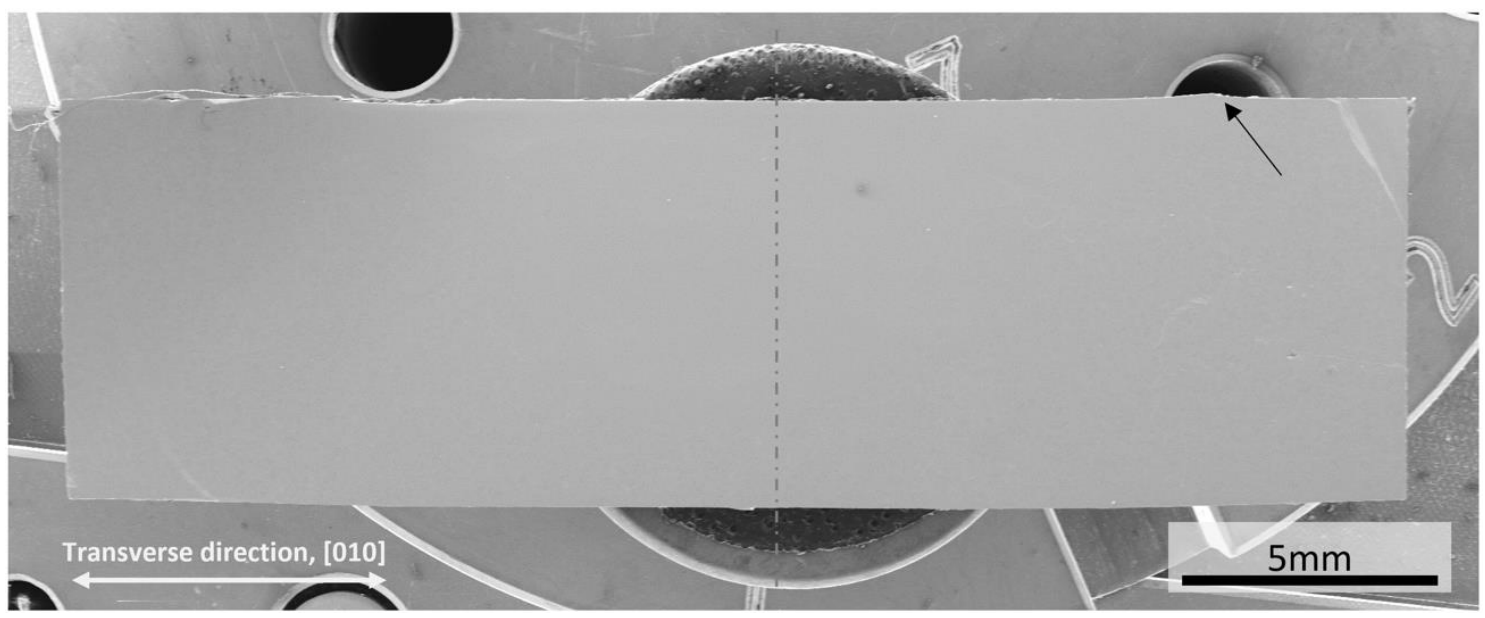

Figure 26. A visual appearance of the investigated 15.6 appm He FSW coupon (304D-5-14). One can see a specific feature: a weak FSW tool undercut at the right (black arrow); the burr at the left is difficult to see. Brightness and contrast were adjusted to improve the visibility of the surface details. No macroscopic cracks or crack-like defects $(\sim 0.5 \mathrm{~mm}$ in length or so) were observed in the SZ or TMAZ. Note the SEM image has some minor distortion due to the low magnification level. (Left) FSW advancing side; (right) FSW retreating side.

\subsection{EBSD ANALYSIS OF GRAIN STRUCTURE AND MORPHOLOGY}

Figure 27 provides a compressed representation of the friction stir weld microstructure. Only the most important scans are included in the compilation, and one can see the complexity of the microstructure, with pronounced gradients in grain size and plastic strain level. Overall, the microstructure is similar to the friction stir weldment with 5.2 appm He (Figure 9), which shows minor grain size variations. 


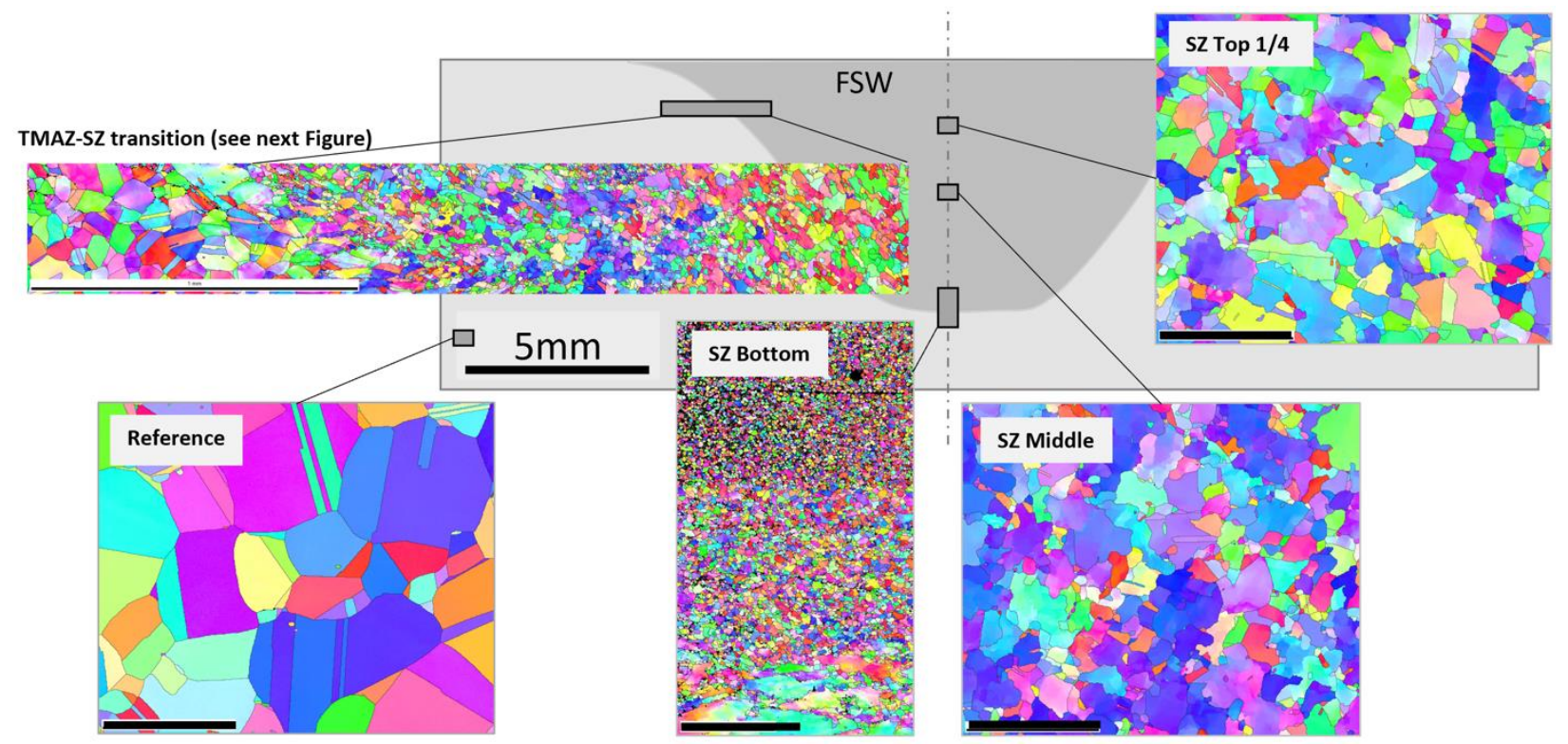

Figure 27. Microstructure of the friction stir weld with $15.6 \mathrm{appm}$ He at key locations. The scale bar is the same for all IPF maps $(=100 \mu \mathrm{m})$, except the stitched TMAZ-SZ map (top left panel).

Figure 28 and Figure 29 show the SZ microstructure at $\sim 1 / 4$ and $\sim 1 / 2$ of the weldment depth, respectively. Grain size is practically the same for both areas, which has a very weak texture. The results show that the SZ microstructure represents roughly shaped, sometimes equiaxed grains, $\sim 20-40 \mu \mathrm{m}$ in size. The SZ area is practically ferrite-free; the preexisting ferrite disappeared at elevated temperatures, but the conditions (e.g., temperature, time at the temperature) were not favorable to form a new ferrite grain population. 

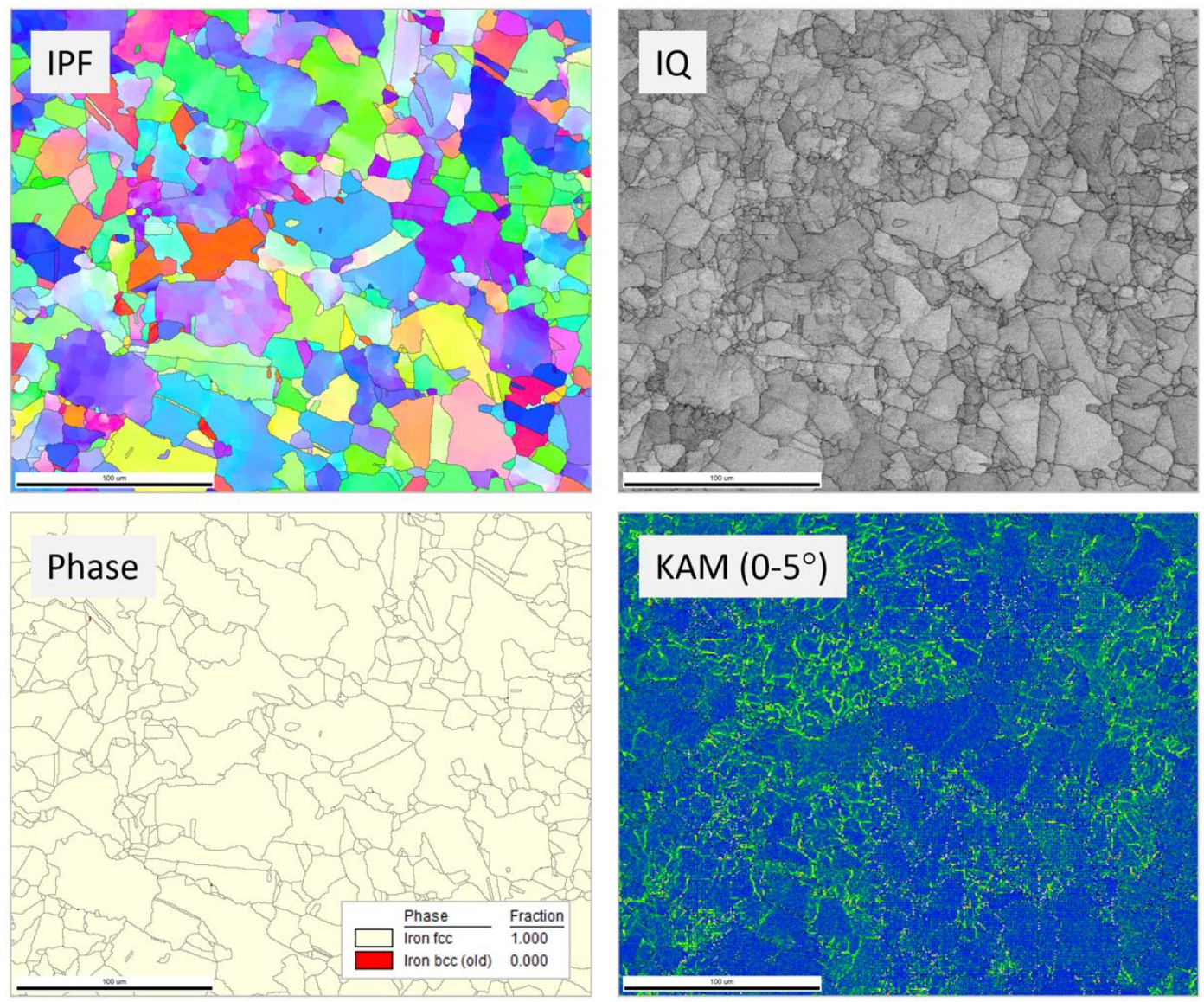

Figure 28. Weldment with 15.6 appm He for the SZ middle at $\sim 1 / 4$ of the depth. The microstructure (see also (see Figure 27) represents a mix of irregularly shaped grains. No ferrite was observed for this location. EBSD step (pitch) size: $1 \mu \mathrm{m}$.

The KAM maps in Figure 28 and Figure 29 suggest the presence of multiple in-grain LABs, likely due to the combination of high-temperature deformation and recrystallization. In addition, one may see the KAM values vary inside grains, suggesting only partial recrystallization for some grains, whereas other grains experienced nearly complete recrystallization. It would be interesting to evaluate the recrystallization degree as a function of grain size and orientation; this work will be attempted in the future. 

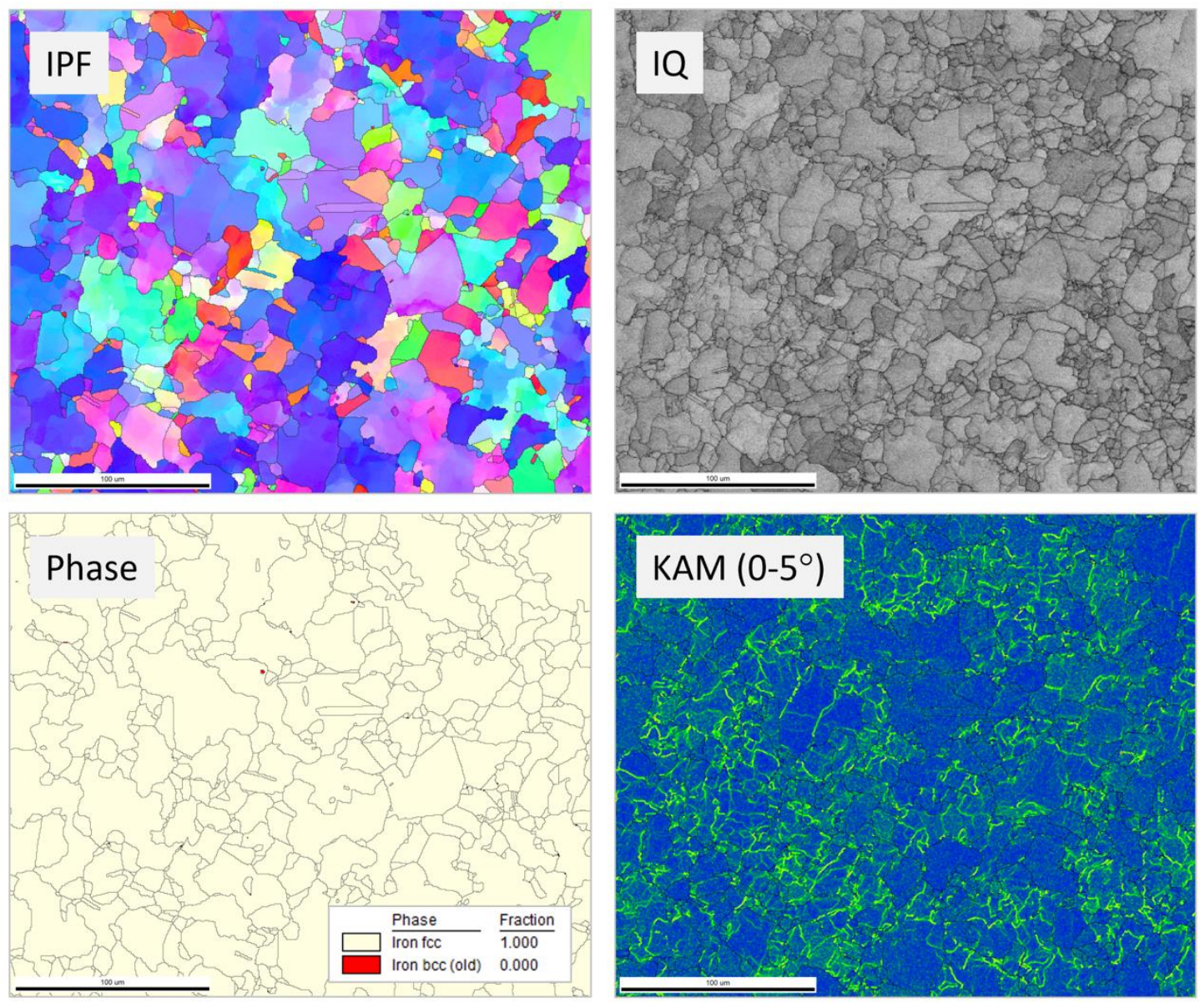

Figure 29. Weldment with $15.6 \mathrm{appm}$ He at the $\mathrm{SZ}$ middle line and middle of the weldment depth. One can see a specific austenite structure with grains of irregular, curved shape. This location revealed scattered, very small ferrite grains; as a rule, the observed ferrite-like features had sizes below $\sim 2-4 \mu \mathrm{m}$. The total ferrite amount was below $\sim 0.1 \%$ (i.e., it was negligibly small). Scan size: $300 \times 250 \mu \mathrm{m}$; EBSD step (pitch) size: 0.5 $\mu \mathrm{m}$.

Figure 30 shows the transition between the SZ and TMAZ at the bottom portion of the weldment. This area looks very similar to the previous weldment with $5.2 \mathrm{appm}$ He (Figure 14) and has very strong grain size gradients in the structure. Within the $\sim 100-150 \mu \mathrm{m}$ distance from top to the bottom of the map, one can see transition from very fine ( $\sim$ microns in size) grains to $\sim 5-10 \mu \mathrm{m}$ grains in the intermediate layer, and after that to TMAZ. Strong grain refinement may be beneficial for strength and general mechanical performance. However, grain size gradients and local plastic strain (see the color gradients in the IPF map) may raise concerns regarding corrosion, stress corrosion cracking, and IASCC behaviors of such material. 

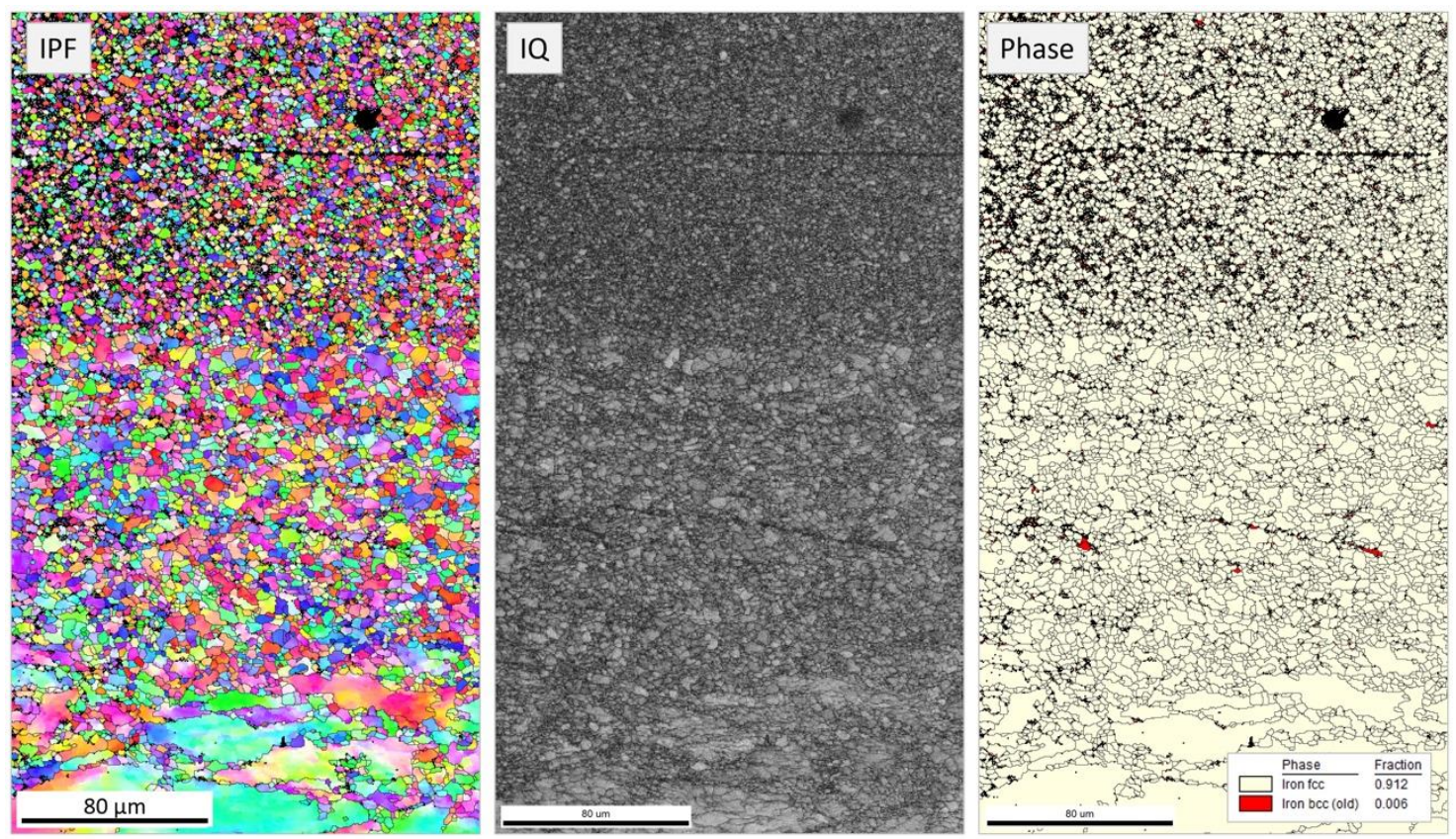

Figure 30. SZ bottom area for 15.6 appm He coupon. This dataset shows the transition location between SZ and TMAZ directly below the weldment center line, see Figure 27.

Figure 31 demonstrates a TMAZ-SZ transition, approximately 1/4 of the weldment depth (see Figure 27 for the exact location). The SZ middle has the largest grain size, with specific red- and green-colored grains (indicating some minor local texturing), followed by a population of blue-colored grains (slightly different local texture) and very small grains (short recrystallization time and, likely, lower temperatures) at the SZ edge. The TMAZ area reveals deformed elongated grains with a size comparable to the reference location. Plastic strain levels quickly decay from right to left inside the TMAZ, and the TMAZ area is followed by HAZ close to the scan's left edge.

In general, the microstructure at $1 / 4$ of the depth close resembles the one observed at approximately half of the depth for the 5.2 appm He weld (Figure 10). The difference in helium level did not result in pronounced variations in grain structure and morphology, according to the EBSD analysis.

Interestingly, the observed signs of plastic deformation-lattice gradients, shear bands, and local changes in the IQ map - are typical for nonirradiated steel. No defect-free channels or deformation bands, typical for irradiated steel, were observed. Most likely, radiation defects at a given location disappeared (i.e., were annealed) before plastic strain occurred. Heating and temperature fields preceded the plastic strains. 

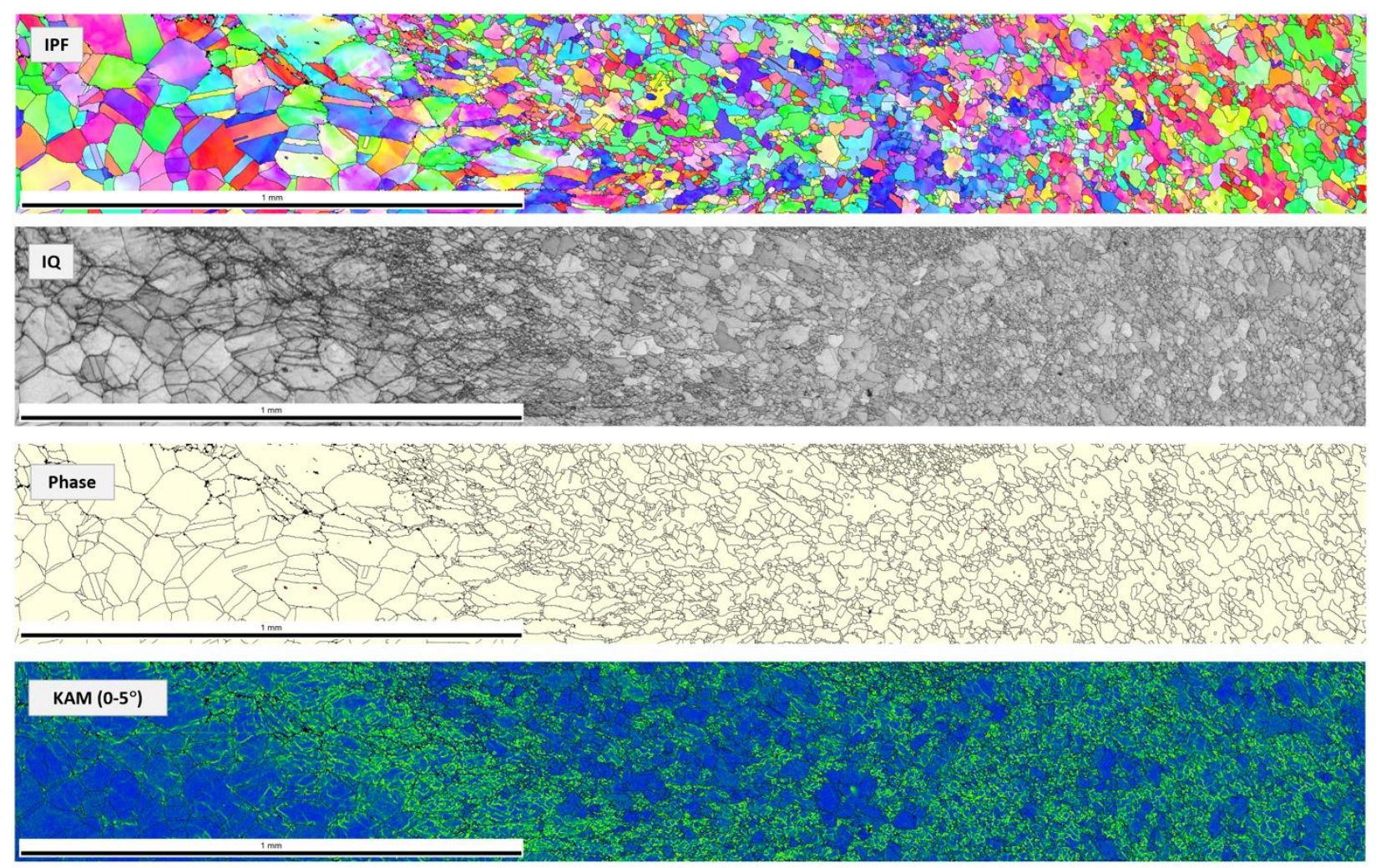

Figure 31. The transition between the SZ and TMAZ areas. SZ is at the right, TMAZ is at the left. EBSD maps show strong microstructure gradients (see Figure 27 to define the exact scan orientation and location). One may see how the microstructure changes from rough, irregular grains in the SZ to the strongly deformed grains at the SZ-TMAZ boundary and, after that, to the weakly deformed grains in the TMAZ.

\subsection{HELIUM IMPACT ON THE SZ MICROSTRUCTURE}

The microstructure inside the SZ (Figure 32) consists of irregularly shaped, deformed grains. Plastic strain (or incomplete recrystallization) is easy to see via specific contrast in the SEM-BSE images. Grain size varies inside the SZ, with the largest grains at $\sim 1 / 4$ depth and in the middle of the depth. Grain size slightly reduces toward the surface and the SZ edges and shows a strong decrease in the root area. The grain size gradients may be explained by energy generation and thermal conductivity: material in the SZ middle stayed at or above the recrystallization temperature long enough to support grain growth, and material in the SZ root experienced the lowest peak temperature.

Most SEM images recorded inside the SZ show specific void-like or bubble-like features $(\sim 1-2 \mu \mathrm{m}$ in size or smaller) of dark color. The observed features had a round shape (likely, spherical in 3D) and significantly varied size. Their density also varies across the SZ, suggesting their appearance was sensitive to the local conditions. Parent (reference) location revealed much smaller counts, and the features presented differently. Additionally, the EDS mapping of void-like features inside the SZ (not discussed here) showed only base material elements (e.g., Fe, Cr, Ni) without strong signs of silicon or oxygen, which would be expected for metallurgical inclusions. A significant fraction of the observed round features may be helium bubbles; however, EELS spectroscopy [15] should be used to confirm. 

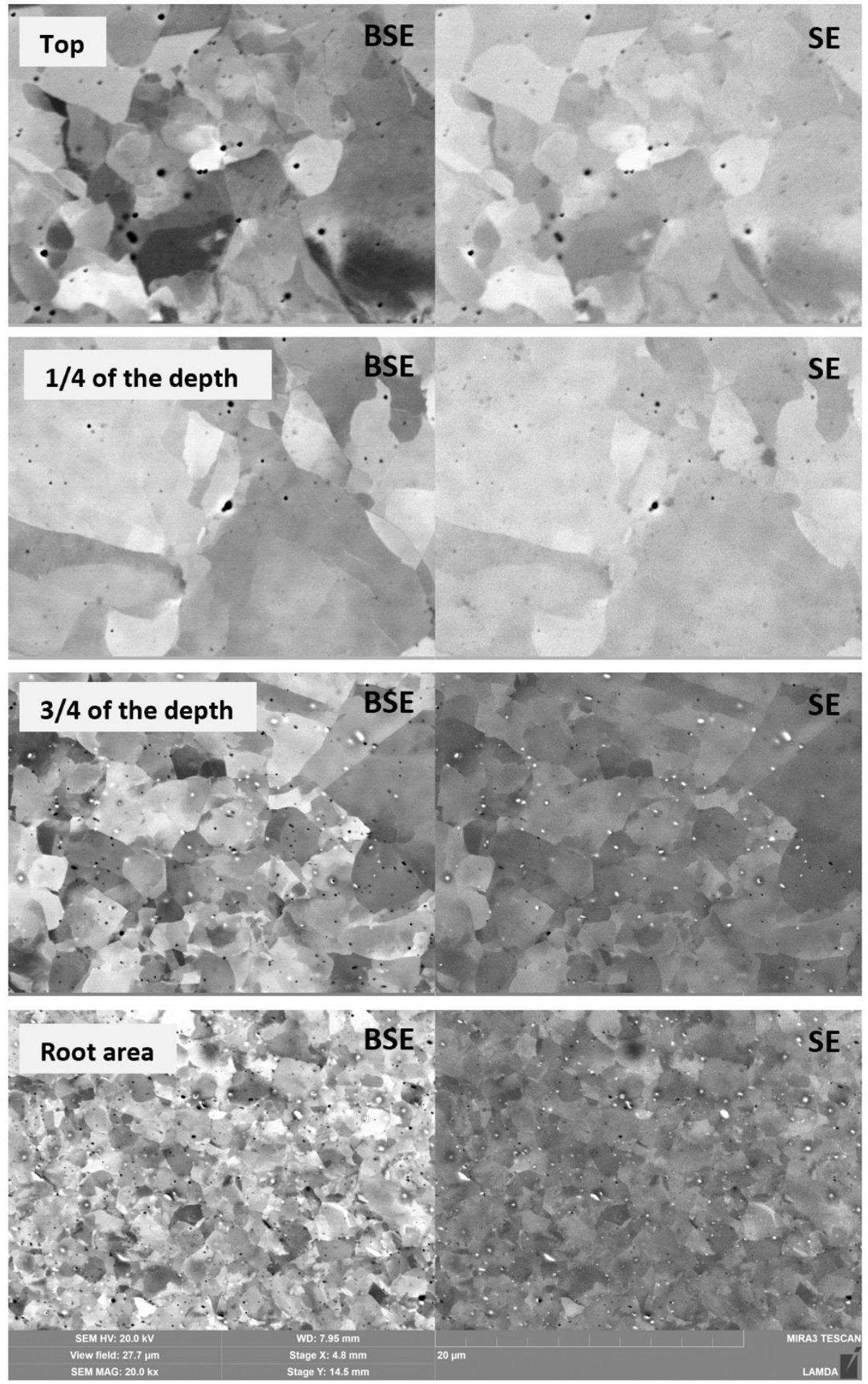

Figure 32. A typical microstructure of the SZ (15.6 appm He friction stir welded coupon [304D-5-14]) along the $S Z$ centerline. The images were recorded slightly below the surface $(\sim 200 \mu \mathrm{m})$, at 1/4, 1/2 (not shown in here), and 3/4 of the SZ depth, and close to the SZ root. Brightness and contrast were adjusted for printing/publication purposes. The scale bar and magnification level (see the bottom right image) are the same for all images. 
Being a light element, helium is difficult to detect via SEM-EDS. Advanced tools such as EELS [15] and transmission electron microscopy are needed to confirm the presence of helium bubbles. In the bottom portion of the SZ (Figure 32), one can see multiple light inclusions in the structure. Their density strongly varies from location to location, often forming specific clusters or bands. The density of the inclusions increases towards the SZ boundary. The light color in the BSE image suggests the presence of heavy element(s) like tungsten, originating, likely, from the FSW tool.

\subsection{HELIUM-INDUCED DAMAGE IN THE TMAZ}

Figure 33 and Figure 34 show typical helium-induced damage in the TMAZ. One can see several short discontinuities below $10 \mu \mathrm{m}$ in size. The discontinuities shown in Figure 33 may be described as helium bubble chains, whereas Figure 34 demonstrates an obvious micro-crack. Additionally, one may see few scattered bubbles at GBs in both figures. The helium-induced features appear differently compared to metallurgical inclusions, typical for reference location. The metallurgical inclusions rarely appear at GBs and, as a rule, do not form continuous chains elongated along GBs.

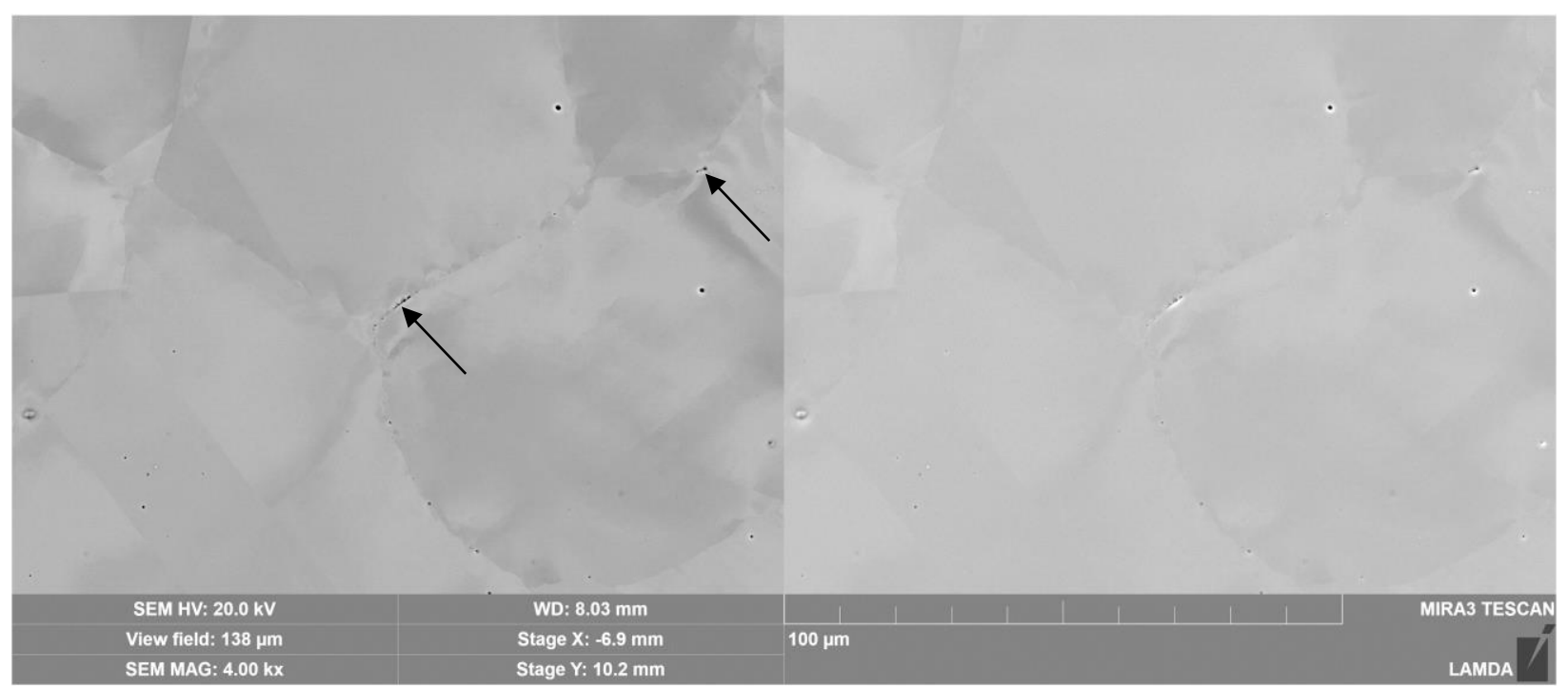

Figure 33. Compromised GBs in the TMAZ area of 304D-5-14 coupon. Retreating side. (Left) BSE image; (right) SE image. Black arrows point the helium-induced degradation.

It is important to emphasize that both Figure 33 and Figure 34 show relatively large areas (at least $100 \times 100 \mu \mathrm{m}$ ) with multiple GBs; however, a very small fraction of GBs was compromised by heliuminduced damage. It may be considered a good sign, promising acceptable mechanical performance and absence of helium-induced embrittlement. 


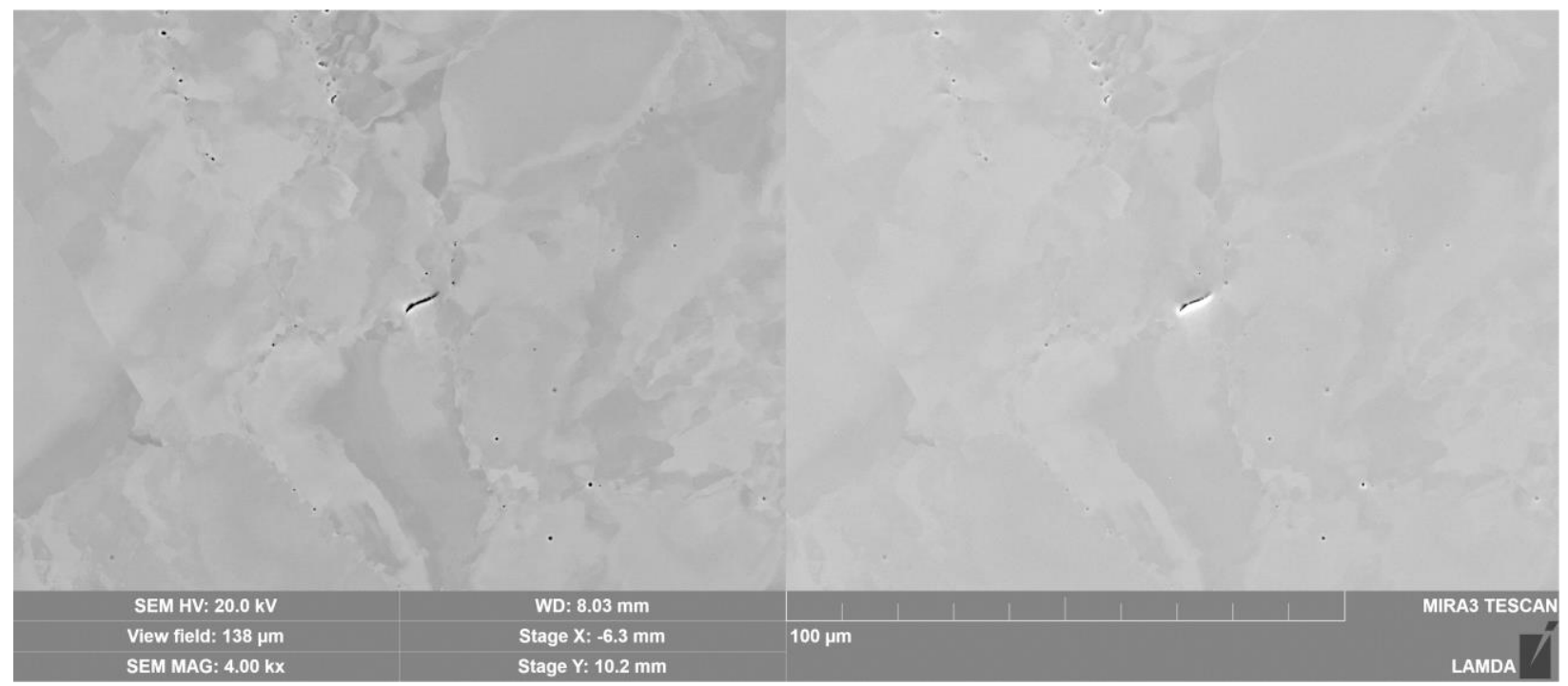

Figure 34. Minor bubbles and a micro-crack in the TMAZ area of the 304D-5-14 coupon. Retreating side. (Left) BSE image; (right) SE image.

Figure 35 shows one of the worst cases: multiple helium bubbles appeared at an $\sim 80 \mu \mathrm{m}$ long GB. The BSE image suggests there are more bubbles directly below the surface. Nevertheless, the GB status cannot be described as "cracked." More than $\sim 2 / 3$ of the total GB length appears damage-free.

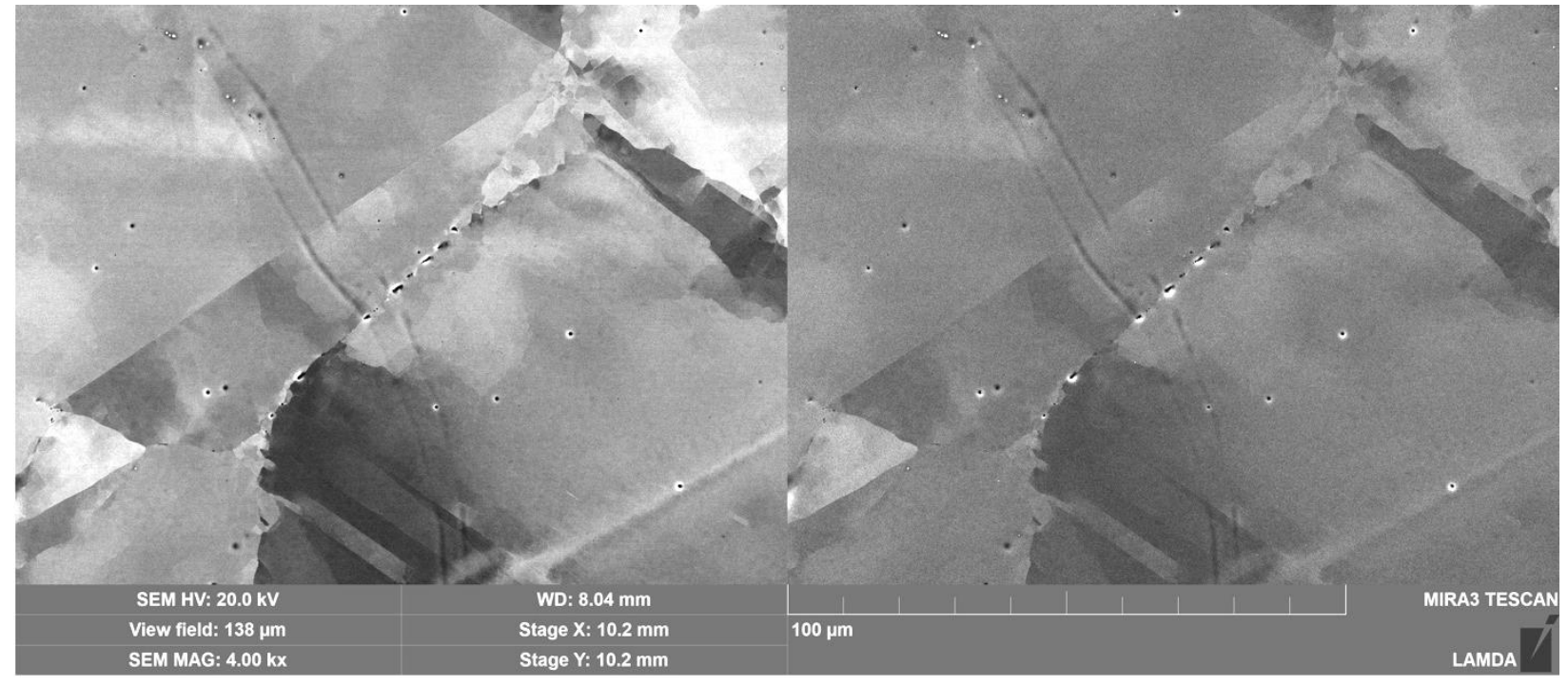

Figure 35. Compromised GB with a sparse chain of bubbles. TMAZ area of 304D-5-14 coupon. Advancing side. (Left) BSE image; (right) SE image.

\subsection{CLUSTERING OF THE HELIUM-INDUCED DAMAGE IN 304D-HEAT}

At first glance, the helium-induced degradation observed in the 304D-heat friction stir weldment appears to be very similar to the microstructure and features found in 304C-heat weldment (see Section 3).

However, surveying multiple areas, collecting statistics, and quantifying and classifying the heliuminduced features revealed a specific issue. In the 304D-5-14 friction stir weld specimen, helium-induced 
features often formed specific clusters or "clouds" of large pores and bubbles, as seen in Figure 36. Such clusters are often associated with the retained ferrite grains, second phases, and preexisting metallurgical inclusions. This kind of damage (i.e., bubble clusters) heavily outnumbers the usual type of heliuminduced features (i.e., helium bubble chains or micro-cracks, normally associated with GBs [Figure 33, Figure 34, Figure 35, see also Section 3] or single bubbles at GBs). No such clustering was observed in the 304C-6-14 friction stir weld specimen. The observed clusters (Figure 36), might actually be the first sign of a specific issue (helium segregation), which will be discussed below.

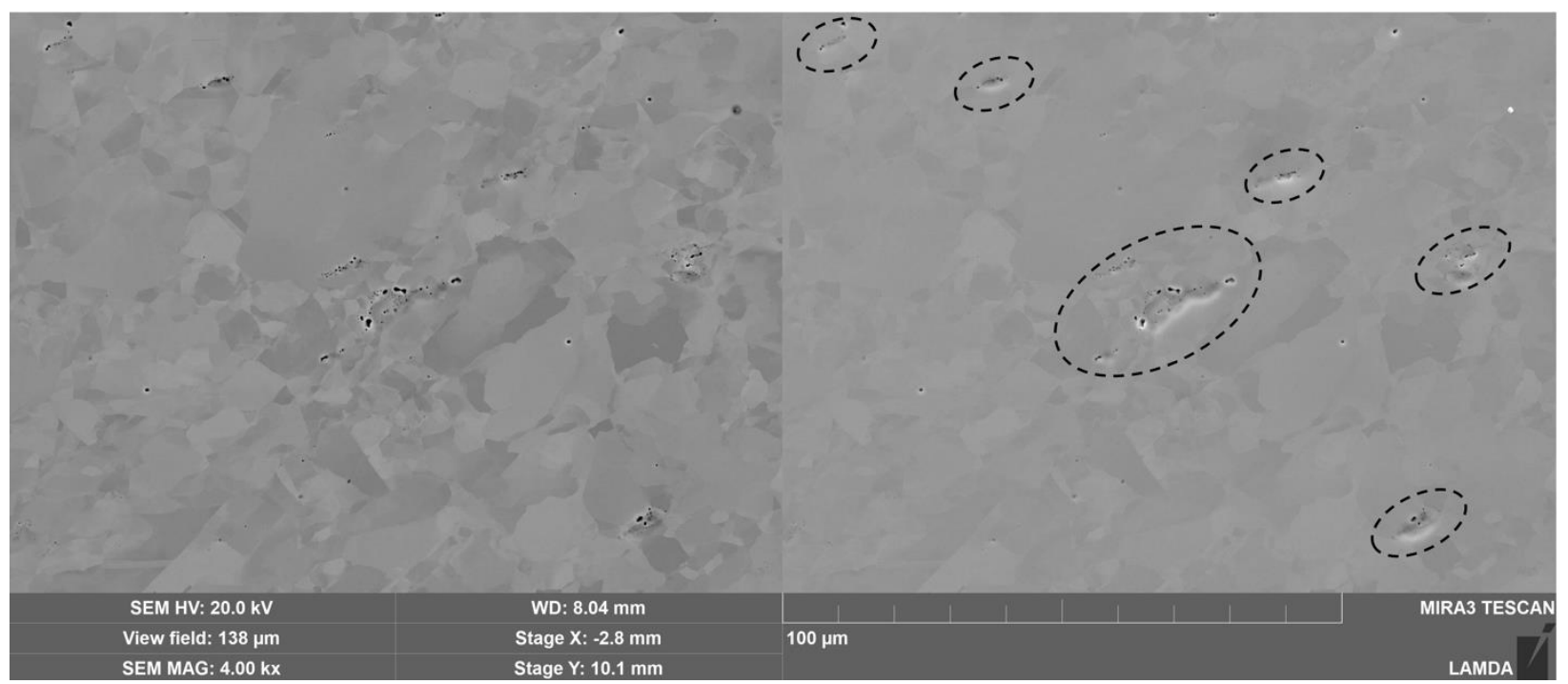

Figure 36. Clustering of the helium-induced damage. Dashed ovals at right show the clusters. (Left) BSE image; (right) SE.

\section{6 “ABNORMAL" FEATURES}

Careful, in-depth examination and imaging of the observed clusters and surrounding areas at higher magnifications revealed multiple very specific, "abnormal" features in the 304D-5-14 friction stir welded specimen. As was mentioned above, the bubble clusters were often associated with inclusions. GBs near such inclusions showed relatively large, up to $\sim 0.5 \mu \mathrm{m}$ helium bubbles. In addition, a "halo" or "cloud" of much smaller bubbles or pores appeared in the grain interior in the inclusion vicinity, as shown in Figure 37. Such in-grain bubbles could range from $\sim 100-200 \mathrm{~nm}$ to $\sim 10 \mathrm{~nm}$ in size and, likely, smaller, below the SEM resolution. The "halo" or "cloud" almost always extended not more than $\sim 3-4 \mu \mathrm{m}$ from the inclusion.

In some cases, as shown in Figure 38, the bubbles formed a well-shaped, perfect circle with $\sim 3-4 \mu \mathrm{m}$ radius surrounding the inclusion. The radius value varied just slightly for different locations. It is important to emphasize that the reference location analysis revealed no such features at the analyzed reference location. The SZ zone was also free of such "halos," which likely were destroyed by strong plastic strain. 


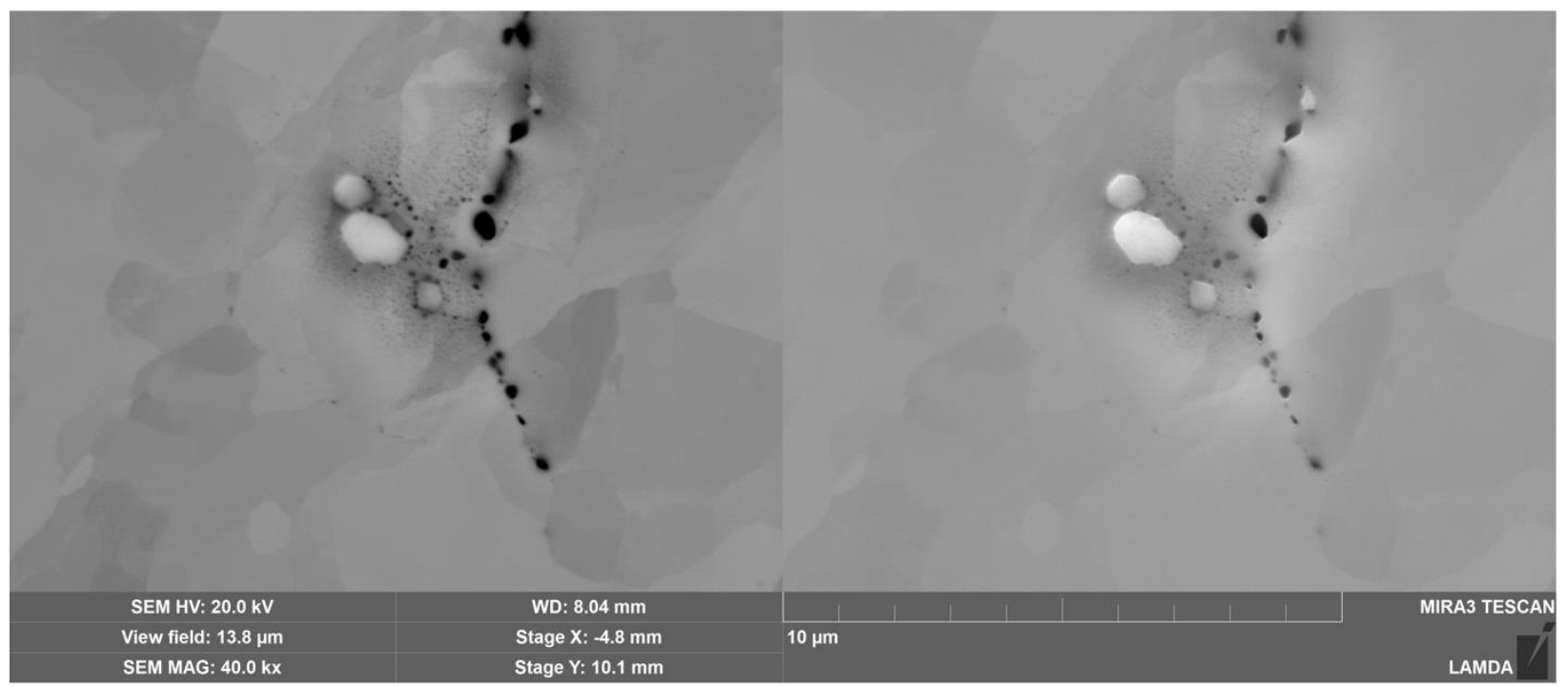

Figure 37. A cluster of helium bubbles near inclusion and along the GB. 304D-5-14 specimen. TMAZ, retreating side.

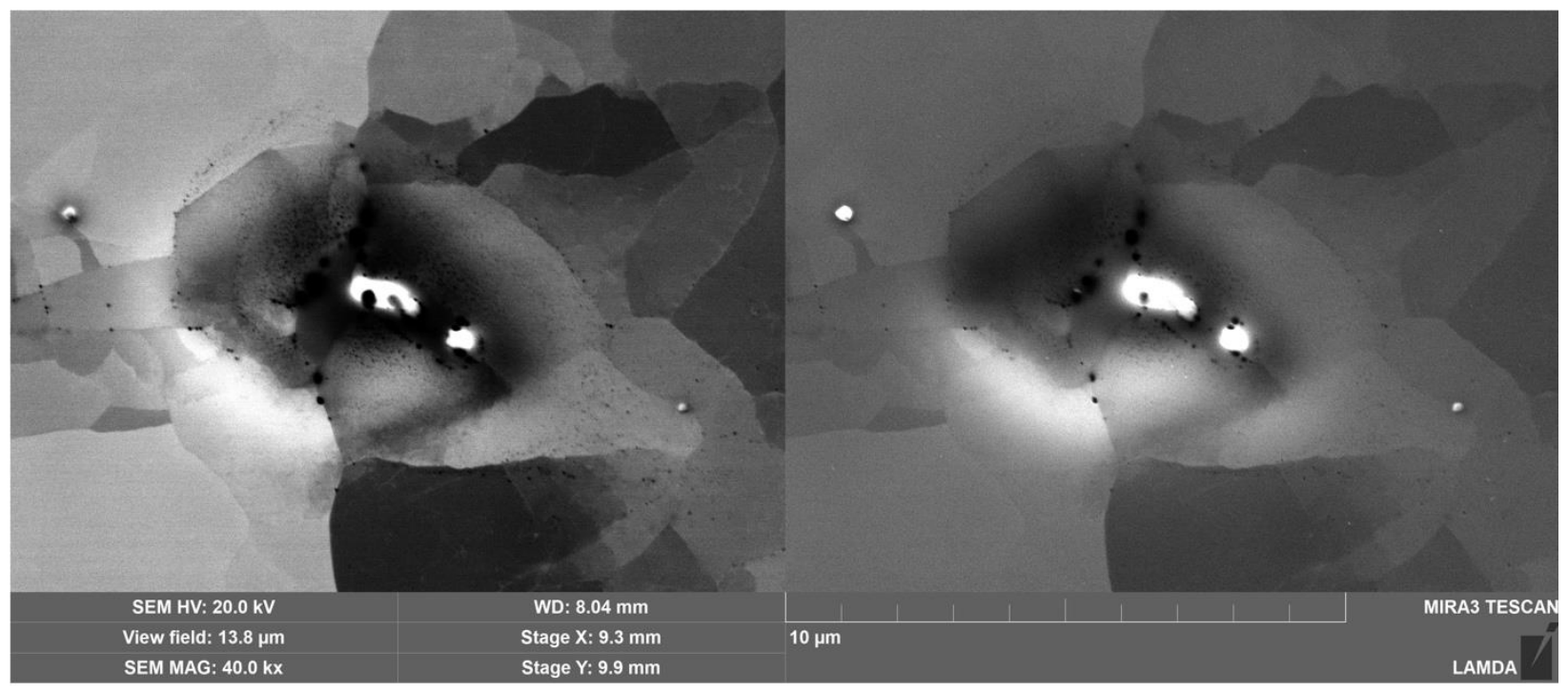

Figure 38. A localized cluster of bubbles and a specific "halo"near two inclusions. TMAZ area.

Figure 39 shows one more example of the "halo" with $\sim 3-4 \mu$ m radius. Again, one can see a large helium bubble at GB and much smaller bubbles forming a circle in the grain interior. 


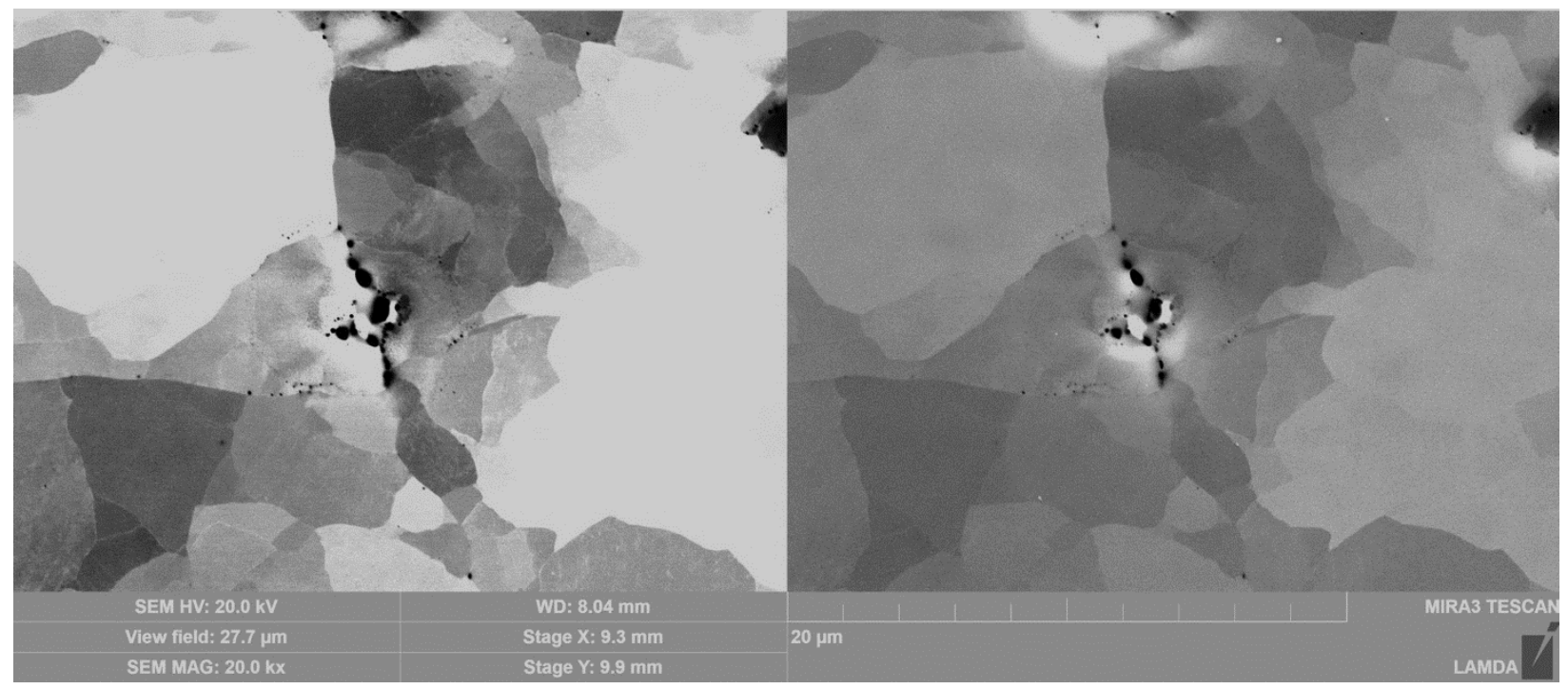

Figure 39. "Halo" and bubble cluster near inclusions. (Right) BSE image; (left) SE image.

Figure 40 demonstrates a ferrite grain (in the middle of the images) and large bubbles at the ferriteaustenite interface. One can also see a cloud of bubbles in the ferrite grain that form several specific lines oriented, as expected, along the LABs inside the ferrite grain. Thus, a "halo" of small bubbles surrounds the ferrite grain. However, the austenitic matrix and GBs outside the "halo" appear free of visible heliuminduced porosity. Such a microstructure suggests very high local helium concentrations in the ferrite grain and elevated helium levels in the area visible as a "halo," but much smaller, close-to-zero, helium concentrations at distances more than $\sim 3 \mu \mathrm{m}$ from the grain.

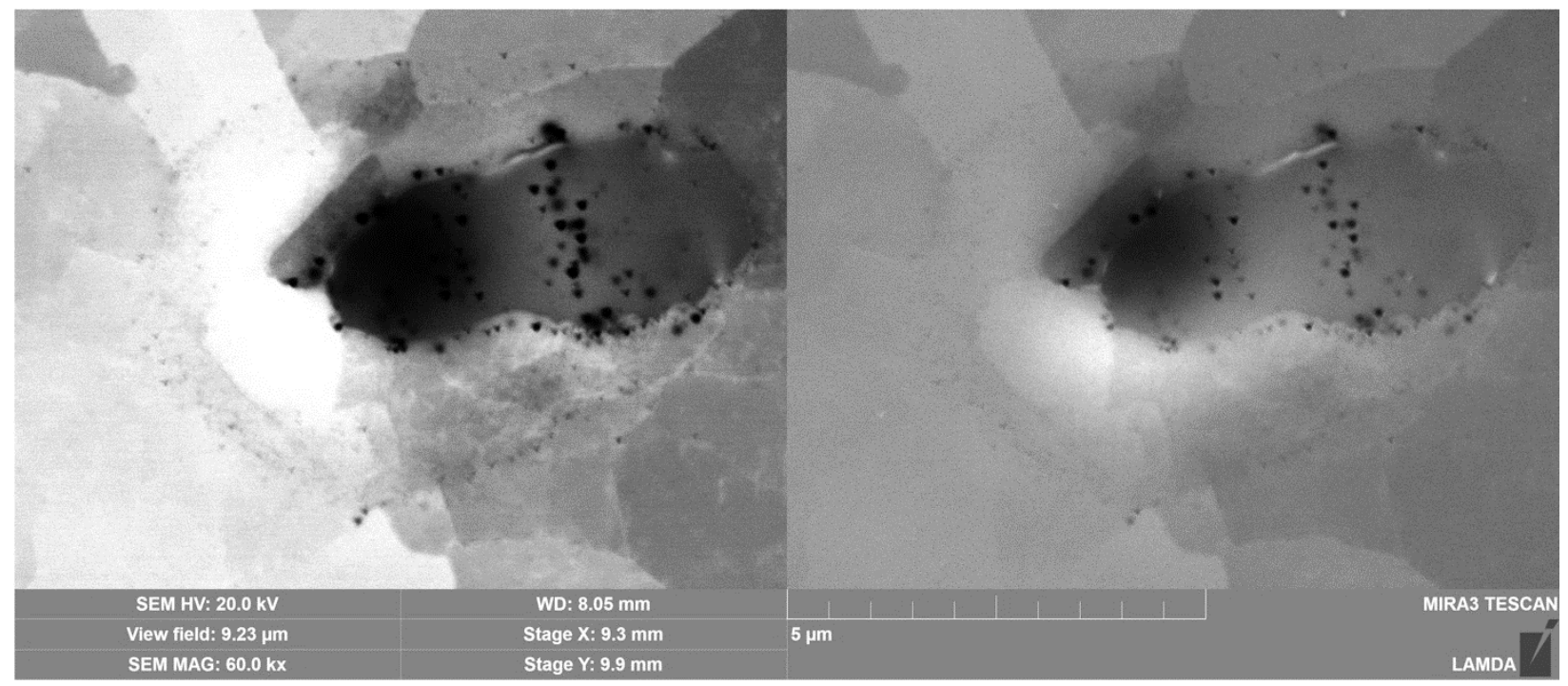

Figure 40. Circle (or "halo") of bubbles associated with retained ferrite. 304D-5-14, TMAZ advancing side.

Figure 41 shows one more example: a large, $\sim 8 \mu \mathrm{m}$ in size, helium-induced "cave" or pore and spongelike objects near and inside the ferrite grain. The visual appearance of grains at this location in the SEM image does not suggest any significant plastic strain, so the most likely explanation is gas-driven porosity. The local pore and helium bubble size and density suggest very high local helium concentrations and, at 
the same time, the absence or very low concentration of helium in the rest of the view field. Thus, one can see almost perfect, helium-damage-free GBs in the top portion of the image.

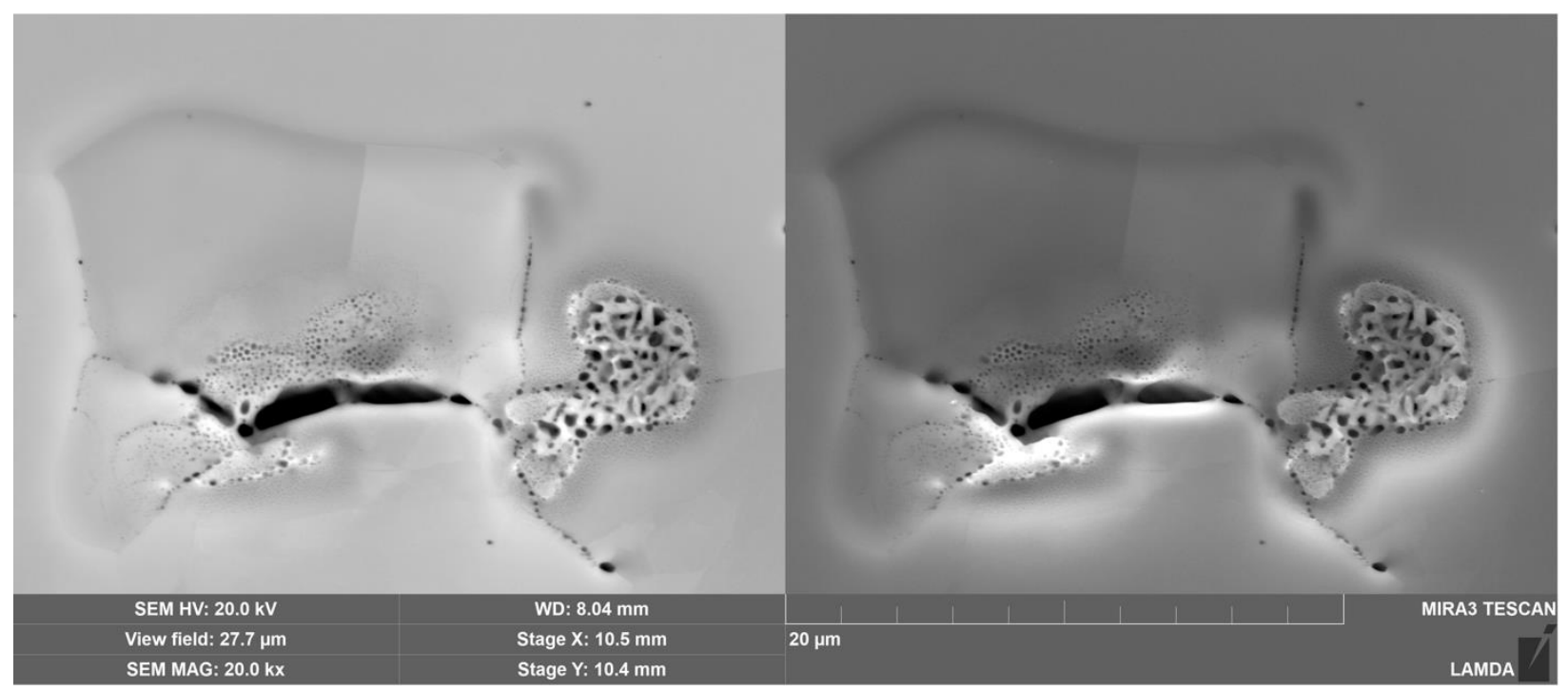

Figure 41. Ferrite particle with anomalous pore density. 304D-5-14, TMAZ, advancing side.

As postulated, the observed anomalous features, as shown in Figure 36-Figure 41, reflect inhomogeneous helium distribution in the irradiated material (custom 304D-heat). Most of the material volume (roughly 90-95\%) is depleted in helium (Figure 36), whereas there are strongly enriched clusters from $\sim 7-8 \mu \mathrm{m}$ to $\sim 20-30 \mu \mathrm{m}$ in size. The measured value $(\sim 15.6 \mathrm{appm} \mathrm{He})$ reflects an average helium concentration. In contrast, the local helium concentrations in the clusters may be at least a few times or even an order of magnitude larger.

The only logical explanation for the observed "clusters" and helium bubble "clouds" is preexisting inhomogeneity of the boron distribution in the parent material. Boron segregations (likely, elevated boron levels in the retained ferrite and metallurgical inclusions) generated, in turn, inhomogeneous helium distribution during irradiation in the HFIR. Furthermore, boron transmutation generates high-energy alpha particles with a penetration depth of $\sim 3 \mu \mathrm{m}$ in steel, which may explain the specific size and shape of the helium bubble "halos" and "clouds."

The custom steel heats should be characterized before irradiation, if a tool to map boron distribution is available, or after irradiation via annealing and analysis of helium-induced porosity. The custom heat may be used for FSW activities only if no bubble clustering is present (i.e., no He segregations) nor other evidence of boron segregation. To summarize, the 304D heat and the available FSW coupons should be used very carefully, considering the metallurgical issues mentioned above. 


\section{CONCLUSIONS AND FUTURE WORK}

The present work describes experimental results on the microstructure and mechanical performance of the friction stir welds made on neutron-irradiated austenitic 304L steel with helium. The report evaluates microstructure conditions, grain size, plastic strain gradients, and mechanical performance of the friction stir welds with helium and the morphology of the helium-induced damage in different weld areas (e.g., SZ, TMAZ).

Our research has shown that helium-induced damage and degradation in the friction stir welded joint with $5.2 \mathrm{appm} \mathrm{He}$ is less pronounced compared to welds made using traditional weld techniques. Scattered helium bubbles, rare degraded GBs (chains and clusters of helium bubbles), and only a few minor cracks below tens of microns in size were observed. No macroscopic damage or cracking was found in the analyzed samples. Preliminary mechanical tests revealed the reliable mechanical performance of the specimens from different FSW zones; helium-induced defects did not lead to sudden fracture or embrittlement.

As an important scientific outcome, it was demonstrated that RLABs and twin boundaries are less prone to helium-induced degradation during FSW compared to RHABs. It suggests that employing grainboundary engineered (GBE) steels may mitigate, at least to some degree, helium-induced issues during welding.

As a minor drawback, the results discussed in Section 5 raise concerns about the quality of boronenriched 304L steel with $15.6 \mathrm{appm}$ He. Therefore, the quality of the custom steel heats should be assessed in terms of uniform helium/boron distribution before the next welding campaign.

It is important to emphasize that, whereas the results and the data provided are believed to be accurate, more work is necessary to understand, quantify, and explain the observed features and peculiarities and compare them with existing and developing literature. The work conducted herein, the selected experimental tools and approaches, and the amount of data obtained resulted from a compromise between scientific and practical importance and available funds.

Future research could include planning and performing in-reactor reirradiation experiments. The welding repairs will be applied to NPP components, and the repaired components are expected to perform in the field on the active NPP. Thus, it is important to ensure the acceptable in-reactor and post-irradiation performance of the helium-containing weldment/joining.

Although more work is necessary, the results show limited helium-induced degradation in the friction stir weldments and good mechanical performance compared to the conventional welding techniques. Thus, it confirms that FSW is a promising technological approach for welding materials with high helium content. 


\section{ACKNOWLEDGMENTS}

This manuscript has been authored by UT-Battelle LLC and sponsored by the DOE Office of Nuclear Energy's LWRS Program under contract DE-AC05-00OR22725 with UT Battelle LLC/ORNL. The authors would like to thank Dr. X. Chen (ORNL) and Dr. T. S. Byun (ORNL) for reviewing the report and providing valuable comments and suggestions, as well as Dr. F. A. Garner (Radiation Effect Consulting) for the detailed and thoughtful discussion on boron and helium segregation, its origins, and possible consequences.

It is important to acknowledge and thank the people and teams who worked on the weldment production and irradiated specimen transportation, handling, and preparation: ORNL's Radiochemical Engineering Development Center, Irradiated Material Examination and Testing Facility, LAMDA, and Materials Joining group. We would like to thank personally A. Smith, K. Kinney, C. Scott White, M. Delph, C. Morris, T. Davis, R. Bowman, S. Thurman, T. Muth, P. Tedder, S. Curlin, T. Dixon, M. McAlister, Z. Feng, J. Chen, R. Miller, S. Clark, K. Leonard, and many others. In addition, the authors would like to thank L. Varma (ORNL) for valuable help with document preparation. 


\section{REFERENCES}

[1] W. Kanne Jr, Remote reactor repair: GTA weld cracking caused by entrapped helium, Weld. J. 67 (1988) 33-39.

[2] K. Asano, S. Nishimura, Y. Saito, H. Sakamoto, Y. Yamada, T. Kato, T. Hashimoto, Weldability of neutron irradiated austenitic stainless steels, J. Nucl. Mater. 264 (1999) 1-9.

[3] S. Kawano, F. Kano, C. Kinoshita, A. Hasegawa, K. Abe, Effect of weld thermal cycle, stress and helium content on helium bubble formation in stainless steels, J. Nucl. Mater. 307 (2002) 327-330.

[4] R.S. Mishra, Z. Ma, Friction stir welding and processing, Mater. Sci. Eng. R Rep. 50 (2005) 1-78.

[5] D. Lohwasser, Z. Chen, Friction stir welding: From basics to applications, Elsevier, 2009.

[6] W. Tang, M. Gussev, Z. Feng, B. Gibson, R. Miller, J. Chen, S. Clark, K. Leonard, J. Tatman, B. Sutton, others, Friction Stir Welding and Preliminary Characterization of Irradiated 304 Stainless Steel, in: ASME 2019 Press. Vessels Pip. Conf., American Society of Mechanical Engineers Digital Collection, 2019.

[7] B.T. Gibson, W. Tang, A.G. Peterson, Z. Feng, G.J. Frederick, Evaluating the potential for remote inprocess monitoring of tool wear in friction stir welding of stainless steel, J. Manuf. Sci. Eng. 140 (2018).

[8] W. Tang, J. Chen, B.T. Gibson, R.G. Miller, S.R. Clark, M.C. Vance, Z. Feng, K.J. Leonard, J.K. Tatman, B. Sutton, others, Advanced welding technology development for nuclear reactor repair, Oak Ridge National Lab.(ORNL), Oak Ridge, TN (United States), 2018.

[9] Z. Feng, R.G. Miller, J. Chen, W. Tang, S.R. Clark, B.T. Gibson, M.C. Vance, G. Frederick, J.K. Tatman, B.J. Sutton, Report on the Progress of Weld Development of Irradiated Materials at the Oak Ridge National Laboratory, Oak Ridge National Lab.(ORNL), Oak Ridge, TN (United States), 2018.

[10]Z. Feng, R.G. Miller, J. Chen, W. Tang, G. Frederick, J.K. Tatman, B.J. Sutton, M. Gussev, Xunxiang, $\mathrm{Hu}$, Recent Technological Advances in Welding Irradiated Austenitic Steel with Helium, M3LW-19OR0406015, Oak Ridge National Lab.(ORNL), Oak Ridge, TN (United States), 2019.

[11]A.J. Schwartz, M. Kumar, B.L. Adams, D.P. Field, Electron backscatter diffraction in materials science, Springer, 2009.

[12]A.J. Wilkinson, T.B. Britton, Strains, planes, and EBSD in materials science, Mater. Today. 15 (2012) 366-376.

[13]M.N. Gussev, G.M. de Bellefon, T.M. Rosseel, Analysis of Localized Deformation Processes in Highly Irradiated Austenitic Stainless Steel through In Situ Techniques, Oak Ridge National Lab.(ORNL), Oak Ridge, TN (United States), 2019.

[14]M.N. Gussev, K.J. Leonard, In situ SEM-EBSD analysis of plastic deformation mechanisms in neutron-irradiated austenitic steel, J. Nucl. Mater. 517 (2019) 45-56.

[15]S. Fréchard, M. Walls, M. Kociak, J. Chevalier, J. Henry, D. Gorse, Study by EELS of helium bubbles in a martensitic steel, J. Nucl. Mater. 393 (2009) 102-107.

[16]C. Gunter, M. Miles, F. Liu, T. Nelson, Solid state crack repair by friction stir processing in 304L stainless steel, J. Mater. Sci. Technol. 34 (2018) 140-147.

[17]K.S. Mao, A.J. French, X. Liu, Y. Wu, L.A. Giannuzzi, C. Sun, M. Dubey, P.D. Freyer, J.K. Tatman, F.A. Garner, others, Microstructure and microchemistry of laser welds of irradiated austenitic steels, Mater. Des. 206 (2021) 109764. 